RESEARCH

SERIES

NUMBER 101

March 2020

\section{CLUSTERS OF HEALTH BEHAVIOURS AMONG YOUNG ADULTS IN IRELAND}

\author{
ANNE NOLAN AND EMER SMYTH
}

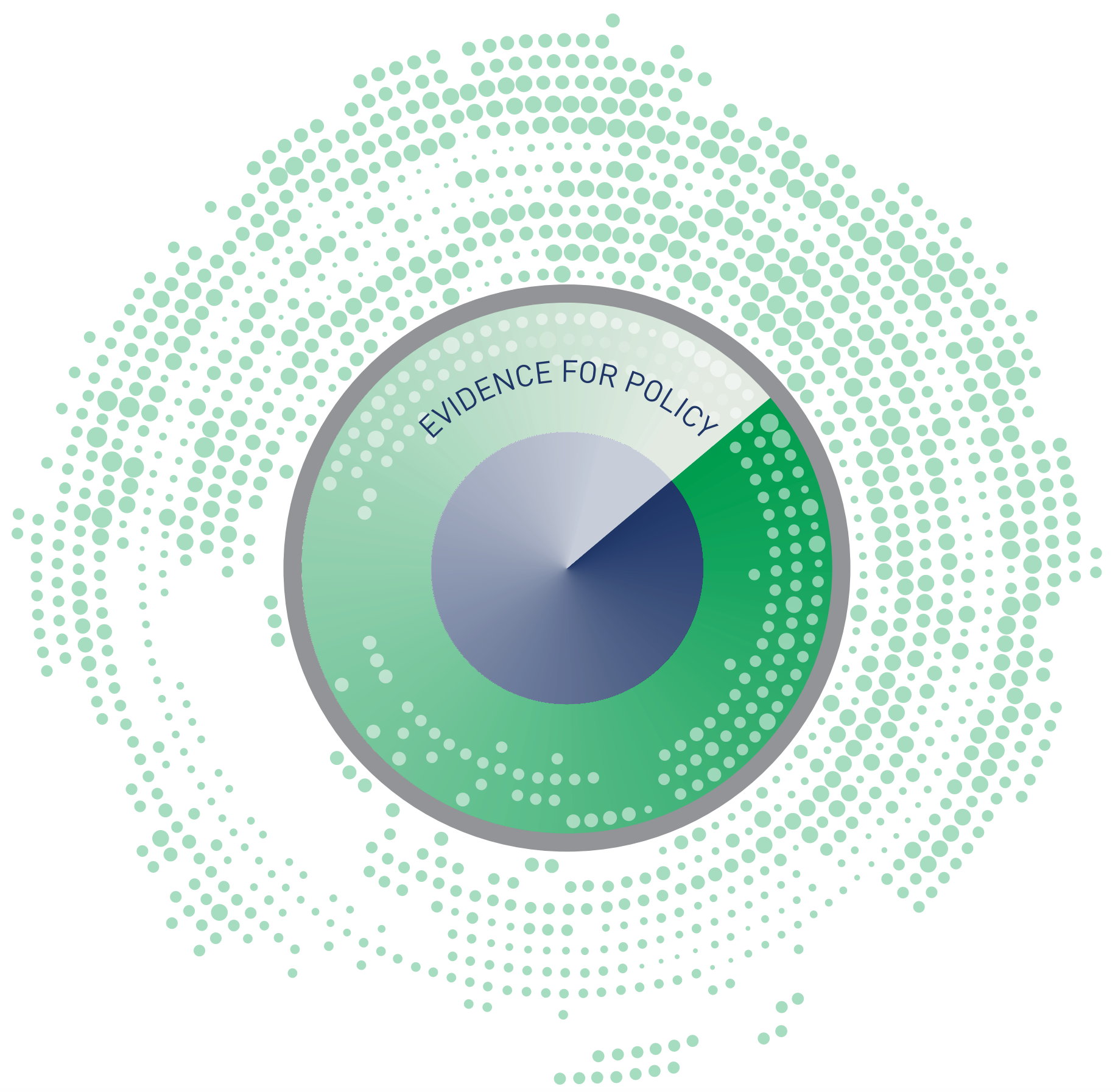




\title{
CLUSTERS OF HEALTH BEHAVIOURS AMONG YOUNG ADULTS IN IRELAND
}

\author{
Anne Nolan \\ Emer Smyth
}

February 2020

\section{RESEARCH SERIES}

\section{NUMBER 101}

Available to download from www.esri.ie

(C) The Economic and Social Research Institute

Whitaker Square, Sir John Rogerson's Quay, Dublin 2

ISBN 978-0-7070-0516-4

https://doi.org/10.26504/rs101

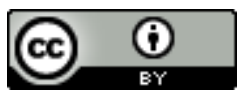

This Open Access work is licensed under a Creative Commons Attribution 4.0 International License (https://creativecommons.org/licenses/by/4.0/), which permits unrestricted use, distribution, and reproduction in any medium, provided the original work is properly credited. 


\section{ABOUT THE ESRI}

The mission of the Economic and Social Research Institute is to advance evidencebased policymaking that supports economic sustainability and social progress in Ireland. ESRI researchers apply the highest standards of academic excellence to challenges facing policymakers, focusing on 12 areas of critical importance to $21^{\text {st }}$ Century Ireland.

The Institute was founded in 1960 by a group of senior civil servants led by Dr T.K. Whitaker, who identified the need for independent and in-depth research analysis to provide a robust evidence base for policymaking in Ireland.

Since then, the Institute has remained committed to independent research and its work is free of any expressed ideology or political position. The Institute publishes all research reaching the appropriate academic standard, irrespective of its findings or who funds the research.

The quality of its research output is guaranteed by a rigorous peer review process. ESRI researchers are experts in their fields and are committed to producing work that meets the highest academic standards and practices.

The work of the Institute is disseminated widely in books, journal articles and reports. ESRI publications are available to download, free of charge, from its website. Additionally, ESRI staff communicate research findings at regular conferences and seminars.

The ESRI is a company limited by guarantee, answerable to its members and governed by a Council, comprising 14 members who represent a cross-section of ESRI members from academia, civil services, state agencies, businesses and civil society. The Institute receives an annual grant-in-aid from the Department of Public Expenditure and Reform to support the scientific and public interest elements of the Institute's activities; the grant accounted for an average of 30 per cent of the Institute's income over the lifetime of the last Research Strategy. The remaining funding comes from research programmes supported by government departments and agencies, public bodies and competitive research programmes.

Further information is available at www.esri.ie 


\section{THE AUTHORS}

Anne Nolan is an Associate Research Professor at the ESRI, and Adjunct Professor at Trinity College Dublin (TCD). Emer Smyth is a Research Professor at the ESRI, and Adjunct Professor at TCD.

\section{ACKNOWLEDGEMENTS}

The research was funded by the Health Service Executive (HSE) Health and Wellbeing Division under a Research Programme on 'Health and Wellbeing in Childhood and Adolescence'. The authors thank the Central Statistics Office (CSO) and Irish Social Science Data Archive (ISSDA) at University College Dublin (UCD) for access to Growing Up in Ireland (GUI) data, and the members of Research Programme Steering Committee for helpful comments and guidance throughout the research process. The report also benefitted considerably from comments received from two internal reviewers and one external reviewer.

GUI has been funded by the Government of Ireland through the Department of Children and Youth Affairs (DCYA) in association with the Central Statistics Office (CSO). These data have been collected in accordance with the Statistics Act, 1993. The DCYA and CSO take no responsibility for the views expressed or the outputs generated from the research undertaken on the GUI data.

This report has been accepted for publication by the Institute, which does not itself take institutional policy positions. All ESRI Research Series reports are peer reviewed prior to publication. The authors are solely responsible for the content and the views expressed. 



\section{Table of contents}

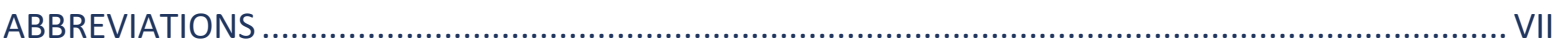

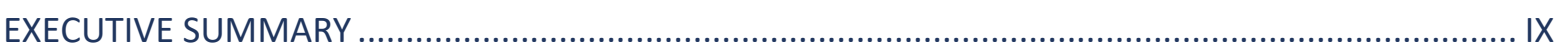

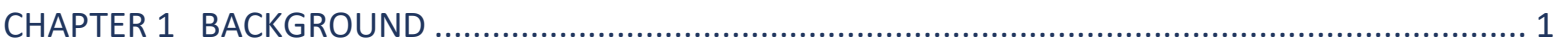

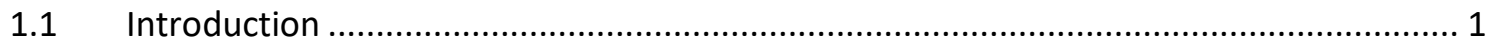

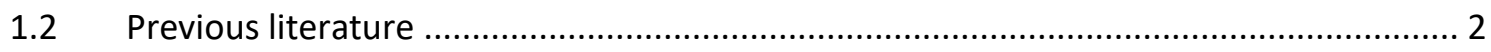

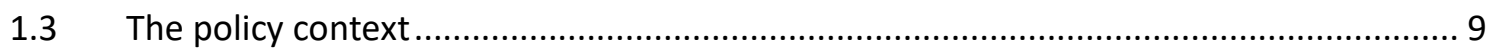

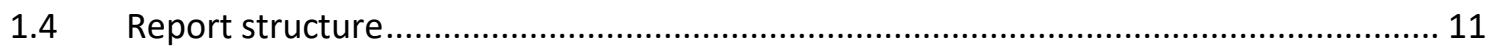

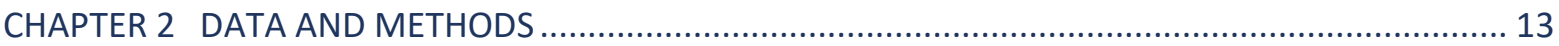

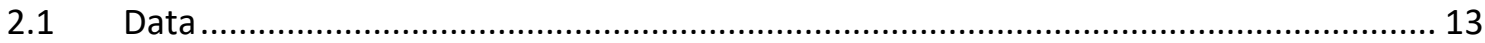

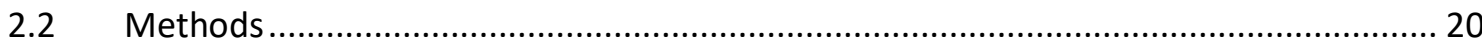

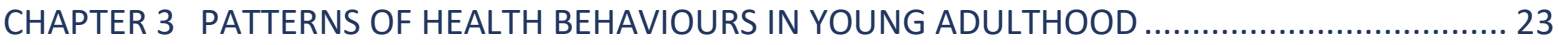

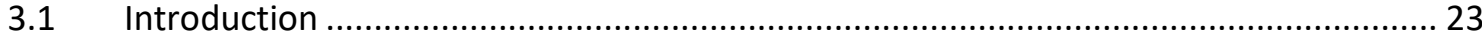

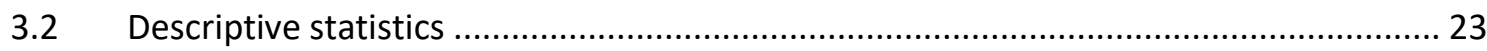

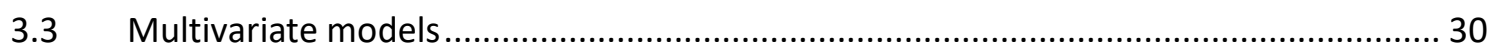

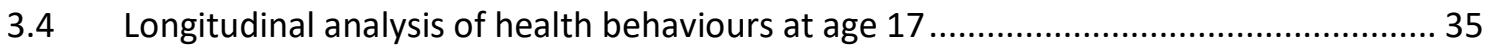

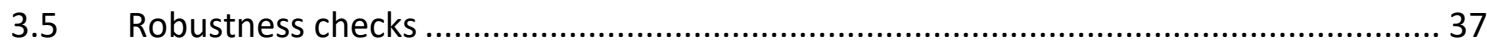

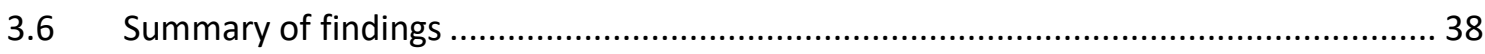

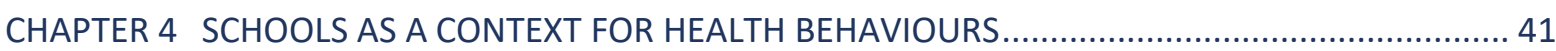

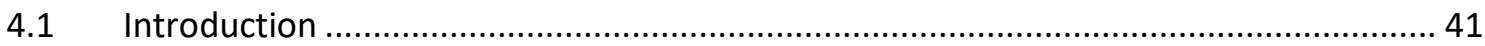

4.2 Physical education and sports facilities .......................................................... 41

4.3 Provision of food and healthy eating policies ..................................................... 47

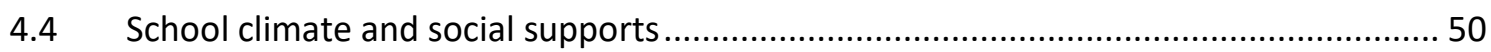

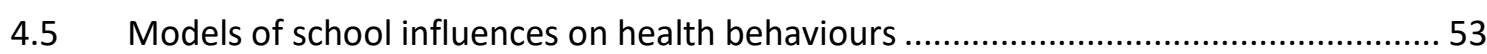

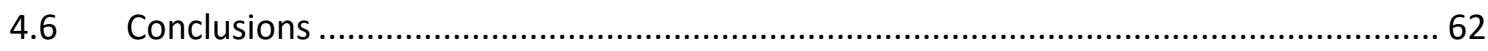

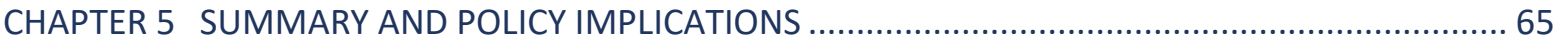

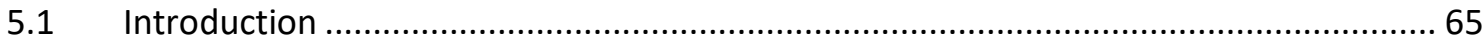

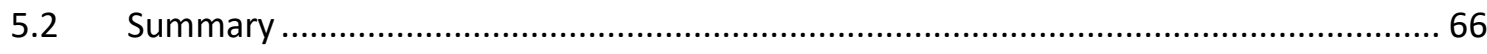

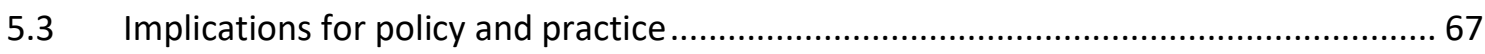

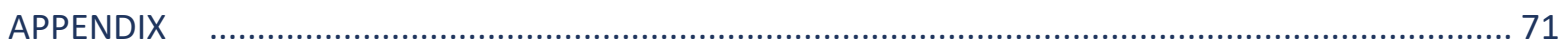

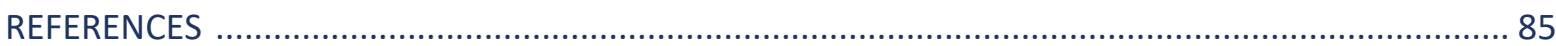





\section{List of tables}

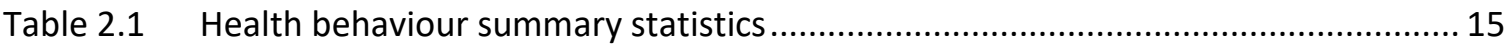

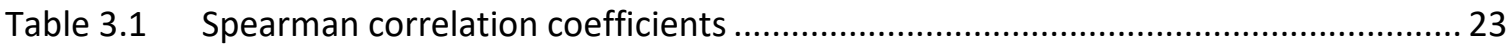

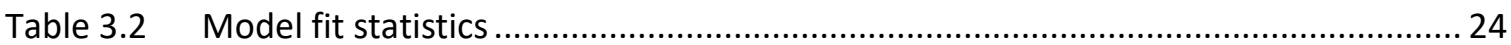

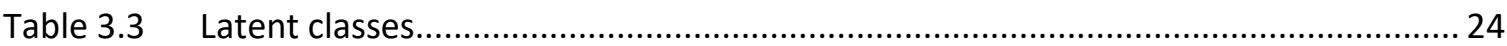

Table 3.4 Demographic and health characteristics by latent class ......................................... 26

Table $3.5 \quad$ Household socio-economic status by latent class ................................................... 27

Table 3.6 Cognitive and non-cognitive skills by latent class ....................................................2 29

Table $3.7 \quad$ Parental health behaviours by latent class .............................................................. 30

Table 3.8a Multinomial logit model of group membership (demographic and socioeconomic characteristics).....

Table 3.8b Multinomial logit model of group membership (cognitive and non-cognitive skills)

Table 3.8c Multinomial logit model of group membership (parental health behaviours)......... 35

Table 3.9 Associations between health behaviours at ages 9 and 13 and health behaviour group membership at age 17 ....

Table 4.1 Multilevel cross-classified multinomial logit model of group membership (relative to membership of the healthy group): random effects

Table 4.2 Multilevel cross-classified multinomial logit model of group membership (relative to membership of the healthy group) (odds ratios): fixed effects

Table 4.3 Multilevel multinomial logit model of group membership (school-level factors)......

Table 4.4 Multilevel multinomial logit model of group membership (school experience,

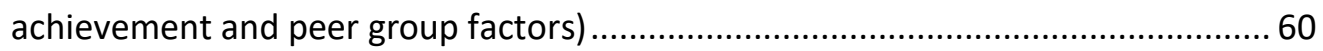

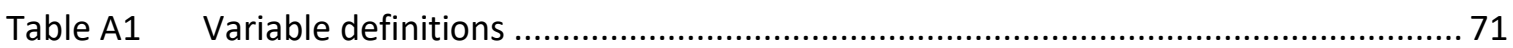

Table A2 Association between detailed diet items and gender........................................... 75

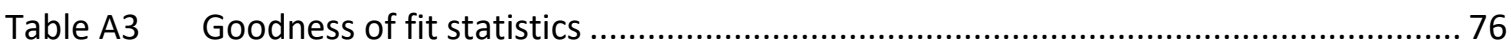

Table A4 Multinomial logit model of group membership (relative risk ratios, Wave 1

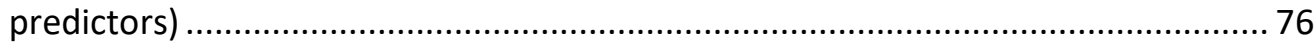

Table A5 Multinomial logit model of group membership (relative risk ratios, Wave 2 predictors)

Table A6 Multilevel multinomial logit model of group membership (relative to membership of the healthy group): effects of school social mix and betweenschool variance, controlling for different sets of factors

Table A7 Multinomial logit model of group membership (relative risk ratios, Wave 2 predictors): effects of school experiences before and after controlling for personality traits at 13 


\section{List of figures}

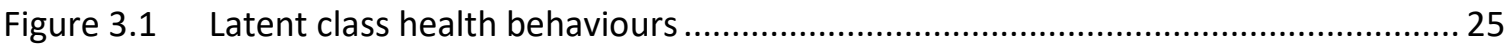

Figure 4.1 Proportion of 17-year-olds who had attended a primary school where $\mathrm{PE} /$ sports was considered 'very important' to school ethos, as a curricular activity and as an extra-curricular activity by gender mix of the school.

Figure 4.2 Proportion of 17-year-olds who had attended a primary school where $\mathrm{PE} /$ sports was considered 'very important' to school ethos, as a curricular activity and as an extra-curricular activity by school size

Figure 4.3 Proportion of young people who attended second-level schools offering individual sports as an extra-curricular activity by gender and social mix of the school

Figure 4.4 The perceived quality of sports facilities in second-level schools by gender and social mix of the school

Figure 4.5 Proportion of 17-year-olds who had attended primary schools which provided breakfast clubs and free lunches (Every day or some days) by school social mix

Figure 4.6 Proportion of young people attending second-level schools with low levels of promoting healthy eating by school gender mix, social mix and size....... 50 


\section{Abbreviations}

$\begin{array}{ll}\text { AIRS } & \text { Adult Identity Resolution Scale } \\ \text { CAPI } & \text { Computer Aided Personal Interview } \\ \text { CSI } & \text { Coping Strategy Indicator } \\ \text { CSO } & \text { Central Statistics Office } \\ \text { DEIS } & \text { Delivering Equality of Opportunity in Schools } \\ \text { EU } & \text { European Union } \\ \text { GUI } & \text { Growing Up in Ireland } \\ \text { HPS } & \text { Health Promoting School } \\ \text { HSE } & \text { Heath Service Executive } \\ \text { IPPA } & \text { Index of Parent and Peer Attachment } \\ \text { NCCA } & \text { National Council for Curriculum and Assessment } \\ \text { PA } & \text { Physical Activity } \\ \text { PE } & \text { Physical Education } \\ \text { SDQ } & \text { Strengths and Difficulties Questionnaire } \\ \text { SES } & \text { Socio Economic Status } \\ \text { SPHE } & \text { Social Personal and Health Education } \\ \text { TIPI } & \text { Ten Item Personality Inventory } \\ \text { UK } & \text { United Kingdom } \\ \text { US } & \text { United States } \\ \text { WHO } & \text { World Health Organization }\end{array}$





\section{EXECUTIVE SUMMARY}

The potential for schools to promote healthy behaviour has long been recognised. In Ireland, some school-based interventions have been associated with improvements in specific behaviours, such as physical activity, but there has been little evidence on whether and how schools can shape healthy behaviour among young people. This study addresses this gap by using Growing Up in Ireland data to look at the individual, family and school factors associated with healthy behaviours among almost 5,000 17-year-olds. It is timely in that wellbeing (physical, mental and emotional) has become a key focus of policy development (DES, 2018). In examining clusters of health behaviour, rather than specific activities such as alcohol use, the findings contribute to an understanding of health behaviours as interdependent (Department of Health, 2016).

\section{Clusters of heath behaviours}

Latent class analysis, based on the prevalence of smoking, alcohol use, physical activity and quality of diet, identified three distinct groups of young people:

1. The 'unhealthy smokers and drinkers' (21 per cent of 17-year-olds), who had the highest level of alcohol consumption, were daily or occasional smokers, had moderate to low levels of physical activity and poor to moderate dietary quality.

2. The 'unhealthy diet and physical activity' group ( 36 per cent of 17-year-olds), who did not smoke, drank alcohol rarely (monthly or less) but had the worst levels of physical activity (just 1-2 days in the previous fortnight) and had the poorest dietary quality.

3. The remaining 'healthy' group (43 per cent) did not smoke, drank rarely, engaged in exercise on six or more days in the previous fortnight and had the best quality diet.

\section{Individual and family factors}

Significant gender differences in health behaviours were evident, with young women more likely to fall into the unhealthy smoker/drinker and, especially, the unhealthy diet/activity groups. These differences were apparent even taking account of a wide range of personal, family and school characteristics.

There was some variation by family background. Young people from working-class backgrounds were more likely to be a smoker/drinker while those from less educated households (Leaving Certificate or less) were more likely to have poor diet/physical activity levels. Young people from lone parent families had higher 
rates of drinking/smoking, a pattern that was at least partly related to their more negative school experiences (see below). Parental health behaviour also made a difference with higher rates of drinking/smoking among young people whose parents had been occasional or regular smokers during their adolescence.

An advantage of the GUI study is the very rich information on young people's dispositions and social networks. Aspects of personality, self-image and coping strategies were found to influence young people's health behaviours. Those who were drinkers/smokers at age 17 were more likely to display conduct problems when they were younger (at nine and 13); the extent to which this may have been related to school disaffection is discussed further below. This group tended to socialise with older peers in adolescence, though had poorer quality relations with these friends. Young people with poor diet/physical activity showed signs of being more socially isolated, having greater peer problems, considering themselves less popular and physically attractive, and having less interaction with their teachers when younger. Both unhealthy groups tended to use avoidance to cope with stressful situations and were less likely to attempt to solve these problems constructively.

\section{The role of schools}

Schools can influence young people's health behaviour through a variety of means, including the provision of $\mathrm{PE}$ and sports, having a healthy eating policy and through the broader school climate. The study findings indicate that schools differ in the emphasis they place on sports and in the quality of $\mathrm{PE} /$ sports facilities, with smaller schools facing particular challenges around available facilities. Second-level schools often adopt healthy eating guidelines for students and their parents and prohibit certain foods or drinks. Smaller schools and single-sex boys' schools are somewhat less likely to adopt these proactive measures.

Young people's health behaviours were found to vary significantly by the secondlevel school and, to a lesser extent, the primary school attended. The measures of school policy examined had little substantive impact, though unhealthy drinking/ smoking was less evident if the school emphasised PE/sports and where students were given a greater say in school life. Instead, school social mix and school climate emerged as more important influences on health behaviour. The concentration of disadvantage in some schools was linked to a greater incidence of unhealthy behaviour. The effect of school-level disadvantage was largely mediated by aspects of school climate, that is, the more negative interaction with teachers and higher levels of disengagement found in working-class schools. A key feature was the interface between the young person and the school environment, with negative interaction with teachers and disaffection from school associated with greater levels of drinking/smoking. As indicated above, those who had unhealthy 
diet/physical activity tended to be more withdrawn in the school setting, having less interaction (positive or negative) with their teachers.

\section{Implications for policy}

The study findings show the interconnectedness of health behaviours, suggesting a multi-faceted approach is needed to address these issues (see Department of Health, 2016). Schools have immense potential as an arena for health promotion (WHO, 1999) and the increasing emphasis on wellbeing as an area of learning and a basis for school self-evaluation is likely to enhance this role. Previous research (see, for example, Nic Gabhainn et al., 2010; Moynihan et al., 2016) has suggested challenges in adopting whole-school approaches to health promotion, with teacher professional development emerging as a key factor. Nonetheless, measures to promote school engagement and promote a more positive school climate are likely to have positive spill-overs for health behaviour. Similarly, an increased emphasis on dispositions and skills at junior cycle has the potential to provide young people with the kinds of coping strategies (namely, problem-solving) that promote healthy behaviour. The broader educational system also appears to play a role, with less physical activity and poorer diets found among sixth year students than those in fifth year. This is consistent with previous research which shows young people report a reduction in the time spent on sports and other leisure activities in the lead up to the Leaving Certificate exam (Smyth et al., 2011; Banks et al., 2018), a pattern that has implications for the ongoing review of senior cycle education.

The study findings point to marked gender differences in the prevalence of healthy behaviour, echoing previous findings on the lower levels of physical activity among girls and women (Lunn et al., 2013). Gender differences in out-of-school activities emerge early and the study findings would suggest that these may be at least partly reinforced by the school context, with a greater emphasis on PE/sports and better facilities in boys' schools. The reasons for this gender gap are complex and merit further research. 



\section{CHAPTER 1}

\section{Background}

\section{$1.1 \quad$ INTRODUCTION}

The Nuffield Foundation in the UK has noted that 'while the importance of investment in the early years is broadly accepted, the comparable importance of the age period 10-24 years is sometimes neglected' (Shah et al., 2019). It is a time when major biological, psychological, and social changes occur, laying the foundations for adult life (Viner et al., 2015; Shah et al., 2019; The Lancet, 2019). Social transitions from dependent child towards stronger peer affiliation, the development of intimate partner relationships, and the transition from primary through second level to further education and employment are accompanied by new health, social and personal behaviours (Viner et al., 2015). Many important health-related behaviours, such as smoking, alcohol consumption, drug use, physical activity and sexual behaviours initiate in adolescence, and these patterns often track into adult life (Viner et al., 2015; Viner et al., 2017; Shah et al., 2019).

Non-communicable or chronic diseases, such as heart and lung disease, cancer and diabetes, are the leading cause of death in developed countries. While most deaths occur in adulthood, exposure to risk factors begins in early life. The World Health Organization (WHO) estimates that about a third of the burden of disease in developed countries is directly attributable to four key health behaviours: smoking, excessive consumption of alcohol, poor diet and low levels of physical activity (WHO, 2002). These modifiable health behaviours, which are strongly socially patterned (Pampel et al., 2010), are associated with premature mortality (Loef and Walach, 2012; Martin-Diener, 2014; Davis et al., 2019), and generate considerable social and economic costs (Scarborough et al., 2011). For young adults in particular, multiple health risk behaviours have been found to be associated with poorer mental health outcomes (Meader et al., 2016).

Previous research on health behaviours in adolescence has tended to focus on one or two of these health behaviours, with relatively less attention devoted to how major risk factors for disease cluster together (Ottevaere et al., 2011; Meader et al., 2016). In contrast, using data from Waves 1-3 of the Growing Up in Ireland (GUI) ' 98 Cohort (corresponding to ages nine, 13 and 17), the purpose of this report is to analyse how these four main health behaviours (smoking, excessive consumption of alcohol, poor diet and low levels of physical activity) cluster among the young adult population, how they are distributed across the young adult population, and the relative importance of individual, family and school characteristics in determining these patterns. Rather than looking at different dimensions of health 
behaviours separately, it analyses the potential effects of the school attended on clusters of health behaviours. Having detailed information at the young person and school level allows us to separate out the potential effects of school composition (for example, the concentration of more socio-economically disadvantaged students) from dimensions of school context (for example, the school climate or adequacy of facilities). Finally, existing research tends to concentrate on adolescence, while GUI data can allow us to disentangle the potential effects of both the primary and second-level schools attended.

\subsection{PREVIOUS LITERATURE}

The purpose of this section is to review the Irish and international literature on health behaviour clusters, focusing in particular on the emerging literature that examines patterns of behaviour among adolescents and young adults. Reflecting the increasing body of research internationally which has identified the way in which outcomes among children and young people differ across schools, even taking into account the social background of students, this chapter also includes a review of the literature that examines the school as a context for health behaviour.

\subsubsection{Identification of health behaviour clusters ${ }^{1}$}

Previous research using GUI has described patterns of health-related behaviours among Irish adolescents, noting inequalities by family social background, and the role of early exposure to health-related behaviours at age 13 in shaping behaviour at age 17. For example, those from the most socially disadvantaged families (in terms of social class) were more likely to be frequent (daily) smokers (17 per cent), compared to 5 per cent from the most advantaged homes. For both smoking and alcohol consumption, those who had recorded these behaviours at age 13 were more likely to be smoking and consuming alcohol at age 17 (Growing Up in Ireland, 2016b). Some gender differences were also apparent; young males were more likely to be engaged in exercise for six or more days in the previous two weeks (74 per cent) than young females (58 per cent) (Growing Up in Ireland, 2016a).

However, there is less information available in the Irish context on how these behaviours cluster together, particularly for children and young adults. A number of studies based on data from the Health Behaviour in School-Aged Children (HBSC) network have examined the co-occurrence of different health behaviours in Irish adolescents. De Looze et al. (2015) examined the clustering and correlates of adolescent risk behaviour across 27 European and North American countries using data from the 2010 HBSC study. A number of dimensions of risky behaviour were

A variety of techniques is used in the literature to identify health behaviour 'clusters', from cross-tabulations that identify the prevalence of particular health behaviour combinations, to more formal statistical techniques such as cluster or latent class analysis. The definition of a health behaviour also varies, as does the number of health behaviours considered. 
analysed; tobacco use, drunkenness, cannabis use and early sexual activity. They found that across the 27 countries, correlations in risky behaviours ranged from 0.48 (drunkenness last month and sexual activity; cannabis use last month and sexual activity) to 0.62 (daily smoking and cannabis use last month). Vereecken et al. (2009) examined the association between daily breakfast consumption and other health behaviours such as smoking, drunkenness, physical activity, TV viewing and diet in 41 countries using data from the 2005-2006 HBSC, while Janssen et al. (2005) found a negative association between obesity, higher physical activity and better diet across 34 countries participating in the HBSC study in 2001-2002.

Analysing the adult population, Conry et al. (2011) used data from the 2007 Survey of Health, Attitudes and Lifestyles in Ireland (SLÁN) to examine clusters of healthrelated behaviours among Irish adults. Patterns of smoking, alcohol consumption, physical activity and diet were examined, and six health-related behaviour clusters identified: former smokers, 21 per cent; temperate, 15 per cent; physically inactive, 18 per cent; healthy lifestyle, 9 per cent; multiple risk factor, 17 per cent; and mixed lifestyle, 20 per cent. Significant associations with psychological health were evident; for example, healthier clusters (former smokers, temperate and healthy lifestyle) reported lower levels of psychological distress, in comparison with those in the multiple risk factor cluster who had the highest levels of psychological distress. Data from Wave 2 of the Healthy Ireland survey, conducted between September 2015 and May 2016, have been used to show how four unhealthy behaviours (smoking, binge drinking, consuming less than five portions of fruit or vegetables daily, spending eight or more hours a day sitting) co-occur among Irish adults. The analysis found that 86 per cent of the adult population had at least one unhealthy health behaviour, and 46 per cent had multiple (2+) unhealthy behaviours. Smokers were most likely to have other unhealthy health behaviours; 50 per cent of smokers had at least three unhealthy behaviours, and 10 per cent had all four unhealthy behaviours. More men ( 59 per cent) had multiple unhealthy health behaviours than women (34 per cent). While the four unhealthy behaviours examined were somewhat arbitrary, there were also significant associations with other health-related behaviours such as eating breakfast, adding salt to food at the table, and drinking sugar-sweetened drinks (Department of Health, 2016).

Noble et al. (2015) carried out a systematic review of the international literature on the clustering of smoking, excessive alcohol intake, physical inactivity and poor nutrition among adults. Reviewing 56 studies, they found that the majority (over 80 per cent) of studies reported a 'healthy' cluster; more than 50 per cent reported a cluster characterised by poor behaviours across all four dimensions; and that more than half the studies identified a cluster defined by smoking and excessive alcohol consumption. Meader et al. (2016) conducted a systematic review of 
37 UK-based studies that examined clusters of a broader set of health behaviours (including smoking, alcohol consumption, physical activity and diet but also sexual activity and illicit drug use). They found that among the general adult population, 'alcohol misuse and smoking' was the most commonly identified risk behaviour cluster. Socio-economic status (specifically occupation and education) was the strongest predictor of engaging in multiple risk behaviours.

Data on English adults have shown that approximately 25 per cent of the population engaged in at least three of four unhealthy behaviours (smoking, excessive alcohol consumption, poor diet and low levels of physical activity) in 2008 , and that socio-economic inequalities in clusters of unhealthy behaviours have been increasing over time (Buck and Frosini, 2012). A series of papers (Mawditt et al., 2016; 2018; 2019) have used data from the National Child Development Study (NCDS) and the British Cohort Study (BCS) to examine clusters of health-related behaviours in mid-life in Britain. ${ }^{2}$ Testing for cohort differences in health-related behaviours, Mawditt et al., (2016) identified three separate clusters for men and women ('risky'; 'moderate smokers'; 'mainstream'). They found that membership of the 'mainstream' cluster was higher in the BCS than the NCDS, while membership of the 'risky' cluster was higher among NCDS women than BCS women (both sets of respondents were aged 33/34 on average at the time of analysis). While the shift to the 'mainstream' cluster was beneficial in many respects (e.g. less smoking, more fruit and vegetable consumption, etc.), a higher proportion of BCS men and women were drinking alcohol above the recommended guidelines. Using data from the BCS and NCDS and a path analysis, Mawditt et al., (2018) examined how pre-adolescent socio-economic status (SES) predicted membership of the three clusters. They found that for both men and women, adult SES largely explained the relationship between pre-adolescent SES and cluster membership.

In contrast to the literature on adults, fewer studies have examined clustering of health behaviours among young adults (Meader et al., 2016). Skalamera and Hummer (2016) used data from the National Longitudinal Study of Adolescent to Adult Health in the US to examine the association between educational attainment and health-related behaviour clusters. Eight health-related behaviours were examined (binge drinking, cigarette smoking, other tobacco use, physical activity, marijuana use, visiting doctor or dentist for preventive care, eating fast food). Using latent class analysis, and stratifying the analysis by gender, they identified three distinct clusters of health-related behaviours (unhealthy; mixed healthy/unhealthy; healthy). Twenty-two per cent of women, and 40 per cent of men were identified as 'unhealthy', and more highly educated individuals, 
especially those with college degrees or higher, were less likely to be members of clusters most characterised by negative practices. The educational gradient was linear for men; any educational attainment above high school was associated with a lower probability of membership of the high-risk behaviour clusters (for women, the effect was only significant above college level). Conscientiousness (i.e. the degree to which a person is willing to comply with conventional rules, norms and standards) was associated with an increased probability of belonging to the healthy cluster.

Alamian and Paradis (2009) examined clusters of five risk factors (physical inactivity, sedentary behaviour, tobacco smoking, alcohol drinking and high body mass index) in a representative sample of Canadian children and adolescents aged 10-17 from the National Longitudinal Study on Children and Youth. They found that only one-in-ten Canadian youth aged 10-17 years had none of the five risk factors; while 25 per cent had one risk factor, 28 per cent had two risk factors, 23 per cent had three risk factors and the remaining 14 per cent had four or five risk factors. The prevalence of multiple risk factors did not differ by gender but increased with age and was higher in those from lower SES families.

Champion et al. (2018) examined the clustering of established (smoking, alcohol use, diet, physical inactivity) and emerging (sedentary behaviour and sleep) chronic disease risk factors in a sample of young Australian adults (average age 18). Three classes were identified ('moderate risk', 'inactive non-smokers' and 'smokers and binge drinkers'), and significant associations between class membership and mental health outcomes were found (i.e. those in the 'smokers and binge drinkers' group showed higher levels of stress, anxiety and depression than the 'moderate risk' group). A couple of recent studies have examined the association between health behaviours in adolescence and measures of cardiorespiratory fitness and physical functioning (Cuenca-García et al., 2013; Hartz et al., 2018). The US study (Hartz et al., 2018) found no association between health behaviour clusters and cardiorespiratory fitness among girls, but a significant association for boys (with those in the cluster characterised by the highest amount of sedentary time performing worse on the cardiorespiratory test). The European study (CuencaGarcía et al., 2013) found that those in the healthy cluster (good diet, high levels of physical activity, low sedentary time) had higher aerobic capacity and speedagility, with girls displaying an additional significant difference in terms of strength.

Focusing on younger children as well as adolescents, Leech et al. (2014) reviewed seven studies that examined the clustering of obesogenic behaviours (diet, physical activity and sedentary behaviour) separately for boys and girls. They found clear differences in the proportion of boys and girls within the clusters. Girls were more likely to be in clusters defined by low physical activity while boys were more likely to be found in clusters characterised by poor diet. In a related study of 
Australian children, Leech et al. (2015) examined clusters of diet, physical activity and sedentary behaviour and their association with objectively-measured weight status, both cross-sectionally and longitudinally. They identified three clusters ('most healthy'; 'energy dense consumers who watch TV'; 'high sedentary behaviour/low vigorous activity'), but these clusters were not associated with baseline body mass index (BMI) or weight status. However, children in the second cluster (energy dense consumers who watch TV) were significantly more likely to be overweight/obese at follow-up.

The availability of longitudinal data from adolescence into adulthood has enabled some emerging research into longitudinal patterns of health behaviour clusters. Using data from the NCDS, Mawditt et al. (2019) used latent transition analysis to examine health-related behaviour cluster transitions between ages 33 and 42 , separately for men and women. They found that for men and women, there was a high probability of remaining in the same cluster ('moderate smoker', 'mainstream', 'risky') at the two time points (ages 33 and 42), but also some evidence of more positive transitions over time (e.g. among men, there was a 17 per cent probability of transitioning from the 'risky' to the 'mainstream' cluster). Interestingly, they found that SES at age 33 was not associated with transitions in cluster membership between ages 33 and 42 .

Frech (2012) used data from the first three waves of the National Longitudinal Study of Adolescent Health in the US to examine the rate of within-individual change in healthy behaviours between the beginning of adolescence (age 13) and the end of young adulthood (age 24). A six-item summary index of health behaviours (incorporating adequate sleep, non-smoking, eating breakfast, adequate exercise, healthy weight, no binge drinking) was constructed. She found that there were significant declines in the health index between the ages of 13 and 24. Girls had worse health behaviours at age 13 than boys, but by age 24 , this pattern had reversed. Higher self-efficacy, lower rates of psychological distress and higher parental SES at age 13 were significant predictors of healthy behaviours at age 13 , and these relationships remained constant over time. In contrast, while strong parent support and school support were positively associated with healthy behaviours at age 13 , these factors were associated with a stronger decline in health behaviours by age 24 . Parental non-smoking at age 13 was associated with healthier behaviours at age 13 , and this effect persisted and became stronger by age 24 , suggesting a cumulative benefit of having a non-smoking parent over time. Daw et al. (2017), using the same data, but with an additional wave (at age 32), examined trajectories in four health-related behaviours (smoking, drinking, obesity $^{3}$ and physical inactivity) over time. With the exception of sedentary 
behaviour, all health-related behaviours become more common as individuals aged. They identified seven classes of trajectories over time, with strong gender effects (i.e. women were much more likely to be in the healthier behaviour clusters).

\subsubsection{School effects on health behaviours}

There is a large body of research internationally that has identified the way in which outcomes among children and young people differ across schools, even taking into account the social background of students. Such studies have mainly focused on educational outcomes, especially attainment (for an overview, see Teddlie and Reynolds, 2000) but increasingly researchers have come to investigate schools as a potentially important context for shaping health behaviour. Much of this research has focused on adolescents rather than younger children and on drinking, smoking and drug use rather than other health behaviours.

A number of studies across different national contexts have shown significant between-school variation in the levels of substance use, even taking account of the characteristics of students attending particular schools. Thus, in one study in Stockholm, rates of drug use and high alcohol consumption were found to vary significantly by school (Olsson, Fritzell, 2015). Similarly, in Flanders, smoking and drinking varied significantly across schools (Maes and Lievens, 2003). In Japan, Takakura et al. (2010) found significant variation between schools in drinking and smoking. In a US study on smoking among adolescents aged 12 to 18 years (Dunn et al., 2015), rates of smoking varied significantly by school, but a significant proportion of the between-school variation reflected student composition in terms of socio-economic status, gender, age and ethnicity.

Studies have tended to vary in the relative size of this 'school effect', with the amount of variation attributable to schools ranging from 2 to 15 per cent. ${ }^{4} A$ useful benchmark in looking at the relative importance of schools is to examine other contexts for health behaviour. A number of studies, using cross-classified multilevel modelling techniques, have sought to disentangle the relative role of schools and neighbourhoods in shaping substance use. Dunn et al. (2015) found that school effects were stronger than neighbourhood effects in the US in relation to smoking. A similar approach was taken in a Norwegian study of alcohol consumption among young people (Pedersen et al., 2017). This study showed roughly equal levels of between-school and neighbourhood variation in the frequency of alcohol consumption. However, almost all neighbourhood variation was explained by family characteristics (including SES, religion and parental alcohol

\footnotetext{
${ }^{4}$ In other words, most of the variation in substance use occurs between individuals attending the same school.
} 
consumption) while significant between-school variation was still evident taking account of these characteristics.

Several studies have gone further than documenting school effects to unpack the factors behind these differences. The social mix of the school has been found to be influential, with higher rates of drug use and alcohol consumption in more advantaged settings (based on parental socio-economic status) (Olsson and Fritzell 2015; Pedersen et al., 2017; Carlson and Almquist, 2016), though one US study indicates higher smoking rates in schools with a greater concentration of welfaredependent families (Dunn et al., 2015). The school climate, especially the quality of teacher-student relationships and level of school disengagement, makes a significant difference to risky behaviours. In a systematic review of school effects on health behaviour, Bonnell et al. (2013) found that schools with higher levels of attainment and attendance had lower rates of substance use (alcohol and drugs). Another systematic review (Fletcher et al., 2008) found that disengagement and poor teacher-student relationships were associated with drug use and other risky behaviours. A study using data from Northern Ireland (Perra et al., 2012) found that positive teacher-student relationships were associated with markedly lower rates of daily smoking, weekly drunkenness and weekly cannabis use. However, school disengagement was associated with greater smoking and cannabis use for females only. In Flanders, regular smoking and drinking was more common among truants, those with negative attitudes to school and poorer relationships with teachers; schools with more developed discipline policies had lower smoking and drinking rates (Maes and Lievens, 2003). More positive attitudes to school at the individual and school level have been associated with lower levels of smoking and alcohol use (Henry et al., 2009; Takakura et al., 2010). In other words, students attending a school characterised by more positive student attitudes were less likely to drink or smoke, over and above their own attitudes to school. Perceived level of teacher support (students seeing teachers as fair and feeling they cared about them) was found to reduce the initiation of use of alcohol, cigarettes and marijuana among US adolescents but had little effect on reduction or cessation (McNeely and Falci, 2004). Peer groups formed within the school context can reinforce less (or more) healthy behaviours. Thus, drinking and smoking may become expressions of broader disaffection among particular groups of young people (West et al., 2004; Fletcher et al., 2008).

More of the research has focused on drinking, smoking and drug use than on physical activity (PA) or diet. However, a number of studies suggest the existence of school effects in these domains. In a systematic review, Zhou and Wang (2019) found that levels of moderate to vigorous physical activity (MVPA) among adolescents were higher in boys-only classes, where there were team activities in PE and where lessons were outdoors; they were lower in girls-only classes and where there was an emphasis on movement activities (such as dance or 
gymnastics). Cradock et al. (2007) found that levels of physical activity among Boston students (aged 12-14) were greater where schools had more space (overall, in the playground and in the building). US schools were found to vary in students' number of days of PE and overall levels of physical activity (Roman and Taylor, 2013). In Denmark, Steenholt et al. (2018) reported significant between-school variation in physical activity during leisure time and in mode of transport to school. Some of this difference was related to schools offering PA after school hours or having a special programme to promote PA. In Canada, variation between primary schools was found in engagement in physical activity and was higher in schools with written physical activity policies and where the schools encouraged active transportation to/from school, controlling for family SES (Harvey et al., 2017). However, the availability of facilities was not found to have a significant effect on levels of physical activity. In contrast, in Germany Czerwinski et al. (2015) found higher levels of physical activity where there was a football ground or swimming pool in the school.

In terms of diet, students in Welsh schools that had more measures to promote healthy eating were more likely to eat fruit or vegetables daily and less likely to eat sweets for lunch (Townsend et al., 2011). However, Krolner et al. (2009) in Denmark found no significant variation between schools for fruit consumption, though some between-school variation for vegetable consumption, with larger between-school variation for boys. In the west of Scotland, unhealthy diet among 11-16-year-olds was more common in schools where more students were disengaged and knew fewer teachers and which had a poorer ethos (West et al., 2004). In Ireland, HBSC data indicated that young people in second-level schools serving disadvantaged populations (DEIS schools) and those from lower socioeconomic classes tended to have poorer quality diet than those in non-DEIS schools or from higher social classes (Kelly et al., 2019).

\subsection{THE POLICY CONTEXT}

Internationally, the potential for schools to encourage healthy behaviours has long been recognised, with the World Health Organization (1999) describing schools as the 'ideal setting' for health promotion. The concept of a health promoting school (HPS) was reinforced with the establishment in 1992 of the European Network of Health Promoting Schools (later becoming the Schools for Health in Europe Network), with Ireland a signatory at the first conference. The idea of a health promoting school centres on a whole-school approach to enhancing the emotional, psychological and physical wellbeing of students (and teachers) (HSE, 2013). Since 2012, primary and second-level schools in Ireland have been able to apply for HPS status on the basis of action plans for health promotion, with a fifth of schools given such status (McHugh and McGowan, 2019). The current strategy for children and young people, Better Outcomes, Brighter Futures, recognises the importance of healthy lifestyles (encompassing physical activity, diet, smoking, alcohol 
consumption and substance misuse) for the promotion of physical and mental health and wellbeing among children and young people (Department of Children and Youth Affairs, 2014). It also highlights the role that schools can play in supporting children and young people to be physically healthy through education, the promotion of healthy eating policies, skills development and the integration of sports, exercise and physical activity into the school day.

In parallel with these developments, the concept of wellbeing in schools has been receiving increasing policy attention (for a discussion of the conceptual background, see O'Brien, 2008). One of the four key themes of Aistear, the curriculum framework spanning pre-school and primary education, is wellbeing (NCCA, 2009). The Framework for Junior Cycle (DES, 2015) designated wellbeing as a new area of learning at junior cycle, which will build up to 400 timetabled hours by 2020 . The aim is to enhance the physical, mental, emotional and social wellbeing of students by adopting a whole-school approach incorporating, but not limited to, existing curricular provision in the form of Social, Personal and Health Education, Relationships and Sexuality Education and Physical Education (NCCA, 2017). The subsequent Wellbeing Policy Statement and Framework for Practice 2018-2023 (DES, 2018) further reinforces the need for a whole-school approach to promoting wellbeing and takes a cross-departmental perspective between the Department of Education and Skills and the Department of Health/Health Services Executive integrating the existing Health Promoting Schools initiative. By 2023, schools will be required to use the school self-evaluation process to assess their own policies and practices regarding wellbeing promotion (McHugh and McGowan, 2019).

In this policy context, the current study is timely in providing an evidence base on the role of schools in health behaviours. In addition, looking at clusters of health behaviours is likely to yield new insights for policy development. The current Irish government health strategy, Healthy Ireland, notes the importance of the four risk factors (alcohol, smoking, poor diet and low levels of physical activity) for population health (Government of Ireland, 2013). To date, strategies in relation to tobacco control, physical activity, sexual health and obesity have been launched, and new legislation in relation to alcohol consumption and the marketing of tobacco has been enacted (Department of Health, 2013; Government of Ireland, 2015; 2016; 2018).

While current strategies in relation to smoking (Department of Health, 2013) and physical activity (Government of Ireland, 2016) make little reference to the relationships between the four main risk factors for chronic disease, there is a recognition that tackling unhealthy behaviour clusters requires a multi-faceted approach that recognises that these behaviours do not exist in isolation, but instead need to be tackled as behaviours that may be interdependent (Department 
of Health, 2016). For example, the HSE Healthy Eating and Active Living programme has responsibility for implementing the recommendations of Healthy Ireland that address diet and physical activity, and the sexual health programme notes the importance of the relationship between alcohol and sexual risk-taking.

\subsection{REPORT STRUCTURE}

This report is structured as follows. Chapter 2 describes the data and methods. Chapter 3 presents the results of an analysis of clusters of health-related behaviours at age 17, using the latent class analysis technique. This chapter also introduces a longitudinal dimension, examining the factors at ages nine and 13 that influence health-related behaviours at age 17 . Chapter 4 analyses the role of the school as a context for health behaviours, looking at the extent to which behaviour varies across schools and is related to school characteristics. Chapter 5 concludes and discusses implications for policy. 



\section{CHAPTER 2}

\section{Data and methods}

\subsection{DATA}

Growing Up in Ireland (GUI), the National Longitudinal Study of Children in Ireland, surveys two cohorts of children and young people. The '08 Cohort (previously known as the Infant Cohort) contains information on 11,134 nine-month-old children and their families who were first surveyed between September 2008 and April 2009 (Quail et al., 2011). The '98 Cohort (previously known as the Child Cohort) represents 8,568 children and their families first surveyed between August 2007 and May 2008, when they were nine years old (Thornton et al., 2011). Children were sampled on the basis of the primary school they attended when they were nine. A nationally representative sample of 1,105 schools was selected from the total of 3,326 primary schools in Ireland at that time. Just over 82 per cent of these (910 schools) were successfully recruited into the survey. The sample of children and their families were then randomly generated from within those schools. Data from the ' 98 Cohort are used in this report. The second wave of data collection for the ' 98 Cohort was carried out between August 2011 and March 2012 (when the young people were approximately 13 years of age), and Wave 3 between April 2015 and August 2016 (when the young people were approximately $17 / 18$ years ${ }^{5}$ of age) (Murphy et al., 2019). Analyses are based on the Anonymised Microdata Files (AMFs), available from the Irish Social Science Data Archive (ISSDA) at University College Dublin.

At each wave (ages nine, 13 and 17), data were collected primarily via computeraided personal interviewing (CAPI) with the primary caregiver (who in most cases was the young person's mother) and the young people themselves. Sensitive questionnaires, which contain questions in relation to some health behaviours, were also conducted with parents and young people in all waves. In this report the main focus is on the four main health behaviours (smoking, alcohol consumption, physical activity and diet) at age 17 . However, data on other individual characteristics, family background and school factors from Wave 1 (age nine) and Wave 2 (age 13) are also employed. The sample for analysis consists of all young people who were singletons with complete information on all four health behaviours at Wave $3 .{ }^{6}$ For example, for the analysis of health behaviours using data from Wave 3 at age 17, the sample size is 5,951 (and 5,073 for the multivariate

5 For simplicity, these young people are referred to as 17-year-olds throughout the remainder of the report.

6195 non-singleton young people were excluded from the analysis because they may share health behaviours with their twins/triplets and data on twins/triplets of respondents are not currently available. 
models in Chapter 3 when observations with missing information on key variables, e.g. household income, are excluded).

At Wave 1, the teacher and principal were interviewed, while at age 13 and 17 (if the young person was still in school), the principal was interviewed. These interviews provide rich information on the type of school attended (including size, gender mix and social mix), principal perceptions of the adequacy of facilities (including PE/sports facilities) and information on the school climate.

\subsubsection{Health behaviours}

Four health-related behaviours at age 17 are examined in this report. Current smoking behaviour is reported by the young person (as part of the sensitive questionnaire) and is summarised by a categorical variable that describes those who smoke daily, occasionally and never (the latter includes those who do not currently smoke but have smoked in the past, or those who have tried smoking once or twice). Current alcohol consumption is also reported by the young person as part of the sensitive questionnaire and is represented by a categorical variable with four values (2+ times per week, 2-3 times per month, monthly or less, never) in response to the question 'which of the following best describes how often you usually drink alcohol?'. ${ }^{7}$ Physical activity is represented by a categorical variable that describes the number of days that the young person engaged in 'hard' exercise in the past 14 days, as reported by the young person (during the main CAPI). ${ }^{8}$ The five categories are none, 1-2 days, 3-5 days, 6-8 days, and 9+ days. Dietary quality is proxied by a summary index that is constructed from responses to a 20-item food frequency questionnaire that is completed by the young person as part of the main CAPI. For each item (e.g. fresh fruit), the young person is asked whether they consumed the item 'once', 'more than once' or 'not at all' in the past 24 hours. Following previous research by Layte and McCrory (2011), we construct an index of dietary quality that assigns positive values ( $1=$ =eaten once, $2=$ =more than once) to foods considered to be beneficial (such as raw vegetables, fresh fruit, etc.) and a negative value to those generally considered less beneficial (burger, sausage, chips, crisps, etc.). Foods such as bread, potatoes, pasta, rice and cereals are deemed as neutral so are excluded from the scale. ${ }^{9}$

Table 2.1 illustrates summary statistics for the four health-related behaviours examined in this report. Overall, just over 20 per cent of 17 -year-olds were smokers

7 The young person is also asked about the number of units of alcohol consumed on a typical day of drinking. In addition, the AUDIT screening tool, which indicates if a person's alcohol consumption may be harmful, is also calculated. 
(with the majority reporting occasional rather than daily smoking). ${ }^{10}$ In terms of alcohol consumption, nearly 15 per cent of 17 -year-olds did not consume alcohol, while 6 per cent consumed it two or more times per week, and a further 36 per cent 2-4 times per month. ${ }^{11}$ Over 14 per cent of 17 -year-olds engaged in no 'hard' exercise over a two-week period, while just under 20 per cent had done so for 9+ days in the same interval. In terms of dietary quality, the mean score was 6.3 (range -9 to 17 , with a median of 6 ).

TABLE 2.1 HEALTH BEHAVIOUR SUMMARY STATISTICS

\begin{tabular}{|c|c|c|c|}
\hline Health Behaviour & Description & $\%$ & Mean (Median) \\
\hline \multirow{3}{*}{ Smoking } & $=1$ if daily & 8.2 & \multirow{3}{*}{$2.7(3)$} \\
\hline & $=2$ if occasionally & 12.3 & \\
\hline & $=3$ if never & 79.5 & \\
\hline \multirow{4}{*}{ Alcohol } & $=1$ if $2+$ times per week & 6.2 & \multirow{4}{*}{$2.7(3)$} \\
\hline & $=2$ if $2-4$ times per month & 35.7 & \\
\hline & $=3$ if monthly or less & 43.2 & \\
\hline & $=4$ if never & 14.9 & \\
\hline \multirow{5}{*}{ Physical Activity } & $=1$ if no days of hard exercise in last two weeks & 14.5 & \multirow{5}{*}{$3.1(3)$} \\
\hline & $=2$ if $1-2$ days & 20.1 & \\
\hline & $=3$ if $3-5$ days & 26.6 & \\
\hline & $=4$ if $6-8$ days & 19.1 & \\
\hline & $=5$ if $9+$ days & 19.7 & \\
\hline Diet & Dietary quality index (range -9 to 17 ) & & $6.3(6)$ \\
\hline
\end{tabular}

Source: $\quad$ GUI, '98 Cohort, Wave 3.

Note: Population weights are employed.

\subsubsection{Independent variables: young people and their families}

According to Frech (2012), adolescent health-related behaviours are shaped by a variety of factors including physical and psychological health, psychosocial resources (e.g. self-efficacy) and structural resources (e.g. household income, parental education, etc.). We use this framework to select the set of variables used to explain membership of the estimated latent classes in Chapter 3. First, we examine how group membership varies across a set of factors that relate to the characteristics of the young person, namely, gender, age, and whether the young person is still in second-level school.

Next, we include variables that relate to the socio-economic status (SES) of the young person's family, as family SES has been shown to be an important predictor of adolescent health behaviours in previous research (Alamian and Paradis, 2009;

10 The corresponding figure for 15-24-year-olds from the 2016 Healthy Ireland survey was 19 per cent (Department of Health, 2016). The question asked was 'do you smoke tobacco products' with those who answered 'yes, daily' or 'yes, occasionally' in answer to the question regarded as smokers. 
Leech et al., 2014; Noble et al., 2015; Growing Up in Ireland 2016a; 2016b). SES (or social background) refers to position in the social stratification system and is usually measured by education, occupation, employment, income, and/or wealth. These components of SES may not be interchangeable and have different kinds of influences on health behaviours and health. SES can reflect diverse underlying theoretical concerns such as material wellbeing, human capital, prestige, and productive relations (Pampel et al., 2010). To capture these elements, we include variables for household equivalised income, ${ }^{12}$ social class, education (of the primary caregiver), lone parent household status and migrant status (of the primary caregiver). Migrant status is included as there is a suggestion in previous research that health behaviours can differ significantly across ethnic/migrant groups. For example, in the systematic review of clusters of health behaviours in the UK, three studies examined patterns by ethnicity and found evidence that those of white ethnicity were significantly more likely to engage in multiple risky behaviours than other ethnic groups (Meader et al., 2016).

Third, we include a set of variables that characterise the cognitive and noncognitive skills of the young person, as previous research has demonstrated associations between these factors and health behaviour clusters (Lawlor et al., 2005). To capture cognitive ability, we include a variable that reflects the young person's score on a financial literacy/numeracy test. ${ }^{13}$ The test comprises three questions that required mathematical calculations relating to percentages, fractions and compound interest and was administered by the interviewer to the young person in the home. The GUI contains an extensive set of variables relating to the young person's non-cognitive skills. While we examine the association between these various measures and health behaviour cluster membership in Section 3.2, as many of these measures are correlated, we use Wald tests to decide on the final set of regressors to include in the multivariate models discussed in Section 3.3.

The Strengths and Difficulties Questionnaire (SDQ) (derived from responses from the primary caregiver) is a measure of psychological adjustment that is suitable for young people up the age of 19 . It contains 25 items which are divided into one positive and four negative subscales; emotional symptoms, conduct problems, hyperactivity/inattention, peer relationship problems and prosocial behaviour. The SDQ is available for all three waves of the GUI '98 Cohort. Personality has been shown to be associated with health behaviours in previous research (Bogg and Roberts, 2004). In GUI at age 17 (and at age 13), it was measured using the Ten

12 Household income is adjusted for the size and composition of the household using the national equivalence scale, which assigns a value of 1 to the first adult, 0.66 to all subsequent adults aged $14+$ and 0.33 to all children aged under 14. 
Item Personality Inventory (TIPI) questionnaire, completed by the young person. The scale contains ten items measuring the five aspects of personality; Openness to Experience, Agreeableness, Conscientiousness, Extraversion and Neuroticism.

Locus of control is a psychological concept that captures individuals' beliefs about the extent to which they are in control of their own lives; those with an external locus of control see control as being out of their hands and dictated either by fate or people with power over them. High internal locus of control has been shown to be associated with better diet and higher levels of physical activity (Cobb-Clark et al., 2012). In GUI at age 17, locus of control is measured by the Rotter locus of control scale, which consists of five items measured on a six-point scale from ' 1 ' strongly agree to ' 6 ' strongly disagree. ${ }^{14}$ Self-esteem is the extent to which individuals feel positive or negative about themselves, and while adults with high self-esteem generally have better health, the relationship with health behaviours is more ambiguous (Baumeister et al., 2003). In GUI, the young person's selfesteem was measured using the Rosenberg Self-Esteem scale (Rosenberg, 1965). The scale measured the young person's belief in their ability to succeed in specific situations and to accomplish tasks. The scale contains six items in total rated on a four-point scale. Higher scores are indicative of higher global self-esteem. Selfefficacy, the degree to which people feel in control of their actions and outcomes or attribute outcomes to chance or luck, has been found to be a crucial driver of many outcomes in adolescence, including health behaviours (Schwarzer and Renner, 2000). In GUI, the self-efficacy scale is an adapted version of the original Sherer scale (Sherer et al., 1982) that contains six items rated on a four-point scale.

Coping mechanisms are the methods a person uses to deal with stress or unanticipated situations, and maladaptive coping strategies are often associated with poorer health behaviours (Doron et al., 2014). Three coping strategies were assessed using a measure of coping derived from the Coping Strategy Indicator (CSI) that was previously used in the Irish context as part of the My World Survey (Dooley and Fitzgerald, 2002). Higher scores on problem solving and seeking social support, and lower scores on avoidance, indicate more well-adjusted coping strategies. Parent and peer relationships are an important determinant of adolescent health behaviours (Noble et al., 2015). The Inventory of Parent and Peer Attachment (IPPA) was developed in order to assess adolescents' perceptions of the positive and negative affective/cognitive dimensions of relationships with their parents and close friends, and how well these figures serve as sources of psychological security. The scale at age 17 focussed on peer attachment and measured three broad dimensions of attachment: degree of mutual trust; quality of communication; and extent of anger and alienation. 
At age 17, the Adult Identity Resolution scale (AIRS) was used to measure the extent to which the young person considers themselves to be an adult. Differences in perceptions of adulthood among adolescents have been found to be associated with health behaviours, with those perceiving themselves to be adults engaged in fewer risky behaviours (Nelson and McNamara Barry, 2005). Finally, the Opposition to Authority scale measured the extent to which the young person was opposed to authority figures. Higher opposition to authority has been found to be associated with more 'delinquent' behaviours in adolescence (Levy, 2001). All cognitive and non-cognitive variables are transformed into z-scores to enable comparison across the different measures. Further details on all the cognitive and non-cognitive measures in GUI at age 17 are available from Murphy et al. (2019).

Finally, we examine the role that parental health behaviours such as smoking and alcohol consumption play in predicting health behaviour cluster membership among adolescents. Unfortunately, no information on parental physical activity or diet is available in GUI. For smoking, a variable with four categories was constructed (neither parent smokes; at least parent one smokes occasionally; one parent smokes daily; both parents smoke daily). For alcohol consumption a fivecategory variable was constructed (neither drink alcohol; at least one drinks once a month; at least one drinks 1-2 times per month; at least one drinks 3-4 times per week; both drink 3-4 times per week). ${ }^{15}$

This section has focused on the independent variables measured at Wave 3, that is, 17 years of age. Chapter 3 includes additional analyses which examine the extent to which the patterns change when these characteristics at ages nine and 13 are considered. Table A1 in the Appendix contains further details on variable definitions for all independent variables used in this report.

\subsubsection{Independent variables: school characteristics}

Chapter 4 builds upon the analyses presented in Chapter 3 by examining the influence of the primary and second-level school attended on health behaviours among young people. Cohort ' 98 was sampled on the basis of the primary school attended at age nine (see above). By 13 years of age, almost all of the cohort had made the transition to second-level education, but the nature of school choice meant that there was no simple mapping between a single 'feeder' primary school and a specific second-level school. The 17-year-olds in the sample were thus drawn from 844 different primary schools and 610 second-level schools. The analyses 
investigate the effects of three sets of factors: school type; school policies and practices regarding health promotion; and the interaction between the young person and the school context in the form of engagement or disengagement.

At both primary and second level, we distinguish between coeducational, singlesex boys' and single-sex girls' schools, given the gender differences in health behaviours found in previous research (see Chapter 1). The GUI study collects rich information on the socio-economic background of children and their families (see above). In addition, as in previous research (see, for example, McCoy et al., 2014), the distinction between DEIS schools, ${ }^{16}$ non-DEIS (non-fee-paying) schools and feepaying schools ${ }^{17}$ is used as a proxy for school social mix. The findings are not intended as an assessment of the impact of participation in the scheme and it may be that any differences between DEIS and non-DEIS schools would be greater in the absence of the supports received. There is no strong basis for expecting health behaviours to vary systematically by school size. However, previous research has shown challenges for small schools in providing the full range of curricular and extracurricular options (Smyth, 2016) as well as less access to sports facilities or gyms (Darmody et al., 2010). We therefore take account of school size in the analyses. School size was measured on the basis of principal reports, using different cut-offs at primary and second level, reflecting the difference in average school size.

A number of aspects of school policy and practice were analysed. At primary level (Wave 1), principals were asked about the importance of PE/sports in terms of overall school ethos as well as curricular and extra-curricular activities. At both primary and second level (Waves 1 and 2), principals were asked about the adequacy of school facilities, including those for PE/sports. At Wave 2, second-level principals were asked about the provision of individual and team sports on an extra-curricular basis and about policies in relation to healthy eating. Principals at Wave 2 were also asked about student involvement in different aspects of school life, parental involvement in the school, teacher engagement and cooperation, and student engagement (see Appendix Table A1).

As previous research had pointed to the role of school disaffection in health behaviour (see Chapter 1), a number of factors relating to school engagement were analysed. At the age of nine, children had been asked about whether they 'always', 'sometimes' or 'never' liked the school they attended, which we take as an

16 Under the Delivering Equality of Opportunity in Schools (DEIS) initiative, schools with a concentration of students from disadvantaged backgrounds receive additional funding and supports. At primary level, there is a distinction between Urban Band 1 (the most deprived), Urban Band 2 and rural DEIS schools. At second-level, there is a single category of DEIS schools. 
indicator of school engagement at primary level. In addition, test scores in the Drumcondra mathematics test are used as a measure of primary school achievement. ${ }^{18}$ At the age of 13 (Wave 2), young people were again asked about their attitudes to school, though, reflecting their age, a more differentiated measure was used, with answers ranging from 'I like it very much' to 'I hate it'. Young people were asked about the frequency of different types of interaction with their teachers, items which yielded two scales on positive interaction (including praise and positive feedback) and negative interaction (including being reprimanded for misbehaviour or schoolwork not being completed). Two measures of cognitive development/achievement were used: test scores in the Drumcondra Numerical Reasoning test, taken at 13, and the number of higher-level subjects taken in the Junior Certificate exam (see Appendix Table A1).

\subsection{METHODS}

In this report, we use latent class analysis to examine how the four main health behaviours (smoking, consumption of alcohol, physical activity and diet) cluster among the young adult population. As the four health behaviours are measured using different units, all four health behaviour variables were standardised using z-scores before analysis. Latent class analysis is used to identify groups of individuals characterised by similar clusters of health behaviours. Latent class analysis is a data-driven and person-centred approach. It does not predefine groups (in this application, what is meant by 'healthy' or 'unhealthy'), but rather identifies groups based on shared characteristics within the data (Hartz et al., 2018). It therefore provides better estimates of the size and composition of the groups identified than using a single indicator (Pearce et al., 2013). It can also be used to examine the proportion of the population falling into each identified group, the types of health behaviours that characterise each group, and the factors (e.g. gender, social background, non-cognitive skills, school environment) that predict membership of the different groups. ${ }^{19}$ To select the number of clusters that best fit the data, a two-class model was estimated first, and the number of classes was then increased. The final model was chosen based on a variety of model fit statistics (likelihood ratio values, AIC, BIC). ${ }^{20}$ This approach has a number of advantages over other data-reduction techniques (such as cluster analysis),

Unfortunately, techniques such as latent transition analysis, which analyses transitions in latent classes over time (Choi et al., 2018), cannot be employed in this study. This is because data on smoking and alcohol consumption are not available at Wave 1 (age nine) and Wave 2 (age 13). In addition, for exercise and diet, the underlying questions used to identify these health behaviours differed between the Wave 1 (age nine), Wave 2 (age 13) and Wave 3 (age 17) questionnaires. However, in Chapter 3 we look at the association between measures of health behaviours at age 17 and earlier health behaviours (at nine and 13), where the latter information is available. 
including using goodness-of-fit statistics to determine the number of groups rather than defining an arbitrary cut-off for group membership (Owen and Videras, 2016).

In Chapter 3, we examine the association between key variables relating to the young person and their family and membership of these latent classes using multinomial logit models (MNL). An MNL model is used in cases where the outcome variable is discrete but does not have a natural ordering. The signs of the coefficients in an MNL cannot be interpreted in the usual way and so we calculate relative risk ratios. The relative risk associated with variable $X_{j}$ for outcome $A$ reflects the relative risk of choosing alternative $A$ rather than alternative $B$ (the base outcome) when $X_{j}$ changes by one unit (Cameron and Trivedi, 2009). Stata 15 was used to conduct all analyses.

In Chapter 4, multilevel modelling is used to provide an accurate estimate of the extent of variation between schools in, and the effect of school characteristics on, health behaviours. This approach takes account of the clustering of students within schools (Goldstein, 2003). Such models therefore provide more accurate estimates of the effects of school characteristics.

We want to look at the effect of both primary and second-level school attended on health behaviours. Because of active school choice in Ireland, there is no simple mapping between individual primary and second-level schools; students from a specific primary school may go on to attend several different second-level schools and a second-level school may draw from several feeder primary schools. To allow for this complex pattern, cross-classified multilevel models are used whereby young people (level 1 of the multilevel model) are seen as belonging to a primary and a second-level school (both at level 2). For all models in Chapter 4, dummy variables have been included to indicate missing values. This approach has the advantage of using the total sample and thus providing more precise estimates. These dummy variables are not of substantive interest so are not reported in the tables. In the analyses, continuous independent variables are centred on their mean values so that the coefficient reflects an increase of one standard deviation in the factor of interest. Analyses presented in this report were carried out using the MLWin computer package developed in the Institute of Education, University of London (see Rasbash et al., 2012). The number of students per primary school varied from 1 to 30 while the number per second-level school ranged from 1 to 49 . Where there are fewer students per school, MLWin shrinks the estimates of school-level residuals to the population mean. As a result, the estimates of school effects should be interpreted as lower bound estimates since having more observations (students) per school would likely increase between-school variation. It is also worth noting that the estimates of the effects of school characteristics are more precise than would be the case if multilevel modelling was not used. 



\section{CHAPTER 3}

\section{Patterns of health behaviours in young adulthood}

\subsection{INTRODUCTION}

Chapter 2 introduced the data and methods that are used in this report. In this chapter, we detail how the four main health behaviours (smoking, alcohol, physical activity, diet) are clustered across the young adult population and how these clusters are associated with a variety of individual and family characteristics. We also examine the extent to which characteristics of the young person at ages nine and 13 influence health behaviour group membership at age 17.

\subsection{DESCRIPTIVE STATISTICS}

Before presenting the results from the latent class analysis, it is instructive to examine the raw correlations between each of the four health-related behaviours examined in this report. As described in Table 2.1 in the previous chapter, all health-related behaviours are scored positively, with higher values indicating 'better' behaviours. The data in Table 3.1 indicate that the strongest correlations are found between smoking and alcohol consumption, a finding echoed in previous analyses (Meader et al., 2016). ${ }^{21}$ The negative correlation between physical activity and alcohol consumption is consistent with previous research that has documented an association between alcohol consumption and sport/physical activity among Irish adolescents (particularly males) (Conry et al., 2011).

\section{TABLE 3.1 SPEARMAN CORRELATION COEFFICIENTS}

\begin{tabular}{l|c|c|c|c}
\hline & Smoking & Alcohol & Physical Activity & Diet \\
\hline Smoking & 1 & $0.3311 * * *$ & $0.0908 * * *$ & $0.0910 * * *$ \\
\hline Alcohol & & 1 & $-0.0342 * * *$ & $0.0280 * *$ \\
\hline Physical Activity & & 1 & $0.2572 * * *$ \\
\hline Diet & & & 1 \\
\hline & & & \\
\hline Source: $\quad$ GUI, '98 Cohort, Wave 3. & & \\
Note: & ${ }^{*}$ significant at 10 per cent; ** significant at 5 per cent; *** significant at 1 per cent.
\end{tabular}

Model fit statistics indicate that a three-class model fits the observed data best (see Table 3.2). Table 3.3 describes the three clusters, and Figure 3.1 presents the

21 Stratifying the analysis by gender, the correlations are replicated, with one exception. For alcohol and physical activity, the correlation is negative for young males, and positive (but non-significant) for young females. As all variables are scored positively, this indicates that males who are heavier consumers of alcohol are also more likely to be engaged in more days of 'hard' physical activity. 
mean z-scores for each of the four health-related behaviours for each cluster. Approximately 20 per cent of 17 -year-olds are grouped into a cluster we term 'unhealthy smokers and drinkers'. They are daily or occasional smokers, have the highest levels of alcohol consumption, relatively low (but not the worst) levels of 'hard' physical activity and score relatively poorly (but again not the worst) in terms of dietary quality. The second class, which we term 'unhealthy diet and physical activity', represent just over a third of the sample. They do not smoke, drink alcohol monthly or less, but have the worst levels of physical activity (just 1-2 days in the previous two weeks) and dietary quality. The remaining 43 per cent are termed 'healthy' as they do not smoke, drink monthly or less, exercise for $6+$ days, and have the highest dietary quality index score.

TABLE 3.2 MODEL FIT STATISTICS

\begin{tabular}{|l|c|c|c|c|}
\hline & Log-Likelihood & $\begin{array}{c}\text { Degrees of } \\
\text { Freedom }\end{array}$ & AIC & BIC \\
\hline Two latent classes & $-30,204.6$ & 13 & $60,435.2$ & $60,522.2$ \\
\hline Three latent classes & $-30,004.9$ & 18 & $60,045.7$ & $60,166.2$ \\
\hline Four latent classes & $-29,998.3$ & 23 & $60,042.6$ & $60,196.5$ \\
\hline
\end{tabular}

Source: GUI, ‘98 Cohort, Wave 3.

TABLE 3.3 LATENT CLASSES

\begin{tabular}{l|l|c}
\hline \multicolumn{1}{c|}{ Class } & \multicolumn{1}{c|}{ Description } & \multicolumn{1}{c}{$\%$} \\
\hline Class 1 & Unhealthy smokers and drinkers & 20.5 \\
Class 2 & Unhealthy diet and physical activity & 36.3 \\
Class 3 & Healthy & 43.2 \\
\hline
\end{tabular}

Source: GUI, '98 Cohort, Wave 3.

Note: Population weights are employed. 


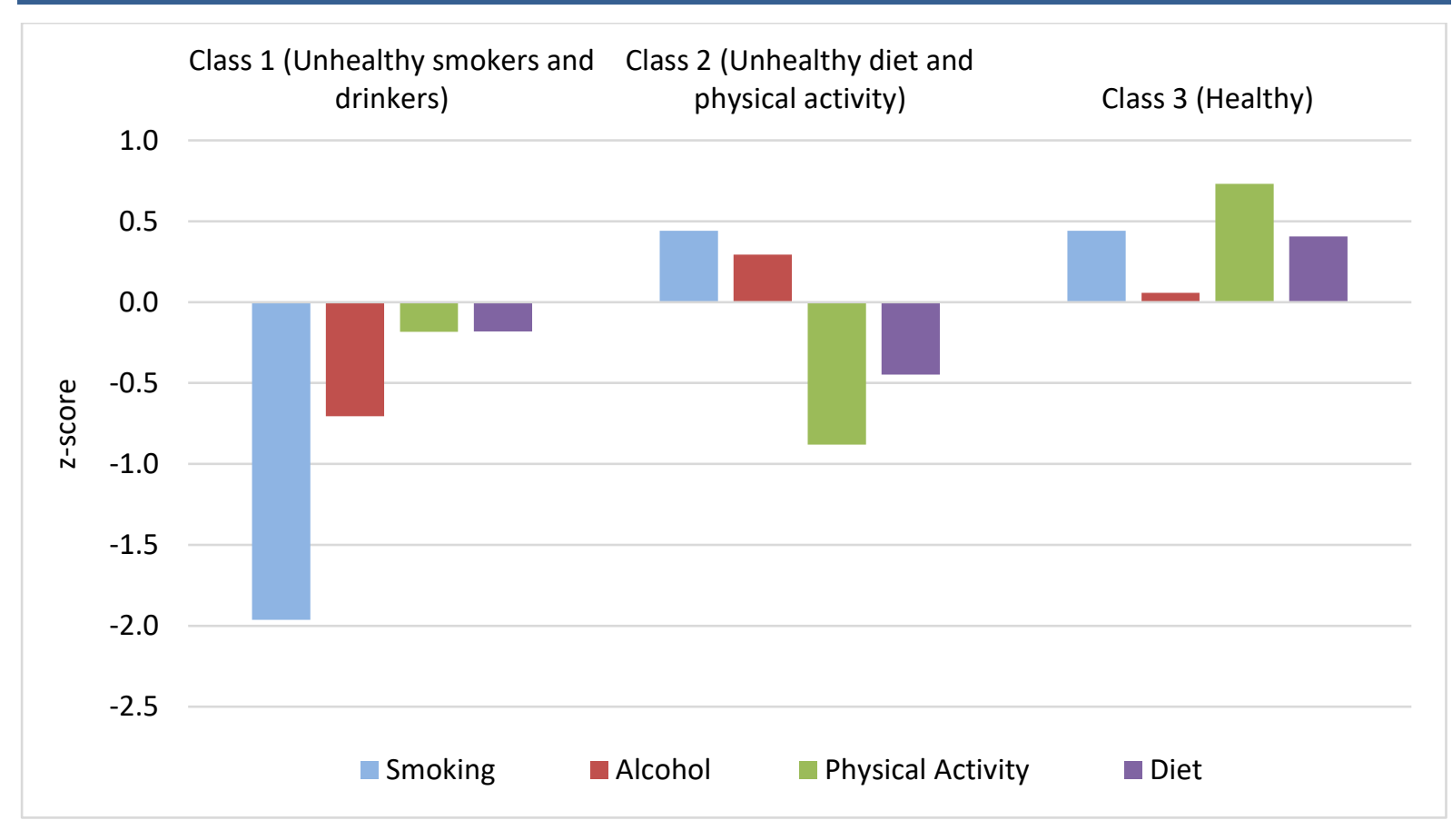

Source: GUI, ‘98 Cohort, Wave 3.

Next, we characterise the three groups based on the characteristics of the young person, their family SES background, their cognitive and non-cognitive skills, and their parental health behaviours. In Section 3.3, we move on to analyse these patterns in a multivariate framework, but for now, we simply examine bivariate associations between health behaviour cluster group and a variety of individual, parental and family characteristics measured at age 17 .

Focusing first on individual characteristics, the data in Table 3.4 indicate a significant difference by gender in the distribution of the three classes. While there is no significant difference in the proportion of young men and women classified as 'unhealthy smokers and drinkers', young women are much more likely than young men to be in the 'unhealthy diet and physical activity' group. Young men are therefore much more likely to be classified as 'healthy' than young women. A more detailed analysis of the behaviours of those who are classified as 'unhealthy diet and physical activity' reveals that females score relatively worse than males in terms of physical activity (consistent with previous research, see for example Leech et al., 2014), but also diet. Previous research has tended to find that young males have a worse diet than young females (Leech et al., 2014). However, our findings point to the opposite picture among this cohort of 17-year-olds. A more detailed analysis of dietary behaviours among young males and females indicates significant gender differences for most items; of the 17 detailed food items that comprise the dietary quality index, males score better than females on seven items, females better than males on seven items, and for three items there is no statistically 
significant gender difference (see Appendix Table A2). However, overall, males have a higher dietary quality index score than females.

Young people who have left school are significantly more likely to be in the 'unhealthy smokers and drinkers' group, perhaps reflecting the greater personal freedom that accompanies the transition to college or work. There is a clear relationship between self-assessed health and group membership; young people who report better health are significantly more likely to be in the 'healthy' group. While the focus of this report is on the four major risk factors for chronic disease identified by the WHO, group membership is also associated with other health- and preventive-type behaviours. For example, those who belong to the 'healthy' group brush their teeth more frequently, eat breakfast more frequently and sleep for more hours per night than those in the other two groups, particularly those in the 'unhealthy smokers and drinkers' group.

TABLE 3.4 DEMOGRAPHIC AND HEALTH CHARACTERISTICS BY LATENT CLASS

\begin{tabular}{|l|c|c|c|}
\hline & $\begin{array}{c}\text { Class 1 } \\
\text { 'Unhealthy smokers } \\
\text { and drinkers' }\end{array}$ & $\begin{array}{c}\text { Class 2 } \\
\text { 'Unhealthy diet and } \\
\text { physical activity' }\end{array}$ & $\begin{array}{c}\text { Class 3 } \\
\text { 'Healthy' }\end{array}$ \\
\hline \% male & 48.0 & 35.5 & 58.7 \\
\hline Age & {$[45.1-51.0]$} & {$[33.4-37.5]$} & $17.9-60.5]$ \\
\hline \% still in school & 17.2 & 17.2 & {$[17.1-17.2]$} \\
\hline \% excellent/very good & {$[17.2-17.2]$} & {$[17.2-17.2]$} & 90.7 \\
\hline self-assessed health & 79.5 & 88.3 & {$[89.6-91.8]$} \\
\hline \% no chronic illness & {$[77.1-81.9]$} & {$[87.0-89.7]$} & 88.9 \\
\hline BMI (measured) & 69.0 & 74.5 & {$[87.7-90.1]$} \\
\hline Number days p/w eat & {$[66.2-71.7]$} & {$[72.6-76.4]$} & 90.1 \\
\hline breakfast & 83.5 & 83.8 & {$[89.0-91.2]$} \\
\hline Frequency of daily teeth & {$[81.3-85.7]$} & {$[82.2-85.4]$} & 22.8 \\
brushing & 23.2 & 23.0 & {$[22.7-22.9]$} \\
\hline Hours of sleep per night & {$[23.0-23.4]$} & {$[22.8-23.2]$} & 6.4 \\
\hline & {$[9.9-5.2]$} & 5.7 & {$[6.3-6.4]$} \\
\hline
\end{tabular}

Source: GUI, '98 Cohort, Wave 3.

Notes: 95 per cent confidence intervals are presented in parentheses.

Moving on to the socio-economic characteristics of the young person's household at age 17, the data presented in Table 3.5 reveal little difference in household equivalised income levels across the three groups, although those in the 'healthy' group do have significantly higher household incomes than those in the 'unhealthy diet and physical activity' group. A similar pattern is evident for deprivation, parental education and social class; those in the 'healthy' cluster are more advantaged than the other two groups. The proportion of lone parent households 
differs significantly across the three groups, with those in the 'unhealthy smokers and drinkers' group most likely to be from lone parent families, and those in the 'healthy' group least likely to be from lone parent families. There is no significant difference across the clusters in the proportion with a primary caregiver who was not born in Ireland.

TABLE 3.5 HOUSEHOLD SOCIO-ECONOMIC STATUS BY LATENT CLASS

\begin{tabular}{|l|c|c|c|}
\hline & $\begin{array}{c}\text { Class 1 } \\
\text { 'Unhealthy smokers } \\
\text { and drinkers' }\end{array}$ & $\begin{array}{c}\text { Class 2 } \\
\text { 'Unhealthy diet and } \\
\text { physical activity' }\end{array}$ & $\begin{array}{c}\text { Class 3 } \\
\text { 'Healthy' }\end{array}$ \\
\hline Equivalised household & 16,341 & 16,061 & 17,174 \\
income & {$[15,757-16,925]$} & {$[15,654-16,468]$} & {$[16,814-17,534]$} \\
\hline Deprivation score & 1.2 & 1.2 & 1.0 \\
\hline PCG third-level education & {$[1.1-1.3]$} & {$[1.1-1.3]$} & {$[0.9-1.0]$} \\
\hline Household professional/ & 29.9 & 27.1 & 34.1 \\
managerial social class & {$[27.2-32.7]$} & {$[25.2-29.0]$} & {$[32.4-35.9]$} \\
\hline PCG lone parent & 46.9 & 46.25 & 55.5 \\
& {$[44.0-49.9]$} & {$[44.1-48.4]$} & $153.7-57.4]$ \\
\hline PCG migrant & 22.4 & 15.8 & 11.5 \\
& {$[19.9-24.9]$} & {$[14.2-17.4]$} & $10.3-12.6]$ \\
\hline
\end{tabular}

Source: $\quad$ GUI, '98 Cohort, Wave 3.

Notes: 95 per cent confidence intervals are presented in parentheses.

As detailed in Section 2.1.2, an extensive set of variables relating to the cognitive and psycho-social or non-cognitive skills of the young person are collected at age 17. In Table 3.6, we analyse how membership of the three health behaviour clusters is associated with these different skills. There is a clear gradient in health behaviour cluster membership according to mathematical ability; those with higher scores are more likely to be in the 'healthy' cluster. Health behaviour cluster membership is also strongly associated with SDQ scores. While lower SDQ scores on all dimensions are associated with a higher probability of membership of the 'healthy' cluster, an examination of the different dimensions of the SDQ reveals some interesting differences across the two 'unhealthy' clusters. For example, the two 'unhealthy' clusters score the same in terms of the SDQ emotional symptoms subscale; but while the 'unhealthy smokers and drinkers' have much higher SDQ conduct problem and hyperactivity/inattention scores, the 'unhealthy diet and physical activity' have much higher SDQ peer relationship problem scores.

In terms of personality, as measured by the ten-item personality inventory (TIPI), those scoring higher in terms of extraversion are significantly less likely to belong to the 'unhealthy diet and physical activity' cluster. Those who are more agreeable are more likely to belong to this cluster. Those who score more highly in terms of conscientiousness and emotional stability are more likely to belong to the 'healthy' cluster, while those who are more open are significantly more likely to belong to 
the 'unhealthy smokers and drinkers' cluster. There is a clear gradient in terms of health behaviour cluster membership and internal locus of control, self-efficacy and self-esteem scores, with those with higher scores on all three measures less likely to belong to the 'unhealthy' groups. In terms of coping strategies, those who use avoidance techniques are much more likely to belong to the "unhealthy smokers and drinkers' group (and they also have much higher IPPA alienation and opposition to authority scores). Those in the 'healthy' group have much higher adult identity scores than those in the other two 'unhealthy' groups. 
TABLE 3.6 COGNITIVE AND NON-COGNITIVE SKILLS BY LATENT CLASS

\begin{tabular}{|c|c|c|c|}
\hline & $\begin{array}{c}\text { Class } 1 \\
\text { 'Unhealthy smokers } \\
\text { and drinkers' }\end{array}$ & $\begin{array}{c}\text { Class } 2 \\
\text { 'Unhealthy diet and } \\
\text { physical activity' }\end{array}$ & $\begin{array}{l}\text { Class } 3 \\
\text { 'Healthy' }\end{array}$ \\
\hline Maths score (z-score) & $\begin{array}{c}-0.18 \\
{[-0.24--0.12]}\end{array}$ & $\begin{array}{c}-0.08 \\
{[-0.13--0.04]}\end{array}$ & $\begin{array}{c}0.14 \\
{[0.11-0.17]}\end{array}$ \\
\hline SDQ (total z-score) & $\begin{array}{c}0.34 \\
{[0.28-0.41]}\end{array}$ & $\begin{array}{c}0.07 \\
{[0.03-0.11]}\end{array}$ & $\begin{array}{c}-0.19 \\
{[-0.22--0.15]}\end{array}$ \\
\hline $\begin{array}{l}\text { SDQ emotional symptoms } \\
\text { (z-score) }\end{array}$ & $\begin{array}{c}0.13 \\
{[0.06-0.19]}\end{array}$ & $\begin{array}{c}0.17 \\
{[0.13-0.22]}\end{array}$ & $\begin{array}{c}-0.18 \\
{[-0.21--0.15]}\end{array}$ \\
\hline $\begin{array}{l}\text { SDQ conduct problems } \\
\text { (z-score) }\end{array}$ & $\begin{array}{c}0.42 \\
{[0.34-0.49]}\end{array}$ & $\begin{array}{c}-0.09 \\
{[-0.13--0.05]}\end{array}$ & $\begin{array}{c}-0.10 \\
{[-0.13--0.06]}\end{array}$ \\
\hline $\begin{array}{l}\text { SDQ hyperactivity/ } \\
\text { inattention (z-score) }\end{array}$ & $\begin{array}{c}0.41 \\
{[0.34-0.47]}\end{array}$ & $\begin{array}{c}-0.06 \\
{[-0.10--0.02]}\end{array}$ & $\begin{array}{c}-0.11 \\
{[-0.15--0.08]}\end{array}$ \\
\hline $\begin{array}{l}\text { SDQ peer relationship } \\
\text { problems (z-score) }\end{array}$ & $\begin{array}{c}-0.00 \\
{[-0.06-0.06]}\end{array}$ & $\begin{array}{c}0.15 \\
{[0.10-0.20]}\end{array}$ & $\begin{array}{c}-0.11 \\
{[-0.15--0.08]}\end{array}$ \\
\hline $\begin{array}{l}\text { SDQ prosocial behaviour } \\
\text { (z-score) }\end{array}$ & $\begin{array}{c}-0.16 \\
{[-0.23--0.10]}\end{array}$ & $\begin{array}{c}0.03 \\
{[-0.01-0.08]}\end{array}$ & $\begin{array}{c}0.04 \\
{[0.00-0.07]}\end{array}$ \\
\hline $\begin{array}{l}\text { Personality - Extraversion } \\
\text { (z-score) }\end{array}$ & $\begin{array}{c}0.16 \\
{[0.10-0.22]}\end{array}$ & $\begin{array}{c}-0.23 \\
{[-0.28--0.19]}\end{array}$ & $\begin{array}{c}0.11 \\
{[0.07-0.15]}\end{array}$ \\
\hline $\begin{array}{l}\text { Personality - } \\
\text { Agreeableness (z-score) }\end{array}$ & $\begin{array}{c}-0.12 \\
{[-0.18--0.06]}\end{array}$ & $\begin{array}{c}0.10 \\
{[0.05-0.14]}\end{array}$ & $\begin{array}{c}-0.03 \\
{[-0.06-0.01]}\end{array}$ \\
\hline $\begin{array}{l}\text { Personality - } \\
\text { Conscientiousness } \\
\text { (z-score) }\end{array}$ & $\begin{array}{c}-0.31 \\
{[-0.37--0.25]}\end{array}$ & $\begin{array}{c}-0.00 \\
{[-0.04-0.04]}\end{array}$ & $\begin{array}{c}0.12 \\
{[0.09-0.16]}\end{array}$ \\
\hline $\begin{array}{l}\text { Personality - Emotional } \\
\text { Stability (z-score) }\end{array}$ & $\begin{array}{c}-0.14 \\
{[-0.21--0.08]}\end{array}$ & $\begin{array}{c}-0.19 \\
{[-0.23--0.14]}\end{array}$ & $\begin{array}{c}0.20 \\
{[0.16-0.23]}\end{array}$ \\
\hline $\begin{array}{l}\text { Personality - Openness } \\
\text { (z-score) }\end{array}$ & $\begin{array}{c}0.14 \\
{[0.08-0.20]}\end{array}$ & $\begin{array}{c}-0.10 \\
{[-0.15--0.06]}\end{array}$ & $\begin{array}{c}0.02 \\
{[-0.01-0.06]}\end{array}$ \\
\hline $\begin{array}{l}\text { Internal locus of control } \\
\text { (z-score) }\end{array}$ & $\begin{array}{c}-0.01 \\
{[-0.08-0.06]}\end{array}$ & $\begin{array}{c}-0.09 \\
{[-0.14--0.04]}\end{array}$ & $\begin{array}{c}0.07 \\
{[0.03-0.11]}\end{array}$ \\
\hline Self-efficacy (z-score) & $\begin{array}{c}-0.19 \\
{[-0.25--0.13]}\end{array}$ & $\begin{array}{c}-0.18 \\
{[-0.22--0.13]}\end{array}$ & $\begin{array}{c}0.21 \\
{[0.17-0.24]}\end{array}$ \\
\hline Self-esteem (z-score) & $\begin{array}{c}-0.27 \\
{[-0.33--0.21]}\end{array}$ & $\begin{array}{c}-0.15 \\
{[-0.20--0.11]}\end{array}$ & $\begin{array}{c}0.22 \\
{[0.18-0.25]}\end{array}$ \\
\hline $\begin{array}{l}\text { Coping Strategies } \\
\text { Indicator (CSI) - problem } \\
\text { solving subscale (z-score) }\end{array}$ & $\begin{array}{c}-0.22 \\
{[-0.28--0.16]}\end{array}$ & $\begin{array}{c}-0.05 \\
{[-0.09--0.01]}\end{array}$ & $\begin{array}{c}0.12 \\
{[0.08-0.16]}\end{array}$ \\
\hline $\begin{array}{l}\text { CSI - support subscale (z- } \\
\text { score) }\end{array}$ & $\begin{array}{c}-0.06 \\
{[-0.12-0.00]}\end{array}$ & $\begin{array}{c}0.01 \\
{[-0.03-0.06]}\end{array}$ & $\begin{array}{c}0.01 \\
{[-0.02-0.05]}\end{array}$ \\
\hline $\begin{array}{l}\text { CSI - avoidance subscale } \\
\text { (z-score) }\end{array}$ & $\begin{array}{c}0.26 \\
{[0.19-0.32]}\end{array}$ & $\begin{array}{c}0.10 \\
{[0.05-0.14]}\end{array}$ & $\begin{array}{c}-0.17 \\
{[-0.21--0.14]}\end{array}$ \\
\hline $\begin{array}{l}\text { Inventory of Parent and } \\
\text { Peer Attachment (IPPA) - } \\
\text { trust subscale (z-score) }\end{array}$ & $\begin{array}{c}-0.13 \\
{[-0.19--0.07]}\end{array}$ & $\begin{array}{c}-0.01 \\
{[-0.06-0.03]}\end{array}$ & $\begin{array}{c}0.06 \\
{[0.03-0.10]}\end{array}$ \\
\hline $\begin{array}{l}\text { IPPA - communication } \\
\text { subscale (z-score) }\end{array}$ & $\begin{array}{c}-0.06 \\
{[-0.12-0.00]}\end{array}$ & $\begin{array}{c}0.02 \\
{[-0.02-0.06]}\end{array}$ & $\begin{array}{c}0.01 \\
{[-0.03-0.05]}\end{array}$ \\
\hline $\begin{array}{l}\text { IPPA - alienation subscale } \\
\text { (z-score) }\end{array}$ & $\begin{array}{c}0.26 \\
{[0.20-0.31]}\end{array}$ & $\begin{array}{c}0.05 \\
{[0.01-0.09]}\end{array}$ & $\begin{array}{c}-0.14 \\
{[-0.17--0.10]}\end{array}$ \\
\hline $\begin{array}{l}\text { Adult Identity Resolution } \\
\text { scale (z-score) }\end{array}$ & $\begin{array}{c}-0.04 \\
{[-0.11-0.02]}\end{array}$ & $\begin{array}{c}-0.07 \\
{[-0.11--0.02]}\end{array}$ & $\begin{array}{c}0.07 \\
{[0.03-0.10]}\end{array}$ \\
\hline $\begin{array}{l}\text { Opposition to Authority } \\
\text { scale (z-score) }\end{array}$ & $\begin{array}{c}0.62 \\
{[0.56-0.68]}\end{array}$ & $\begin{array}{c}-0.13 \\
{[-0.17--0.09]}\end{array}$ & $\begin{array}{c}-0.15 \\
{[-0.18--0.11]}\end{array}$ \\
\hline
\end{tabular}

Source: GUI, '98 Cohort, Wave 3.

Notes: $\quad 95$ per cent confidence intervals are presented in parentheses. 
The data in Table 3.7 indicate a clear correlation between parental smoking and the young person's health behaviour cluster membership. Those with at least one parent who smokes daily or occasionally are significantly more likely to belong to the 'unhealthy smokers and drinkers' group. The pattern for parental alcohol consumption is more complex; while there is no difference in the alcohol consumption of the parents of those in the 'unhealthy smokers and drinkers' and 'healthy' groups, those in the 'unhealthy diet and physical activity' are more likely to have a parent with less frequent alcohol consumption.

\section{TABLE 3.7 PARENTAL HEALTH BEHAVIOURS BY LATENT CLASS}

\begin{tabular}{|l|c|c|c|} 
& $\begin{array}{c}\text { Class 1 } \\
\text { 'Unhealthy smokers } \\
\text { and drinkers' }\end{array}$ & $\begin{array}{c}\text { Class 2 } \\
\text { 'Unhealthy diet and } \\
\text { physical activity' }\end{array}$ & $\begin{array}{c}\text { Class 3 } \\
\text { 'Healthy' }\end{array}$ \\
\hline At least one parent smokes & 37.9 & 24.4 & 22.5 \\
occasionally/daily & {$[35.0-40.9]$} & {$[22.5-26.2]$} & {$[20.9-24.8]$} \\
\hline At least one parent drinks & 59.8 & 53.2 & 59.9 \\
1-2 times per week or more & {$[56.9-62.7]$} & {$[51.0-55.3]$} & {$[58.1-61.8]$}
\end{tabular}

Source: GUI, '98 Cohort, Wave 3.

Notes: 95 per cent confidence intervals are presented in parentheses.

\subsection{MULTIVARIATE MODELS}

Up to now we have presented data on the bivariate association between different characteristics of the young person and their family and their health behaviour cluster membership. In this section, we take into account the fact that many of these individual and family characteristics are correlated (e.g. family SES 22 and parental health behaviours) in an attempt to isolate the independent effect of different explanatory variables. While we cannot infer causality from these models, the results will give an indication of the most important influences on health behaviour cluster membership. In Section 3.4, we expand this analysis to consider the influence of individual and family characteristics measured at earlier time points, at ages nine and 13 .

Table 3.8a presents relative risk ratios from a multinomial logit model of health behaviour group membership, focusing on the results for demographic and socioeconomic characteristics. This model also controls for cognitive and non-cognitive skills (results presented in Table 3.8b) and for parental health behaviours (results presented in Table 3.8c). The reference health behaviour cluster refers to those in the 'healthy' group. The results confirm the descriptive patterns by gender in Table 3.4; young females are significantly more likely than young males to be in the 'unhealthy diet and physical activity' group. However, the results now indicate that

22 As noted in Section 2.1.2, we include three broad indicators of family social background: household equivalised income, highest level of education of the primary caregiver and family social class. See Section 3.5 for details of further robustness checks. 
young women are also more likely than young men to be in the 'unhealthy smokers and drinkers' group. Those who have left second-level education are significantly more likely to be in the 'unhealthy smokers and drinkers' group. This effect persists even when controlling for age, suggesting that the greater freedoms (and perhaps economic resources) that accompany non-school based activities may encourage relatively more unhealthy behaviours.

We find no effect for household income once all controls have been added to the models, though those from more advantaged social classes (as well as the never employed) are less likely to fall into the 'unhealthy smokers and drinkers' group and those from families with a primary caregiver with at least post-secondary education are less likely to be in the 'unhealthy diet and physical activity' group. In addition, young people from lone parent families with one child are significantly more likely to be in the 'unhealthy smokers and drinkers' group. Examining the association between health behaviour cluster group membership and family SES without other controls for cognitive and non-cognitive skills and parental health behaviours reveals that the patterns shown in Table 3.8a for family SES continue to hold, suggesting that the effect of family SES is not mediated by the cognitive or non-cognitive skills of the young person, or their parents' health behaviours (results not shown).

TABLE 3.8A MULTINOMIAL LOGIT MODEL OF GROUP MEMBERSHIP (DEMOGRAPHIC AND SOCIOECONOMIC CHARACTERISTICS)

\begin{tabular}{|c|c|c|}
\hline & $\begin{array}{c}\text { Class } 1 \\
\text { 'Unhealthy smokers and } \\
\text { drinkers' }\end{array}$ & $\begin{array}{c}\text { Class } 2 \\
\text { 'Unhealthy diet and } \\
\text { physical activity' }\end{array}$ \\
\hline Male & Ref & Ref \\
\hline \multirow[t]{2}{*}{ Female } & $1.575^{* * *}$ & $2.344 * * *$ \\
\hline & $(0.161)$ & (0.192) \\
\hline \multirow[t]{2}{*}{ Age } & 1.187 & $1.211^{* *}$ \\
\hline & $(0.133)$ & $(0.106)$ \\
\hline Still in second-level school & Ref & Ref \\
\hline \multirow[t]{2}{*}{ Left second-level school } & $2.086 * * *$ & 1.072 \\
\hline & $(0.265)$ & $(0.123)$ \\
\hline Two parents with 1 or 2 children & Ref & Ref \\
\hline \multirow[t]{2}{*}{ Two parents with $3+$ children } & $0.796 * *$ & 0.941 \\
\hline & $(0.084)$ & $(0.075)$ \\
\hline \multirow[t]{2}{*}{ Lone parent with 1 or 2 children } & $1.467^{* * *}$ & 0.994 \\
\hline & $(0.195)$ & $(0.112)$ \\
\hline \multirow[t]{2}{*}{ Lone parent with $3+$ children } & 1.493 & 1.347 \\
\hline & $(0.384)$ & $(0.275)$ \\
\hline
\end{tabular}


TABLE 3.8A CONTD.

\begin{tabular}{|l|c|c|}
\hline & $\begin{array}{c}\text { Class 1 } \\
\text { 'Unhealthy smokers and } \\
\text { drinkers' }\end{array}$ & $\begin{array}{c}\text { Class 2 } \\
\text { 'Unhealthy diet and } \\
\text { physical activity' }\end{array}$ \\
\hline Household equivalised income (lowest) & $\begin{array}{c}\text { Ref } \\
\text { Ref }\end{array}$ & 1.195 \\
\hline Household equivalised income (Q2) & 0.973 & $(0.153)$ \\
\hline Household equivalised income (Q3) & $(0.155)$ & 1.045 \\
\hline Household equivalised income (Q4) & 0.903 & $(0.134)$ \\
\hline Household equivalised income (highest) & $(0.144)$ & 1.169 \\
\hline
\end{tabular}

\begin{tabular}{|c|c|c|}
\hline Primary caregiver (PCG) primary level education & Ref & Ref \\
\hline \multirow[t]{2}{*}{ PCG lower secondary education } & 1.313 & 0.761 \\
\hline & $(0.435)$ & $(0.207)$ \\
\hline \multirow[t]{2}{*}{ PCG upper secondary education } & 1.538 & 0.675 \\
\hline & $(0.474)$ & $(0.175)$ \\
\hline \multirow[t]{2}{*}{ PCG post-secondary education } & 1.565 & $0.541 * *$ \\
\hline & $(0.499)$ & $(0.145)$ \\
\hline \multirow[t]{2}{*}{ PCG degree education } & 1.572 & $0.527 * *$ \\
\hline & $(0.512)$ & $(0.144)$ \\
\hline \multirow[t]{2}{*}{ PCG postgraduate degree education } & 1.713 & $0.581^{*}$ \\
\hline & $(0.578)$ & $(0.163)$ \\
\hline \multirow[t]{2}{*}{ Professional } & $0.563^{* * *}$ & 0.914 \\
\hline & $(0.112)$ & $(0.142)$ \\
\hline \multirow[t]{2}{*}{ Managerial/technical } & $0.727^{* *}$ & 1.024 \\
\hline & $(0.118)$ & $(0.137)$ \\
\hline \multirow[t]{2}{*}{ Other non-manual } & $0.749 *$ & 1.064 \\
\hline & $(0.125)$ & $(0.144)$ \\
\hline \multirow[t]{2}{*}{ Skilled manual } & 0.965 & 1.102 \\
\hline & $(0.182)$ & $(0.173)$ \\
\hline Semi-/unskilled manual & Ref & Ref \\
\hline \multirow[t]{2}{*}{ Never employed } & $0.680 * *$ & 1.234 \\
\hline & $(0.133)$ & $(0.191)$ \\
\hline
\end{tabular}

\begin{tabular}{|l|c|c|}
\hline PCG born in Ireland & Ref & Ref \\
\hline PCG not born in Ireland & 0.981 & 1.085 \\
& $(0.122)$ & $(0.105)$ \\
\hline
\end{tabular}

N 5,073

Log-Likelihood $-4,569.23$

Source: $\quad$ GUI, '98 Cohort, Wave 3.

Notes: $\quad *$ significant at 10 per cent level; ${ }^{* *}$ significant at 5 per cent level; ${ }^{* * *}$ significant at 1 per cent level.

The model also contains controls for cognitive and non-cognitive skills (Table 3.8b) and parental health behaviours (Table 3.8c). Results presented in the form of relative risk ratios. All models used predictors measured at Wave 3. 
Table 3.8b focuses on the results for the young person's cognitive and noncognitive skills. Higher numeracy/financial literacy is associated with a lower probability of belonging to the two 'unhealthy' groups, particularly the 'unhealthy diet and physical activity' group. In terms of SDQ scores, while different scores on the emotional problems subscale no longer predict group membership after controlling for all other covariates, the patterns identified in Table 3.6 for conduct, hyperactivity and peer relationship problems persist. Those with worse scores on the conduct and hyperactivity subscales are significantly more likely to be in the 'unhealthy smokers and drinkers' group, while those with peer relationship problem scores are more likely to be in the 'unhealthy diet and physical activity' group. The significant results for personality presented in Table 3.6 are also robust to the inclusion of additional control variables, with lower conscientiousness and higher openness predictive of membership of the 'unhealthy smokers and drinkers' group. Use of an 'avoidance' coping strategy is associated with a significantly higher probability of being in the 'unhealthy smokers and drinkers' group, as is a higher degree of alienation from peers. Opposition to authority scale scores have particularly large effects on group membership, with those scoring higher on opposition to authority being significantly more likely to belong to the 'unhealthy smokers and drinkers' group.

TABLE 3.8B MULTINOMIAL LOGIT MODEL OF GROUP MEMBERSHIP (COGNITIVE AND NONCOGNITIVE SKILLS)

\begin{tabular}{|l|c|c|}
\hline & $\begin{array}{c}\text { Class 1 } \\
\text { 'Unhealthy smokers and } \\
\text { drinkers' }\end{array}$ & $\begin{array}{c}\text { Class 2 } \\
\text { 'Unhealthy diet and } \\
\text { physical activity' }\end{array}$ \\
\hline Cognitive test score (numeracy) & $0.923^{*}$ & $(0.035)$ \\
\hline SDQ Emotional & $(0.043)$ & 1.043 \\
\hline SDQ Conduct & 0.949 & $(0.044)$ \\
\hline SDQ Hyperactivity & $(0.051)$ & $0.906 * *$ \\
\hline SDQ Peer & $1.297^{* * *}$ & $(0.040)$ \\
\hline SDQ Prosocial & $(0.066)$ & 1.040 \\
\hline Extraversion & $1.171^{* * *}$ & $(0.046)$ \\
\hline
\end{tabular}


TABLE 3.8B CONTD.

\begin{tabular}{|c|c|c|}
\hline & $\begin{array}{c}\text { Class } 1 \\
\text { 'Unhealthy smokers and } \\
\text { drinkers' }\end{array}$ & $\begin{array}{c}\text { Class } 2 \\
\text { 'Unhealthy diet and } \\
\text { physical activity' }\end{array}$ \\
\hline \multirow[t]{2}{*}{ Agreeableness } & 1.017 & $1.092 * *$ \\
\hline & $(0.046)$ & $(0.039)$ \\
\hline \multirow[t]{2}{*}{ Conscientiousness } & $0.809 * * *$ & $0.881 * * *$ \\
\hline & $(0.037)$ & $(0.033)$ \\
\hline \multirow[t]{2}{*}{ Emotional Stability } & 0.953 & $0.876 * * *$ \\
\hline & $(0.051)$ & $(0.036)$ \\
\hline \multirow[t]{2}{*}{ Openness } & $1.105^{* *}$ & 0.947 \\
\hline & $(0.053)$ & $(0.033)$ \\
\hline \multirow[t]{2}{*}{ Coping Strategies Inventory (CSI) (problem-solving) } & $0.853^{* * *}$ & $0.916^{* *}$ \\
\hline & $(0.046)$ & $(0.037)$ \\
\hline \multirow[t]{2}{*}{ CSI (support) } & $1.128 *$ & 1.021 \\
\hline & $(0.071)$ & $(0.050)$ \\
\hline \multirow[t]{2}{*}{ CSI (avoidance) } & & $1.116^{* * *}$ \\
\hline & $(0.062)$ & $(0.047)$ \\
\hline \multirow[t]{2}{*}{ Peer attachment (trust) } & 0.939 & 0.978 \\
\hline & $(0.076)$ & $(0.063)$ \\
\hline \multirow[t]{2}{*}{ Peer attachment (communication) } & 1.086 & 0.970 \\
\hline & $(0.093)$ & $(0.067)$ \\
\hline \multirow[t]{2}{*}{ Peer attachment (alienation) } & $1.180^{* * *}$ & 0.976 \\
\hline & $(0.064)$ & $(0.044)$ \\
\hline \multirow[t]{2}{*}{ Opposition to authority } & $1.832 * * *$ & 0.948 \\
\hline & $(0.095)$ & $(0.039)$ \\
\hline$N$ & \multicolumn{2}{|c|}{5,073} \\
\hline Log-Likelihood & \multicolumn{2}{|c|}{$-4,569.23$} \\
\hline
\end{tabular}

Source: $\quad$ GUI, '98 Cohort, Wave 3.

Notes: $\quad *$ significant at 10 per cent level; ${ }^{* *}$ significant at 5 per cent level; ${ }^{* * *}$ significant at 1 per cent level.

The model also contains controls for demographic and socioeconomic characteristics (Table 3.8a) and parental health behaviours (Table 3.8c). Results presented in the form of relative risk ratios. All models used predictors measured at Wave 3.

In Table 3.8c, we present the results for controls for parental smoking and alcohol consumption. As shown in Table 3.7, parental smoking is strongly related to the young person's probability of being in the 'unhealthy smokers and drinkers' group. The findings for alcohol consumption are now clearer; those whose parents drink alcohol more frequently are themselves more likely to drink alcohol frequently and to be in the 'unhealthy smokers and drinkers' group.

Finally, it is instructive to assess the relative contribution of the different sets of factors (social background, cognitive and non-cognitive skills, parental health 
behaviours) to the explanatory power of the model. While pseudo- $\mathrm{R}^{2}$ cannot be interpreted as the proportion of the variance in the dependent variable that is explained by the model, the results in Table $A 3$ show the change in the pseudo- $\mathrm{R}^{2}$ as different sets of explanatory variables are added to the base model which controls for sex, age and school status only. Family background adds very little to the initial model (explaining 4 per cent as opposed to 2.8 per cent of the variance). In contrast, adding cognitive and non-cognitive skills considerably improves model fit (to 12.5 per cent) while parental health behaviours make only a slight difference.

TABLE 3.8C MULTINOMIAL LOGIT MODEL OF GROUP MEMBERSHIP (PARENTAL HEALTH BEHAVIOURS)

\begin{tabular}{|c|c|c|}
\hline & $\begin{array}{c}\text { Class } 1 \\
\text { 'Unhealthy smokers and } \\
\text { drinkers' }\end{array}$ & $\begin{array}{c}\text { Class } 2 \\
\text { 'Unhealthy diet and } \\
\text { physical activity' }\end{array}$ \\
\hline Neither parent smokes & Ref & Ref \\
\hline \multirow{2}{*}{ At least one parent smokes occasionally } & $1.761^{* * *}$ & 0.857 \\
\hline & $(0.265)$ & (0.123) \\
\hline \multirow[t]{2}{*}{ One parent smokes daily } & $1.587^{* * *}$ & 1.038 \\
\hline & $(0.179)$ & $(0.100)$ \\
\hline \multirow[t]{2}{*}{ Both parents smoke daily } & 1.243 & 1.007 \\
\hline & $(0.309)$ & $(0.213)$ \\
\hline Neither parent drinks & Ref & Ref \\
\hline \multirow[t]{2}{*}{ At least one parent drinks monthly or less } & $1.627^{* *}$ & 1.078 \\
\hline & $(0.323)$ & $(0.153)$ \\
\hline \multirow[t]{2}{*}{ At least one parent drinks 1-2 times per month } & 1.236 & $0.774^{*}$ \\
\hline & $(0.243)$ & $(0.107)$ \\
\hline \multirow[t]{2}{*}{ At least one parent drinks 1-2 times per week } & $1.383^{*}$ & 0.844 \\
\hline & $(0.257)$ & $(0.111)$ \\
\hline \multirow[t]{2}{*}{ At least one parent drinks 3-4 times per week } & $1.575^{* *}$ & $0.761^{*}$ \\
\hline & $(0.309)$ & $(0.109)$ \\
\hline $\mathrm{N}$ & \multicolumn{2}{|c|}{5,073} \\
\hline Log-Likelihood & \multicolumn{2}{|c|}{$-4,569.23$} \\
\hline
\end{tabular}

Source: GUI, '98 Cohort, Wave 3.

Notes: $\quad *$ significant at 10 per cent level; ${ }^{* *}$ significant at 5 per cent level; ${ }^{* * *}$ significant at 1 per cent level. The model also contains controls for demographic and socioeconomic characteristics (Table 3.8a) and cognitive and non-cognitive skills (Table 3.8b). Results presented in the form of relative risk ratios. All models used predictors measured at Wave 3.

\subsection{LONGITUDINAL ANALYSIS OF HEALTH BEHAVIOURS AT AGE 17}

As noted, data on smoking and alcohol consumption are not available at Wave 1 (age nine) or Wave 2 (age 13). In addition, for exercise and diet, the questions used to identify these health behaviours differed between the Wave 1 (age nine), Wave 2 (age 13) and Wave 3 (age 17) questionnaires. This means that we cannot use techniques such as latent transition analysis to examine trajectories of health 
behaviour clusters over time. However, we do find that cluster group membership at age 17 is significantly related to health behaviours at age nine and 13 . Information on eating breakfast, exercise and dietary quality are available at ages nine and 13 , albeit using different instruments in each wave.

The data presented in Table 3.9 indicate that there is a significant association between both eating breakfast and engaging in hard exercise, and cluster group membership at age 17 . While having a better quality diet at age nine is associated with cluster group membership at age 17 , there is no association with the measure of dietary quality at age 13 . In general, however, those who exhibit 'better' health behaviours at ages nine and 13 are more likely to be in the 'healthy' group at age 17.

TABLE 3.9 ASSOCIATIONS BETWEEN HEALTH BEHAVIOURS AT AGES 9 AND 13 AND HEALTH BEHAVIOUR GROUP MEMBERSHIP AT AGE 17

\begin{tabular}{l|r|r}
\hline \multicolumn{1}{c}{ Behaviour } & Age 9 & Age 13 \\
\hline Eats breakfast & $9.094^{* * *}$ & $51.112 * * *$ \\
\hline Hard exercise & $77.207^{* * *}$ & $456.789 * * *$ \\
\hline Dietary quality index & $114.490 * * *$ & 62.744 \\
\hline
\end{tabular}

Source: $\quad$ GUI, '98 cohort, Waves 1, 2 and 3.

Notes: Results of chi-squared tests of association between health behaviour of eating breakfast, hard exercise or dietary quality (measured at age nine or 13) and categorical variable describing health behaviour cluster membership at age 17.

In Tables A4 and A5, we present MNL models predicting cluster group membership at age 17, using predictors measured at ages nine (Table A4) and 13 (Table A5) respectively. The purpose of these analyses is to examine the extent to which the predictors of cluster group membership at age 17 are stable over time. The addition of pregnancy/early life characteristics, reported at age nine, also allows us to examine the influence of these characteristics on health behaviours at age 17 .

The results in Table A4 indicate that while mothers' smoking behaviour in pregnancy has no effect on the probability of cluster group membership at age 17, the children of mothers who drank alcohol occasionally in pregnancy are significantly more likely to belong to the 'unhealthy smokers and drinkers' group at age 17. The effect for breastfeeding is interesting; those who were not breastfed in early life are significantly more likely to belong to the 'unhealthy diet and physical activity' group at age 17. Like the results at age 17, SDQ conduct and hyperactivity problems, this time measured at age nine, are highly predictive of belonging to the 'unhealthy smokers and drinkers' group at age 17 . In addition to SDQ scores, Wave 1 at age nine also includes scores on the Piers-Harris 
self-concept scale. ${ }^{23}$ Across the six sub-domains, higher scores on the physical appearance subscale are associated with a lower probability of membership of the 'unhealthy diet and physical activity' cluster at age 17, while higher scores on the behaviour, intellectual and school subscales are associated with a lower probability of membership of the 'unhealthy drinkers and smokers' cluster at age 17.

Consistent with the findings at age 17, negative parental health behaviours particularly smoking - at age nine are associated with a higher probability of belonging to the 'unhealthy smokers and drinkers' group at age 17, suggesting strong intergenerational transmission of health behaviours over time. Finally, family SES, as measured at age nine, has little significant direct effect on cluster group membership at age 17, with the exception of significant associations with lone parent status at age nine. ${ }^{24}$

Examining a similar set of variables, this time measured at age 13 (Table A5) reveals similar patterns. A few findings are worth noting here. First, peer relationship problems at age 13 are associated with a higher probability of membership of the 'unhealthy diet and physical activity' group at age 17 . This was not so evident at age nine, but was evident at age 13, indicating that peer relationships in early adolescence can play a crucial role in future health behaviours. Second, while higher scores on the Piers Harris physical appearance scale no longer predict membership of the 'unhealthy smokers and drinkers' cluster, higher scores on the popularity subscale now predict a lower probability of membership of the 'unhealthy diet and physical activity' cluster, which possibly reflects again the importance of differing perceptions of self over time in shaping behaviours. Parental education is now statistically significant in predicting membership of the 'unhealthy diet and physical activity' group, with those from higher educational backgrounds less likely to belong to this group at age 17 . Finally, parental health behaviours at age 13 (in terms of smoking and alcohol consumption) are again highly predictive of cluster group membership at age 17 .

\subsection{ROBUSTNESS CHECKS}

A number of robustness checks were carried out to test the sensitivity of the results in Tables 3.8, A3 and A4 to different specifications of the models. First, while our indicator of dietary quality has been used in previous research using GUI (Layte and McCrory, 2011), it could be argued that simply aggregating daily consumption domains capture scores in relation to behavioural adjustment, intellectual and school status, physical appearance and attributes, freedom from anxiety, popularity, and happiness and satisfaction. It was completed by the young person at age nine (Thornton et al., 2011). 
across 20 food items is a crude measure of dietary quality. We investigated the use of an alternative indicator, fruit consumption, as a diet low in fruit is one of the major dietary risks identified by the WHO in its global burden of disease analysis (Martin-Diener et al., 2014). We find while the proportion of young adults who are now classified as 'healthy' increases from 43 per cent to 57 per cent, the proportion classified as 'unhealthy smokers and drinkers' remains the same. The gender pattern that was evident, whereby females were much less likely to belong to the 'healthy' group, is replicated when fruit consumption is used instead to proxy dietary quality. Second, we checked the robustness of the results to the use of an alternative indicator of alcohol consumption, the AUDIT screening tool for harmful or hazardous drinking. Results were robust to the use of this indicator of alcohol consumption. Third, as noted in Section 2.2, all health behaviour variables were expressed as z-scores to aid comparison across behaviours. The creation of the clusters is robust to the use of the untransformed variables. Fourth, we tested the inclusion of an indicator for multiple deprivation as it is possible that household income alone does not fully capture patterns of household disadvantage. The Basic Deprivation scale is made up of 11 items relating to the lack of items such as food, clothing, furniture, debt and minimal participation in social life. While the indicator was non-significant when measured at Wave 1 (age nine) and Wave 2 (age 13), it was marginally significant in predicting membership of the 'unhealthy diet and physical activity' group at age 17, i.e. those from families with a higher deprivation score were more likely to belong to this group. Next, while we included different measures of family background to reflect the differing dimensions of socioeconomic status (i.e. economic resources, power, prestige, etc.), household equivalised income, mother's education and family social class are correlated. ${ }^{25}$ However, the results in Tables 3.8, A3 and A4 are robust to the inclusion of each measure alone. Finally, as noted above in the context of the discussion around Table 3.8, we tested whether some of the SES effects were being captured by the association between SES and the other variables included in the models. In Wave 1 in particular (Appendix Table A4), we found that SES had little direct effect on group membership once other variables were added to the models, but running the models without these other controls showed that household income, education and social class became marginally significant in determining membership of the 'unhealthy diet and physical activity' group.

\subsection{SUMMARY OF FINDINGS}

Examining the four main risk factors for chronic disease identified by the WHO, the analysis in this chapter identified three clusters of behaviours; 'unhealthy smokers and drinkers' who accounted for 21 per cent of the young adult population; 'unhealthy diet and physical activity' who accounted for 36 per cent of the 
population; and a 'healthy' group who accounted for the remaining 43 per cent of the population. Significant associations between cluster group membership and a variety of individual and family characteristics were identified. Young females were significantly more likely to belong to the 'unhealthy diet and physical activity' group than young males, largely due to their relatively poorer diets and physical activity levels. They were also more likely to be in the 'unhealthy smokers and drinkers' group. Non-cognitive skills, such as personality, behavioural problems, and higher levels of maladaptive coping strategies, peer alienation and opposition to authority, were significantly associated with cluster group membership at age 17. Family background had a relatively weaker impact, but lone parent families, and those from lower social class and educational backgrounds had a higher probability of belonging to the 'unhealthy smokers and drinkers' group. An analysis of the factors associated with cluster group membership over time found consistent results, with suggestive evidence emerging that perceptions of appearance (at age nine) and popularity (at age 13) predict membership of the 'unhealthy' groups by age 17 . 



\section{CHAPTER 4}

\section{Schools as a context for health behaviours}

\subsection{INTRODUCTION}

Schools can influence young people's engagement in physical activity through formal Physical Education (PE) classes and, more broadly, through the provision of sports as an extracurricular activity (Steenholt et al., 2018). They can help shape eating habits through the provision of healthy food (at breakfast or lunchtime), through access to less healthy options in the form of vending machines, and/or through a healthy eating policy (Townsend et al., 2011). More subtly, the school climate (that is, the day-to-day interactions among students and between students and teachers) is highly influential in terms of young people's socio-emotional wellbeing, which, in turn, is likely to affect behaviours such as smoking and excessive alcohol consumption (Saab and Klinger, 2010; Perra et al., 2012), participation in extracurricular activities (such as sports) (Martinez et al., 2016), and use of different coping strategies (Frydenberg et al., 2009). Peer groups formed within the school context can reinforce less (or more) healthy behaviours. Thus, drinking and smoking may become expressions of broader disaffection among particular groups of young people who have disengaged from school and dropped out or engage in truancy (West et al., 2004; Fletcher et al., 2008). Unpacking these influences helps to identify potential levers for intervention at school level.

This chapter draws on the three waves of Growing Up in Ireland data to document the school as a context for young people's health behaviours. The second section looks at access to Physical Education and sports, the third section at provision of food and healthy eating policies while the fourth section examines school climate. The fifth section uses multilevel models to document the scale of difference between schools in health behaviours and the factors shaping these differences.

\subsection{PHYSICAL EDUCATION AND SPORTS FACILITIES}

At all three waves of the survey (when the young people were nine, 13 and 17 years of age), principals in the schools attended by the cohort were asked a series of questions relating to their perceptions of PE and sports facilities and the relative importance of $\mathrm{PE} /$ sports in the school.

\subsubsection{Primary schools}

The primary school principals surveyed placed a strong emphasis on PE and sports; over three-quarters (78 per cent) of the cohort were attending schools where sport was seen as very important to the ethos of the school while the vast majority 
(88 per cent) were in schools where $\mathrm{PE} /$ sports were seen as an important curricular activity and almost four-fifths (78 per cent) were in schools where PE/sports were seen as an important extra-curricular activity. Male students were more likely to attend schools where sport was seen as very important to the school ethos (82 per cent compared with 73 per cent for females), a pattern which reflected the greater emphasis on sports in boys' schools (88 per cent compared with 79 per cent in coeducational and 58 per cent in girls' schools) (see Figure 4.1). The emphasis on sports was particularly high in fee-paying schools (96 per cent) and lowest in the most disadvantaged settings, Urban Band 1 DEIS schools (67 per cent). Very small schools (that is, with fewer than 50 students) placed less emphasis on sports as part of the school ethos (60 per cent compared with 76-82 per cent in other school sizes) (Figure 4.2).

FIGURE 4.1 PROPORTION OF 17-YEAR-OLDS WHO HAD ATTENDED A PRIMARY SCHOOL WHERE PE/SPORTS WAS CONSIDERED 'VERY IMPORTANT' TO SCHOOL ETHOS, AS A CURRICULAR ACTIVITY AND AS AN EXTRA-CURRICULAR ACTIVITY BY GENDER MIX OF THE SCHOOL

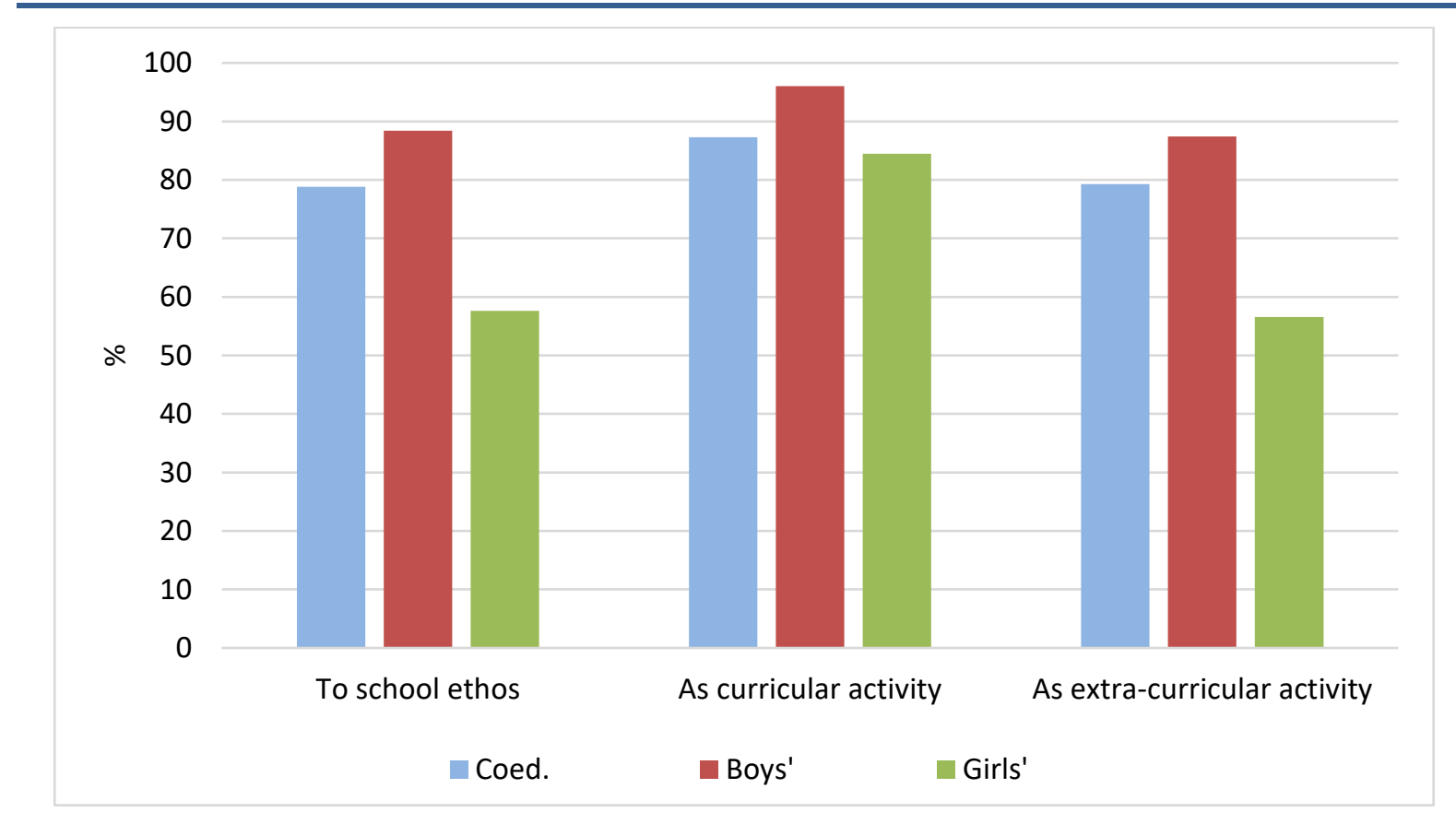

As with PE and school ethos, female students were less likely to attend schools where $\mathrm{PE} / \mathrm{sports}$ was deemed a very important curricular activity ( 86 per cent compared with 90 per cent), again reflecting the strong emphasis in boys' schools (96 per cent compared with 85-87 per cent in coeducational and girls' schools). There was some social differentiation in the perceived importance of sports/PE as a curricular activity, with those from families with lower levels of education or from working-class backgrounds somewhat less likely to attend primary schools where this subject was seen as very important ( 85 per cent of the semi/unskilled manual group as opposed to 93 per cent of the professional group). The social gap was 
larger when household income was considered, with 93 per cent of the top income quintile in schools where $\mathrm{PE} / \mathrm{sport}$ was very important compared with 83 per cent of those in the lowest income quintile. There were very marked differences by school size, with only 70 per cent of very small schools placing a strong emphasis on PE/sport compared with 92 per cent of large schools (300+ students). Urban students were more likely to attend schools that placed a strong emphasis within the curriculum on sports/PE (94 per cent compared with 84 per cent), a pattern that held even taking account of the smaller average size of rural schools. Rural DEIS schools mirrored this pattern, with only 64 per cent deeming it very important compared with 96 per cent of fee-paying schools.

FIGURE 4.2 PROPORTION OF 17-YEAR-OLDS WHO HAD ATTENDED A PRIMARY SCHOOL WHERE PE/SPORTS WAS CONSIDERED 'VERY IMPORTANT' TO SCHOOL ETHOS, AS A CURRICULAR ACTIVITY AND AS AN EXTRA-CURRICULAR ACTIVITY BY SCHOOL SIZE

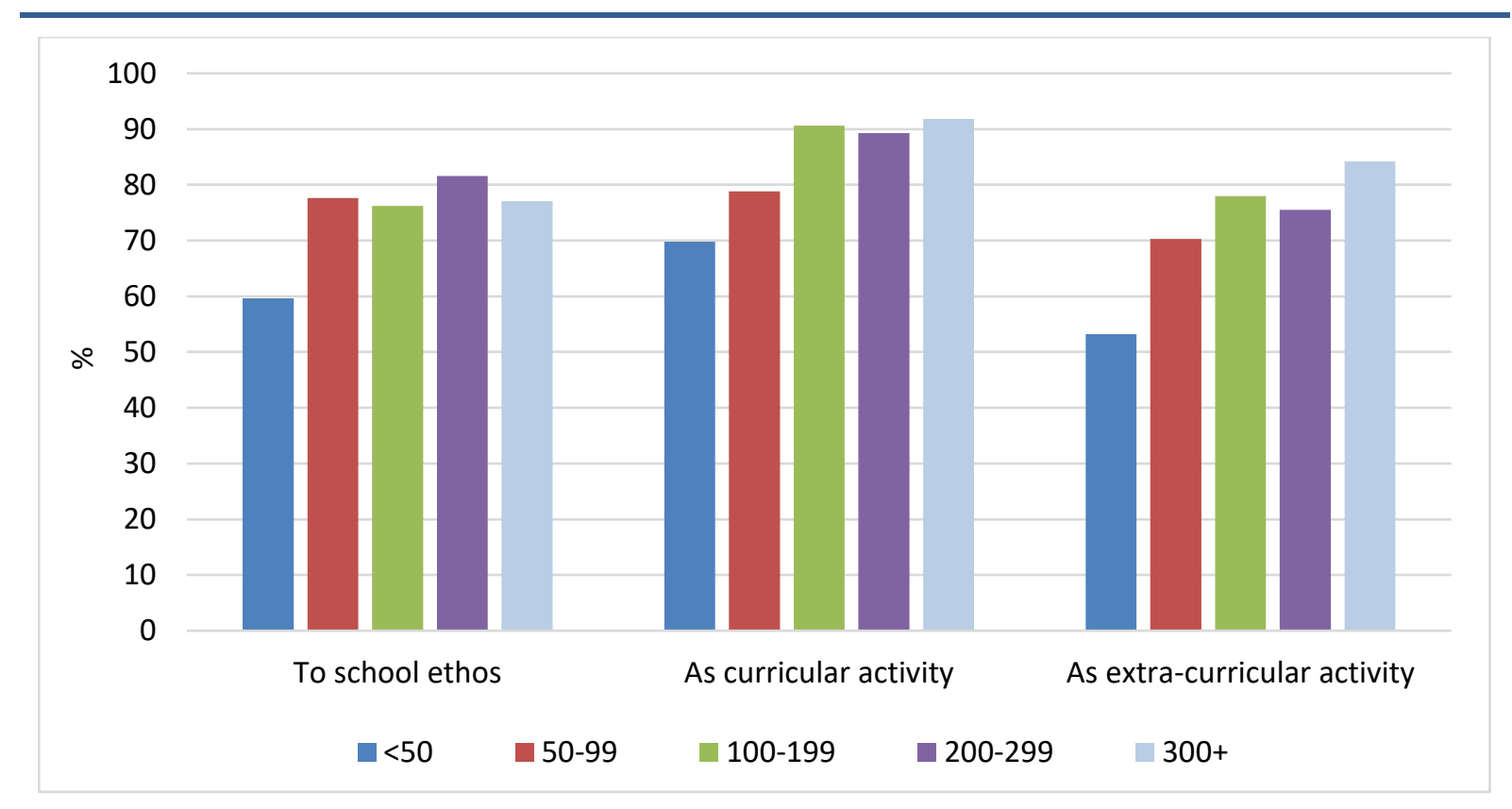

Source: $\quad$ GUI, ‘98 Cohort, Wave 1.

The patterns for the perceived importance of sports/PE as an extra-curricular activity were broadly similar, with more middle-class students, those with more highly educated mothers and those from higher income groups more likely to attend schools that placed a strong emphasis on the activity. A gender gap was also evident, largely reflecting the lower emphasis placed on sports/PE in girls' schools. The main difference by school social mix related to the higher emphasis in nonDEIS schools (79 per cent), though in contrast to curricular activity, the patterns for fee-paying schools were similar to those in the most socially disadvantaged schools (72-74 per cent). Language medium of the school also played a part, with a very strong emphasis on extra-curricular sports in gaelscoileanna (90 per cent). Significant variation by school size was evident, with larger schools rating extracurricular sports/PE as more important to their ethos. The urban-rural gap was also 
evident for extra-curricular sports/PE but this pattern was partly related to differences in school size.

Despite the perceived importance of physical activity, principal perceptions of the quality of facilities were quite mixed. Eighteen per cent of students attended schools where PE/sports facilities were described as poor, with a further 26 per cent in settings where they were deemed 'fair' (rather than good or excellent). Ratings of playground facilities were broadly similar, with 17 per cent considered poor and 22 per cent considered fair. Male students were more likely to attend schools where sports/PE facilities were described as 'excellent' (24 per cent compared with 15 per cent), which reflected better perceived facilities in boys' schools, but no gender differences were evident in relation to the school having poor or fair facilities. Rural schools were somewhat more likely to report poor facilities (20 per cent compared with 14 per cent). The vast majority (84 per cent) of those in fee-paying schools had excellent facilities while over a third of those in rural DEIS schools had access to poor facilities. Those in smaller schools tended to have worse facilities (44 per cent poor compared with 11 per cent in schools with $300+$ students).

In contrast to perceptions of sports/PE facilities, there were fewer differences by individual social background or school type in relation to playground facilities. However, urban schools were somewhat more likely to be described as having poor playgrounds (18 per cent compared with 16 per cent) and non-DEIS and rural DEIS schools were more likely to describe their playgrounds as excellent (18 per cent). Gaelscoileanna and boys' schools were more likely to report poor playground facilities (26 per cent and 21 per cent respectively).

The emphasis placed on PE in the school can also be assessed by looking at the time devoted to it as a subject per week, as reported by the primary classroom teachers when the young people were aged nine. The average amount of time spent on PE was 1.1 hours per week, with no marked variation by individual social background. Male students tended to spend more time on PE per week than female students, though the actual difference was small (2-3 minutes a week). Boys' schools spent more time on PE than coeducational or girls' schools (1.19 hours compared with 1.09 and 1.04 respectively). Significant differences were evident by school social mix, with the time spent amounting to 1.39 hours in fee-paying schools, 1.09 in Urban Band 1 DEIS schools and 1.04 in rural DEIS schools. Gaelscoileanna also devoted more time to PE (1.2 hours compared with 1.1 hours in English medium schools). Those attending very small schools spent less time on PE than those in other settings. 


\subsubsection{Second-level schools}

Almost all young people were in second-level education by the age of 13 . At that stage, their school principals were asked about the provision of (team-based and/or individual) sports as an extra-curricular activity and about the quality of sports facilities available to the school. Almost all (99 per cent) young people attended a school where team sports were offered as an extra-curricular activity while 82 per cent were in schools where individual sports were offered. Young people from more advantaged backgrounds were more likely to attend schools offering individual sports; 91 per cent of those whose mothers had a postgraduate degree compared to 78 per cent where their mothers had a Junior Certificate (or lower) qualification. The social mix of the school also made a difference with greater levels of provision in fee-paying schools (97 per cent) compared with 86 per cent in non-DEIS schools and only 80 per cent in DEIS schools (Figure 4.3). Female students were less likely to attend a school offering individual sports ( 15 per cent compared with 21 per cent for males), a pattern that reflected lower levels of provision in girls' schools (76 per cent compared with 92 per cent in boys' schools and 81 per cent in coeducational schools). Those in urban areas had slightly greater access to extra-curricular individual sports ( 84 per cent compared with 81 per cent). Differences by school size were notable, with 85 per cent of large schools offering individual sports compared with 67 per cent of small schools.

FIGURE 4.3 PROPORTION OF YOUNG PEOPLE WHO ATTENDED SECOND-LEVEL SCHOOLS OFFERING INDIVIDUAL SPORTS AS AN EXTRA-CURRICULAR ACTIVITY BY GENDER AND SOCIAL MIX OF THE SCHOOL

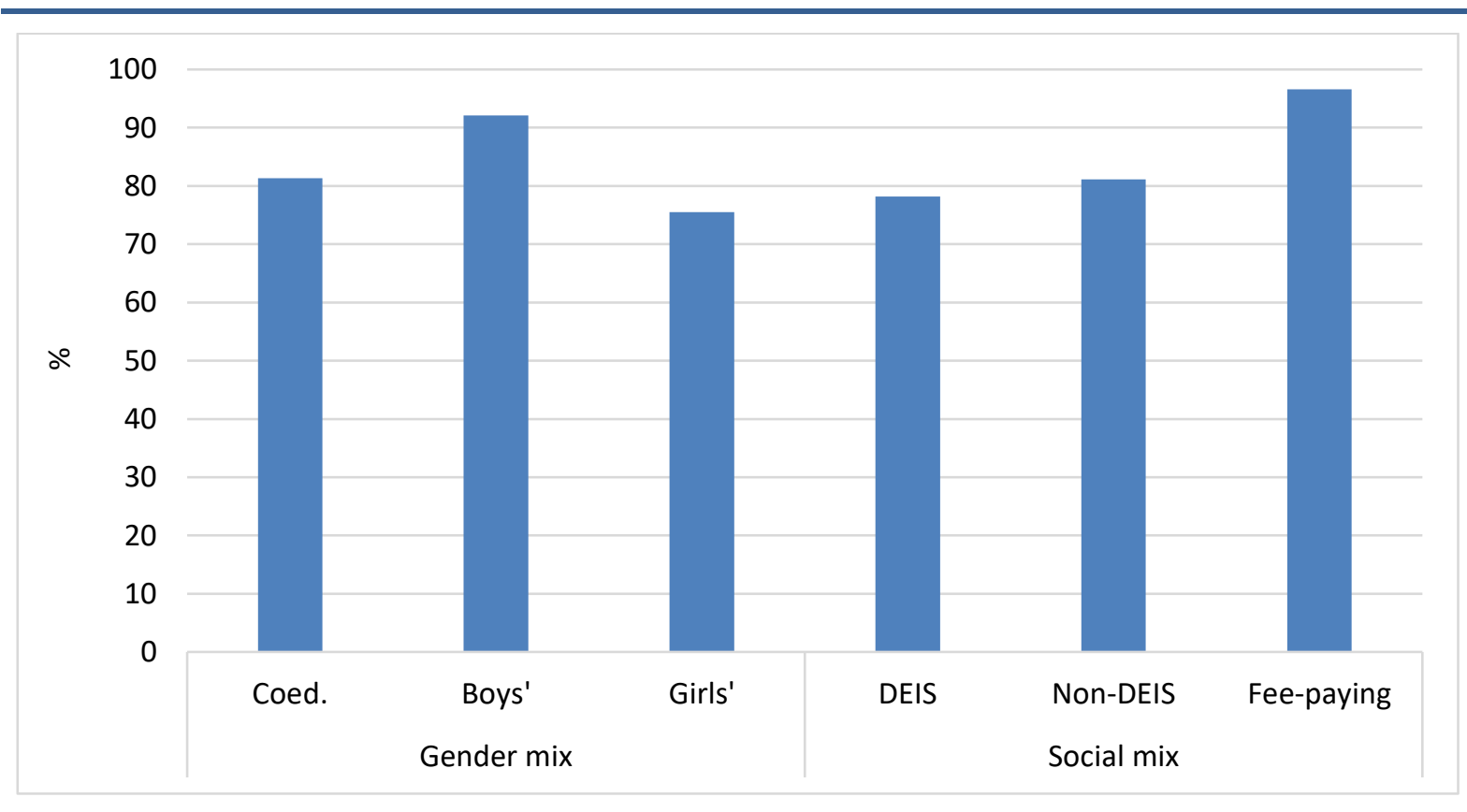

GUI, ‘98 Cohort, Wave 2.

Principals were asked about the quality of sports facilities and other outdoor space.

Thirty per cent of young people attended schools where sports facilities were 
described as poor or fair (as opposed to good or excellent) while perceptions of outdoor space were somewhat more negative (38 per cent poor/fair). Those from more advantaged backgrounds were more likely to attend schools with better sports facilities; almost half ( 46 per cent) of the top income quintile were in schools with 'excellent' facilities compared with 35 per cent of those from the lowest income group. Significant differences were also found by school social mix, with much better facilities in fee-paying schools and poorer facilities in DEIS schools (Figure 4.4). Female students were somewhat more likely to attend schools with poorer facilities, which related to poorer quality in girls' schools (21 per cent with poor facilities compared with 16 per cent in coeducational and just 7 per cent in boys' schools). Facilities were more likely to be described as excellent in urban than in rural areas (42 per cent compared with 31 per cent). As at primary level, the quality of facilities varied markedly by school size, with larger schools more likely to have excellent sports facilities ( 40 per cent compared with 11 per cent in small schools). Young people attending schools with better quality sports facilities were more likely to have access to individual sports as an extra-curricular activity; 87 per cent of those in schools with excellent facilities had such access compared with 73 per cent in the case of schools with poor facilities.

\section{FIGURE 4.4 THE PERCEIVED QUALITY OF SPORTS FACILITIES IN SECOND-LEVEL SCHOOLS BY GENDER AND SOCIAL MIX OF THE SCHOOL}

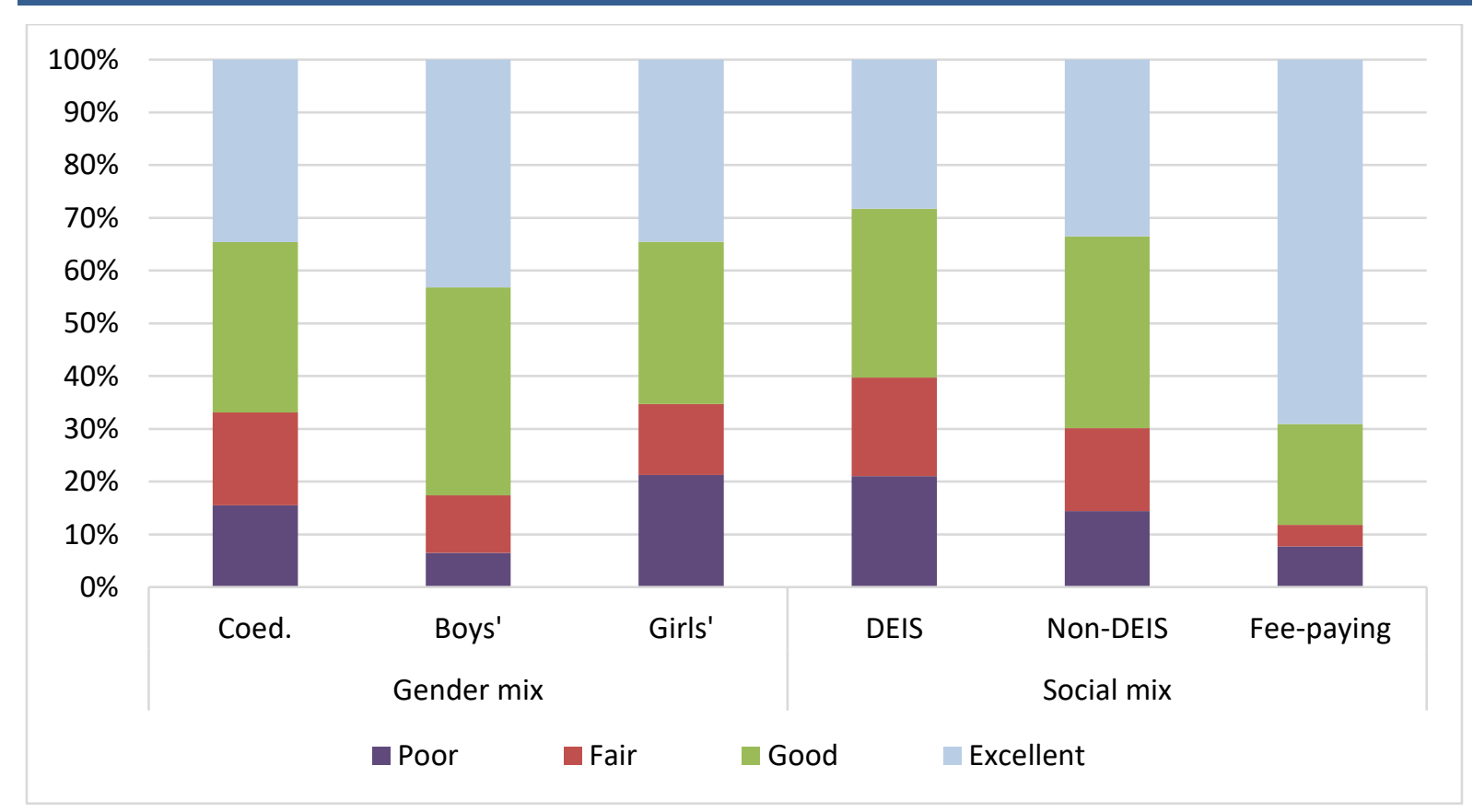

The pattern for other outdoor space was similar to that for sports facilities, with young people from more advantaged families having access to better quality provision. Those in urban areas attended schools with better outdoor space. In comparison to the patterns for sports facilities, gender differences in the quality of 
outdoor space were small, though those in girls' schools were more likely to have poor quality provision (25 per cent compared with 18-19 per cent in coeducational and boys' schools). Outdoor space was better quality in larger schools (32 per cent excellent compared with 15 per cent for small schools) and in fee-paying schools (50 per cent excellent compared with 20 per cent in DEIS schools).

\subsection{PROVISION OF FOOD AND HEALTHY EATING POLICIES}

\subsubsection{Primary schools}

Primary school principals were asked about whether their school had a breakfast club and whether free lunches were provided to students. Overall, 13 per cent of young people had access to a breakfast club at primary level while 20 per cent were in schools providing free lunches. Schools tend to use funding provided by the Department of Employment Affairs and Social Protection (DEASP) given to more disadvantaged schools and/or provision under the School Completion Programme to offer such meals. However, in other instances, schools may fund-raise or use other resources to provide meals. Not surprisingly then, DEIS schools were found to be more likely to provide meals every day or on some days. The majority (63 per cent) of those who had attended an Urban Band 1 DEIS school had access to a breakfast club while only 5 per cent of those in non-DEIS schools did so (Figure 4.5). Interestingly, fee-paying schools were more likely to provide breakfast than other non-DEIS schools ( 25 per cent compared with 5 per cent). Those attending larger schools were more likely to have had access to a breakfast club (17 per cent for $300+$ schools compared with 2 per cent of very small schools).

The variation in provision by school characteristics resulted in differences by social background and location. Twenty-two per cent of those from never-employed families were in schools with a breakfast club compared with 9 per cent of those from professional backgrounds, and breakfast club access varied markedly by household income ( 21 per cent of the bottom quintile compared with 11 per cent of the top quintile). Children from lone parent families were also more likely to be in schools with breakfast clubs (18 per cent compared with 12 per cent of those from two-parent families). Children from migrant families were also somewhat more likely to attend schools with a breakfast club. Children in rural schools were much less likely to have access to a breakfast club than urban children ( 6 per cent compared with 22 per cent). 


\section{FIGURE 4.5 PROPORTION OF 17-YEAR-OLDS WHO HAD ATTENDED PRIMARY SCHOOLS WHICH PROVIDED BREAKFAST CLUBS AND FREE LUNCHES (EVERY DAY OR SOME DAYS) BY SCHOOL SOCIAL MIX}

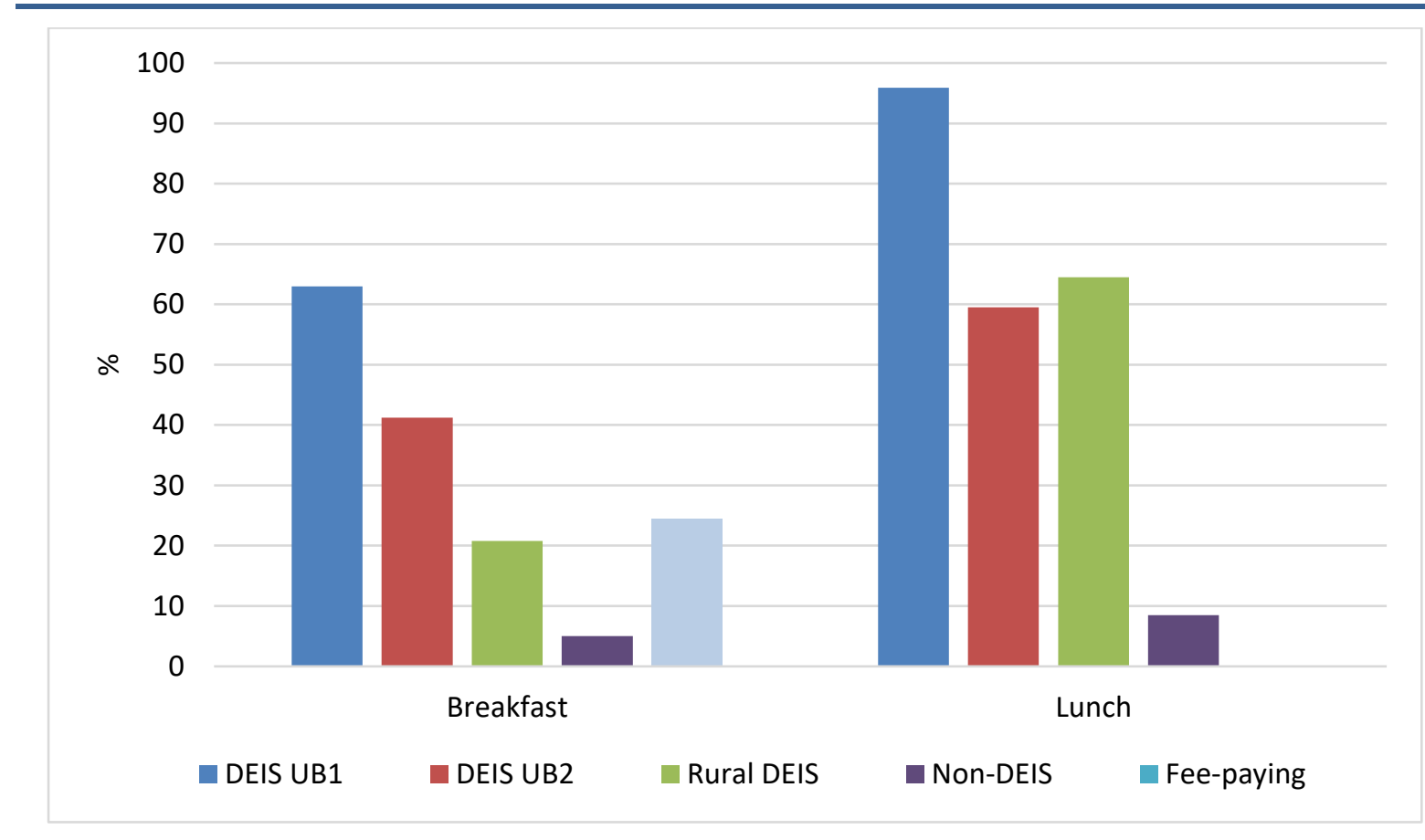

Source: $\quad$ GUI, '98 Cohort, Wave 1.

Note: $\quad$ No fee-paying schools offered free lunches.

The pattern for free lunches was broadly similar, being highest for less advantaged groups (40 per cent of those from never employed families compared with 10 per cent of those from professional families) and those in urban areas (30 per cent compared with 13 per cent). Almost all (96 per cent) Urban Band 1 DEIS schools provided free lunches while only 9 per cent of non-DEIS schools and no fee-paying schools did so. Differences by school size were less evident in relation to lunch provision than in relation to breakfast clubs, though levels of provision were somewhat lower in smaller schools (14 per cent in schools with fewer than 50 students compared with 23 per cent in schools with 300 or more students).

\subsubsection{Second-level schools}

Over a quarter ( 27 per cent) and just under a fifth (18 per cent) of the 17-year-olds had attended second-level schools providing a breakfast club and free lunches respectively. As at primary level, levels of provision were greater in DEIS schools than in other schools (79 per cent for breakfast clubs and 47 per cent for free lunches). Single-sex schools were less likely to provide such supports, reflecting their socio-economic profile.

Young people from more socio-economically disadvantaged backgrounds were more likely to have access to breakfast clubs or free lunches; for example, 39 per cent of those whose mothers had Junior Certificate-level education had access to 
a breakfast club compared with 18 per cent where their mothers had a postgraduate degree. Young people from lone parent families were also more likely to have access to breakfast or lunch provision. In contrast to the pattern at primary level, those in urban schools had somewhat lower levels of provision (24 per cent compared with 29 per cent) for breakfast clubs, with little difference in relation to free lunches.

At the second wave of the study, additional questions were included on whether the school had a healthy eating policy and whether vending machines were provided in the school (see Table A1). Over half (58 per cent) of young people attended schools which described themselves as having a healthy eating policy. Regardless of whether the school had such a policy or not, all principals were asked about the adoption of a number of health-promoting policies in the school. In almost all cases (95 per cent and 91 per cent respectively), students were attending schools where they were given guidelines on healthy eating, and healthy eating was addressed in subject lessons; 75 per cent of young people were in schools where mostly healthy food was provided in the school and 72 per cent were in schools where certain foods/drinks were prohibited. In just under half (47 per cent) of cases, guidelines on healthy eating were given to parents. In addition, over half (58 per cent) of young people were in schools where they were not allowed outside school at lunchtime. Almost half (45 per cent) of young people had attended a school which had vending machines which sold food and/or drink. Principals were asked about the drink content of these machines but not about food quality. In almost all cases, the machines sold water, unsweetened fruit juice and/or diet drinks but in over a third of cases (36 per cent), these machines sold sugary drinks.

In order to assess the number of measures adopted by schools to promote healthy eating, a summary index was derived which was based on the frequency of the following: having a healthy eating policy; giving guidelines to students on healthy eating; giving guidelines to their parents on healthy eating; providing mostly healthy food; prohibiting certain foods/drinks; and not having a vending machine which sold sugary drinks. ${ }^{26}$ 'Students not being allowed out at lunchtime' was not included as it could also reflect the location of the school or concerns about student misbehaviour rather than being aimed at constraining unhealthy eating. Scores were relatively high, with 23 per cent of young people attending schools which adopted all of these measures, 24 per cent adopting six of the measures and 21 per cent adopting five measures. Exposure to school-based healthy eating measures did not vary markedly by individual social background, but there was a slightly greater exposure to such measures among young people from the lowest income quintile. Both disadvantaged (DEIS) and highly advantaged (fee-paying) schools were more likely to adopt such measures than non-DEIS non-fee-paying 
schools. Female students were somewhat more likely to be in schools with more such measures (5.26 compared with 5.15), though the difference was small. Differences were more marked by school gender mix, with coeducational schools having the highest incidence of healthy eating measures and boys' schools having the lowest levels. Larger schools tended to have more healthy eating measures in place than smaller schools. In order to capture these patterns in a more intuitive way, Figure 4.6 shows the profile of schools with three or fewer healthy eating measures. Schools that are less proactive in promoting healthy eating tend to be smaller, more socially mixed and more likely to be single-sex, especially boysonly. ${ }^{27}$

FIGURE 4.6 PROPORTION OF YOUNG PEOPLE ATTENDING SECOND-LEVEL SCHOOLS WITH LOW LEVELS OF PROMOTING HEALTHY EATING BY SCHOOL GENDER MIX, SOCIAL MIX AND SIZE

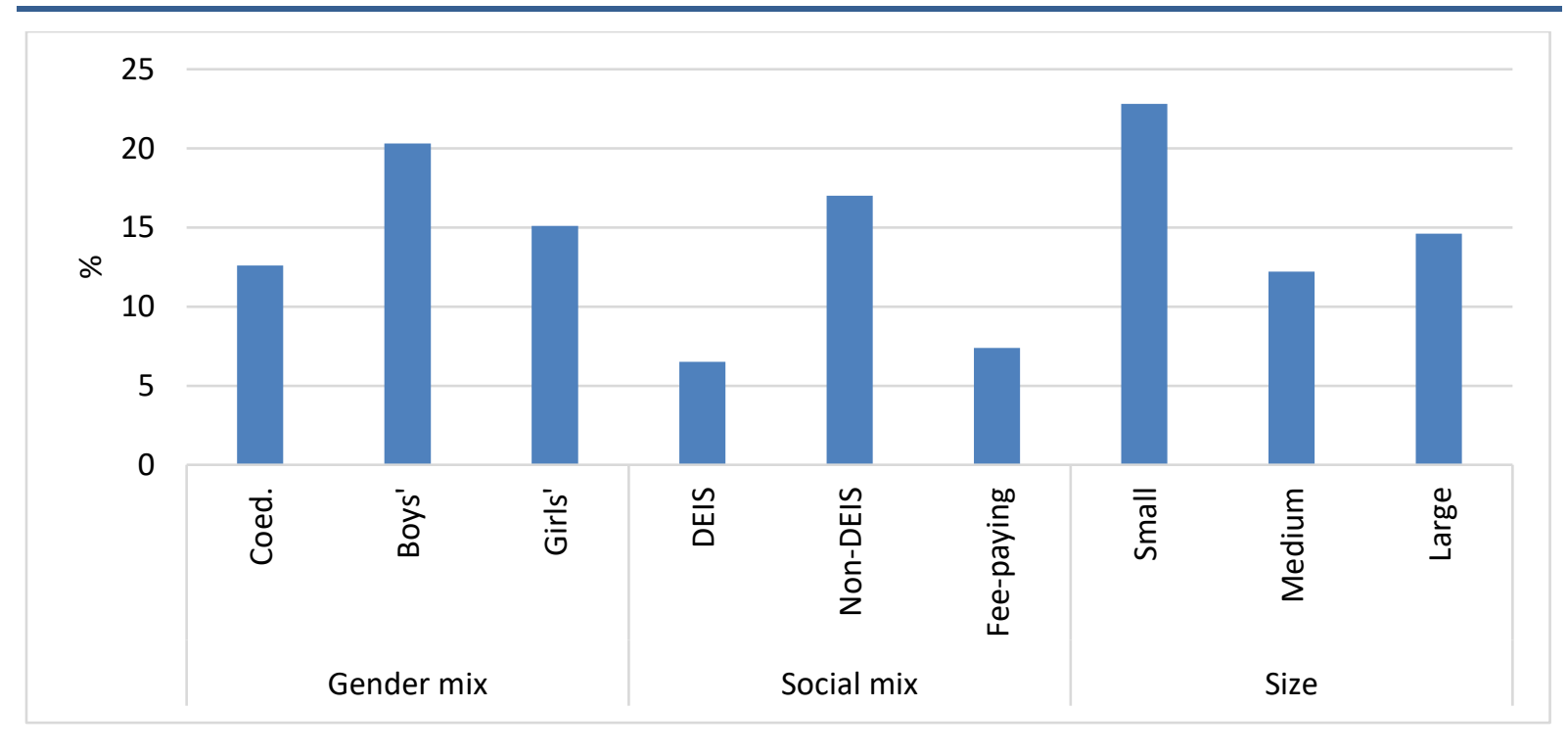

\subsection{SCHOOL CLIMATE AND SOCIAL SUPPORTS}

Section 3.1 has indicated the ways in which schools can influence health behaviours indirectly through the school climate, that is, the quality of the relationship between teachers and students and among students themselves. In Section 4.5, much of this influence will be captured through young people's reports of their engagement in school and the nature of their interaction with teachers and other students. However, useful information was collected from the school principals on the socio-emotional supports provided to students, the school's approach to bullying and their perceptions of school climate (see Table A1).

27 A multivariate analysis (not shown here) indicates that all three dimensions are associated with a less proactive approach when considered together. 


\subsubsection{Primary schools}

When they were at primary level, most young people had been in schools where support to children with emotional/behavioural problems was usually provided by the classroom teacher (96 per cent), the principal (95 per cent) or a learning support teacher (89 per cent). Other teachers/staff were involved in over half (55 per cent) of cases while external assistance was named by 8 per cent. Urban DEIS schools, especially Urban Band 1 schools, were more likely to mention the involvement of other staff ( 72 per cent compared with 54 per cent of non-DEIS schools), most likely because of resources provided through DEIS or the School Completion Programme. Girls' schools were also somewhat more likely to involve other staff ( 62 per cent compared with 54 per cent of boys' and coeducational schools). Very small schools were much less likely to involve other staff (because of the small number of staff in the school).

Almost all (97 per cent) young people attended a primary school where the principal stated that their school had an explicit anti-bullying strategy, with this representing a written policy in almost all cases. In over a quarter (26 per cent) of cases, bullying was seen as a major problem, with it seen as a minor problem in 62 per cent of cases and 'no problem at all' in 12 per cent of cases. The perceived prevalence of bullying did not vary markedly by gender or individual background factors. In terms of school type, responses from rural DEIS and fee-paying schools were more polarised, being more likely to report a major problem or no problem at all. Bullying was more likely to be seen as a major problem in boys' schools (36 per cent compared with 25 per cent in girls' schools and 24 per cent in coeducational schools). Schools with fewer than 100 students reported less bullying than larger schools.

Principals were asked whether the scale of day-to-day problems in their school was (much or slightly) greater (15 per cent), about the same (52 per cent) or (much or slightly) less (33 per cent) than in other schools. Young people from more disadvantaged backgrounds were more likely to attend schools with greater problems as were those from lone parent or migrant families. Greater problems were reported in Urban Band 1 DEIS schools (65 per cent) compared with only 9 per cent in non-DEIS schools. Gaelscoileanna were more likely to report fewer problems than other school types. Boys' schools reported slightly greater problems than coeducational or girls' schools (20 per cent compared with 11-14 per cent).

\subsubsection{Second-level schools}

The larger size and staffing structures of second-level schools means that potentially a more diverse range of supports is available to students. Young people attended schools where the guidance counsellor ( 86 per cent), the pastoral care team ( 80 per cent), year heads (69 per cent), the principal ( 57 per cent) and class 
tutors (37 per cent) were involved 'to a great extent' in providing supports to students. The pastoral care team and the guidance counsellor were equally likely to be deemed the most important source of support to students in the school. In addition to regular support for students, most second-level schools put in place procedures to assist the transition of first year students into the school. Almost all of the young people in the cohort attended schools where there were class tutors (98 per cent), induction days (95 per cent) and links with feeder primary schools (92 per cent). The vast majority had student mentors ( 87 per cent) and offered study skills programmes to students (76 per cent). Sixty-three per cent of young people attended schools that offered formal transition or integration programmes. Access to such a programme did not differ by gender or individual background. However, such programmes were less likely to be offered in boys' schools (54 per cent) compared to girls' (59 per cent) and coeducational schools ( 68 per cent). Feepaying and DEIS schools were more likely to have such programmes (84 per cent and 78 per cent respectively) than non-DEIS schools (58 per cent). Schools differed in the approach to integrating first years that they regarded as most important, with the largest group ( 27 per cent) mentioning class tutors and 18-20 per cent each mentioning the induction day, links with primary schools and the formal integration programme.

School principals were asked a series of questions to capture school climate from the perspective of parental involvement, student engagement and teacher engagement. They were also asked about the extent to which students were involved in decision-making in the school.

The vast majority (95 per cent) of young people attended schools where the principal reported that 'nearly all' parents thought it was a good school, and in the majority (76 per cent) of cases nearly all parents were seen as showing support for the school. In four-in-ten cases, nearly all parents were described as attending school events or meetings and helping or supporting their children with their schoolwork. A summary index was derived to reflect the extent of parental involvement or support for the school. ${ }^{28}$ Young people from advantaged families were more likely to attend schools with higher levels of parental support and support was seen as somewhat greater in rural areas than in urban settings. Boys' schools, larger schools and fee-paying schools reported somewhat higher support than other school types.

The vast majority (94 per cent) of young people attended schools where 'nearly all' teachers were described by the principal as positive about the school. Similarly, the majority attended schools where the principal stated that 'nearly all' teachers 
received help and support from colleagues ( 84 per cent), were open to new developments (69 per cent) and were eager to engage in continuous professional development (61 per cent). Using a summary index ${ }^{29}$ to combine these dimensions indicated that female and more disadvantaged students were slightly more likely to attend schools where teachers were seen as more engaged. Teacher engagement was slightly lower in boys' schools and higher in DEIS schools, with no variation by school size.

Principal perceptions of student engagement were very positive, with the majority of young people attending schools where 'nearly all' students were described as showing respect for teachers (91 per cent), being rewarding to work with (87 per cent), being well-behaved in class ( 87 per cent) and enjoying being at school ( 85 per cent). A summary index ${ }^{30}$ indicated that young people from more advantaged backgrounds and females were slightly more likely to attend schools with higher levels of student engagement. Student engagement levels were higher in girls' schools, larger schools and non-DEIS or fee-paying schools.

Almost all schools reporting having a student council, with representatives solely elected by students in three-quarters of cases. Despite this formal representation, in only a minority of cases were students described by the principal as involved in school decision-making 'to a large extent' in relation to school rules (32 per cent), school uniforms ( 32 per cent), teaching/learning materials ( 8 per cent) and the way classes are taught ( 7 per cent). These measures were combined to form a summary index. ${ }^{31}$ There was very little variation across types of schools, although levels of involvement were somewhat lower in boys' schools.

\subsection{MODELS OF SCHOOL INFLUENCES ON HEALTH BEHAVIOURS}

This subsection builds upon the analyses presented in Chapter 3 to look at three main issues: firstly, whether health behaviours vary according to the primary and/or second-level school attended; secondly, whether some characteristics of the school make a difference to health behaviours; and thirdly, whether young people's engagement with, or disengagement from, their school environment can make a difference to their health behaviour. 


\subsubsection{The extent of between-school differences in health behaviours}

TABLE 4.1 MULTILEVEL CROSS-CLASSIFIED MULTINOMIAL LOGIT MODEL OF GROUP MEMBERSHIP (RELATIVE TO MEMBERSHIP OF THE HEALTHY GROUP): RANDOM EFFECTS

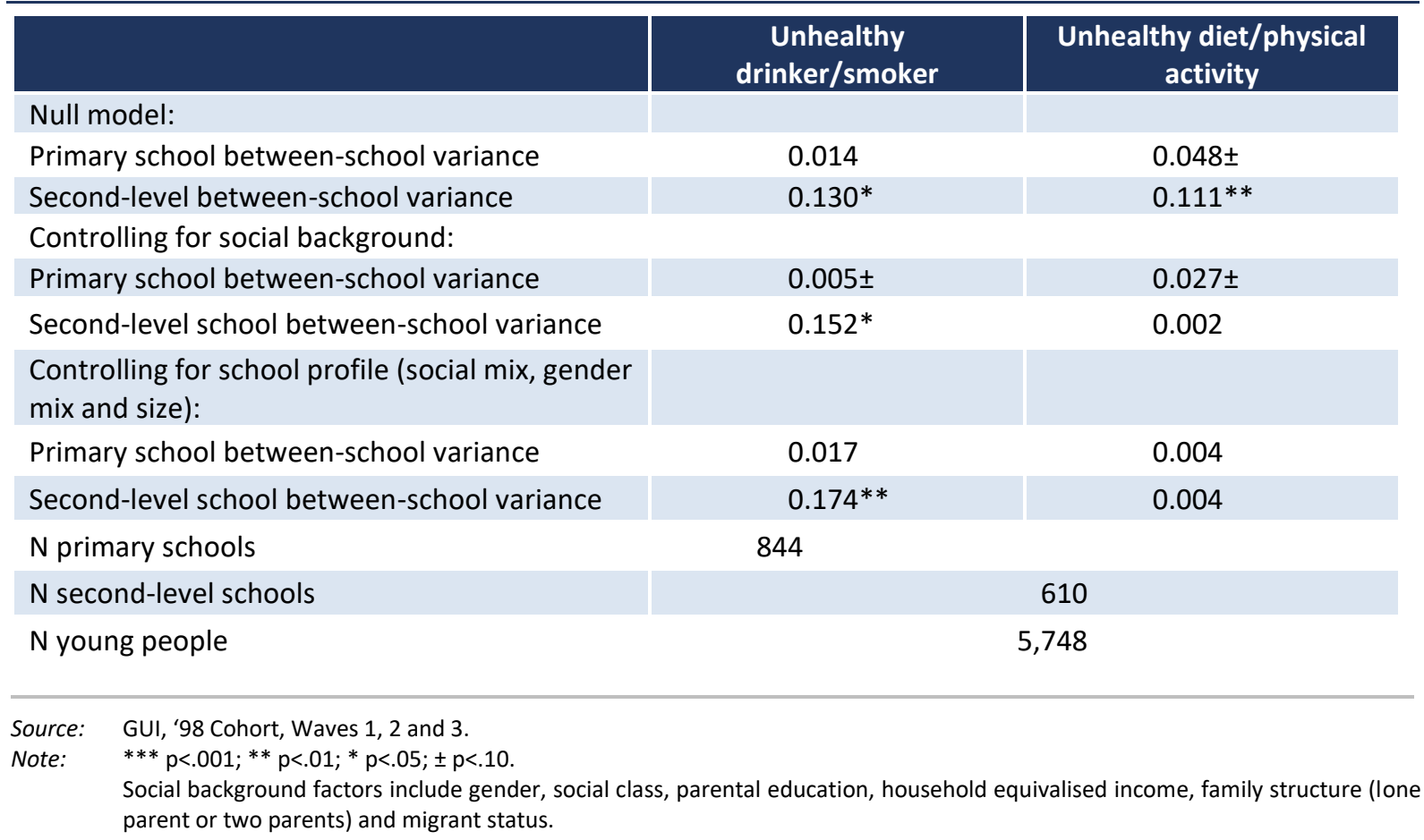

Table 4.1 presents the results of a series of multilevel cross-classified models which estimate the differences between individual schools in the likelihood of young people falling into either of the unhealthy groups. The models are described as 'cross classified' as they take account of both the primary and the second-level school attended. The null model findings show between-school differences before taking any other factors into account. These results show that there is little variation between primary schools when the second-level school attended is taken into account. The difference between primary schools in relation to falling into the unhealthy diet/activity group is at the margins of significance only (at the 10 per cent level). In contrast, second-level schools are found to differ significantly in the likelihood of young people falling into the two unhealthy behaviours groups. Taking account of the social background of young people (gender, mother's education, social class, household income, migrant status and family structure) explains the differences between second-level schools in unhealthy diet/activity. In other words, young people in some schools have poorer diet and levels of physical activity because of the profile of students in particular schools. In contrast, even taking account of background factors, second-level schools differ in the proportion of young people in the unhealthy drinker/smoker group. This between-school difference is still evident when school social mix, gender mix and size are taken into account. Thus, over and above the effects of family socio-economic background, the second-level school attended is associated with the likelihood of falling into the unhealthy/drinker smoker group. 


\subsubsection{School type and health behaviours}

TABLE 4.2 MULTILEVEL CROSS-CLASSIFIED MULTINOMIAL LOGIT MODEL OF GROUP MEMBERSHIP (RELATIVE TO MEMBERSHIP OF THE HEALTHY GROUP) (ODDS RATIOS): FIXED EFFECTS

\begin{tabular}{|c|c|c|}
\hline & $\begin{array}{c}\text { Unhealthy } \\
\text { drinker/smoker }\end{array}$ & $\begin{array}{c}\text { Unhealthy } \\
\text { diet/physical activity }\end{array}$ \\
\hline Constant & 0.600 & 0.661 \\
\hline Male & Ref & Ref \\
\hline Female & $1.365^{* *}$ & $2.737 * * *$ \\
\hline \multicolumn{3}{|l|}{ Mother's education: } \\
\hline Lower secondary or less & Ref & Ref \\
\hline Leaving Certificate (upper secondary) & 0.957 & 0.870 \\
\hline Post-secondary & 0.898 & $0.687^{*}$ \\
\hline Degree & 0.891 & $0.660 * *$ \\
\hline Post-graduate degree & 1.048 & $0.766^{*}$ \\
\hline \multicolumn{3}{|l|}{ Social class: } \\
\hline Professional & $0.519 * * *$ & 0.893 \\
\hline Managerial/technical & $0.745^{*}$ & 0.998 \\
\hline Other non-manual & $0.784 *$ & 1.089 \\
\hline Skilled manual & 1.016 & 1.044 \\
\hline Semi/unskilled manual & Ref & Ref \\
\hline Never employed & $0.713^{*}$ & $1.196 \pm$ \\
\hline \multicolumn{3}{|c|}{ Equivalised household income (at Wave 3): } \\
\hline Lowest quintile & Ref & Ref \\
\hline Quintile 2 & 0.882 & 1.091 \\
\hline Quintile 3 & 0.829 & 0.992 \\
\hline Quintile 4 & 0.918 & 1.139 \\
\hline Highest quintile & 0.871 & 0.999 \\
\hline PCG born in Ireland & Ref & Ref \\
\hline PCG born outside Ireland & 0.944 & $0.877 \pm$ \\
\hline Two-parent family & Ref & Ref \\
\hline Lone parent family & $1.912^{* * *}$ & $1.383^{* *}$ \\
\hline Rural & Ref & Ref \\
\hline Urban & 0.944 & $0.882^{*}$ \\
\hline \multicolumn{3}{|l|}{ Primary school characteristics } \\
\hline \multicolumn{3}{|l|}{ Social mix: } \\
\hline Urban Band 1 DEIS & $1.389 \pm$ & $1.652^{* * *}$ \\
\hline Urban Band 2 DEIS & 1.015 & 1.196 \\
\hline Rural DEIS & $1.384 \pm$ & 0.959 \\
\hline Non-DEIS & Ref & Ref \\
\hline Fee-paying & 1.439 & 0.591 \\
\hline \multicolumn{3}{|l|}{ Gender mix: } \\
\hline Coeducational & Ref & Ref \\
\hline Boys only & 1.003 & 1.078 \\
\hline Girls only & $1.269 *$ & 1.125 \\
\hline
\end{tabular}


TABLE 4.2 CONTD.

\begin{tabular}{|l|c|c|}
\hline & \multicolumn{1}{|c|}{$\begin{array}{c}\text { Unhealthy } \\
\text { drinker/smoker }\end{array}$} & $\begin{array}{c}\text { Unhealthy } \\
\text { diet/physical activity }\end{array}$ \\
\hline School size: & Ref & 0.898 \\
\hline$<50$ & 0.769 & 0.757 \\
\hline $50-99$ & 0.843 & 0.819 \\
\hline $100-199$ & 0.874 & 0.911 \\
\hline $200-299$ & 0.869 & \\
\hline $300+$ & & $1.326^{* *}$ \\
\hline Second-level school characteristics & & Ref \\
\hline Social mix: & $1.236 \pm$ & $0.816^{*}$ \\
\hline DEIS & Ref & \\
\hline Non-DEIS & 1.181 & Ref \\
\hline Fee-paying & & 0.882 \\
\hline Gender mix: & Ref & $1.165 \pm$ \\
\hline Coeducational & 0.845 & \\
\hline Boys only & 0.950 & Ref \\
\hline Girls only & & 0.938 \\
\hline School size & Ref & \\
\hline Small & 0.954 & \\
\hline Medium/large & & \\
\hline
\end{tabular}

Source: $\quad$ GUI, ' 98 Cohort, Waves 1, 2 and 3.

Note: $\quad * * * p<.001 ;{ }^{* *} p<.01 ;{ }^{*} p<.05 ; \pm p<.10$.

Table 4.2 shows that both individual social background and the social mix of the school are associated with health behaviours at age 17. As shown in Chapter 2, young women are much more likely to fall into the unhealthy diet/activity group and somewhat more likely to be in the unhealthy drinking/smoking group (when other factors are considered). More advantaged social classes, especially those in the professional class, are much less likely to fall into the unhealthy smoker/drinker category. Interestingly, those in jobless households (never employed) are somewhat less likely to be drinkers/smokers than the traditional working-class groups (skilled or semi/unskilled manual). Being from a lone parent family is associated with a greater likelihood of being in the unhealthy drinker/smoker group. Over and above individual social background, those who attended an Urban Band 1 or rural DEIS primary school and those who attended a second-level DEIS school are somewhat more likely to fall into this group. School size (at either primary or second level) is not significantly related to being an unhealthy drinker/ smoker. The gender mix of the school has little impact, though those who attended single-sex girls' primary schools are slightly more likely to fall into this group.

Young people whose mothers had a post-secondary or higher qualification are less likely to fall into the unhealthy diet/activity group while those in lone parent and never employed households are more likely to do so. Attending a DEIS second-level school or an Urban Band 1 primary school is associated with increased chances of 
falling into this group while those in fee-paying second-level schools have lower chances of being in this group. Thus, the prevalence of unhealthy behaviour relating to diet and physical activity reflects not only family socio-economic background but also the concentration of advantage or disadvantage in certain schools. There is little variation by school size or gender mix, though girls in girls' schools are slightly more likely to fall into this group. There is no overall difference between urban and rural areas in the prevalence of unhealthy behaviours. However, when type of school is taken into account, those in urban areas are somewhat less likely to fall into the unhealthy diet/activity group than might be expected.

\subsubsection{School processes and health behaviours}

TABLE 4.3 MULTILEVEL MULTINOMIAL LOGIT MODEL OF GROUP MEMBERSHIP (SCHOOL-LEVEL FACTORS)

\begin{tabular}{|l|c|c|}
\hline & $\begin{array}{c}\text { Unhealthy } \\
\text { drinker/smoker }\end{array}$ & $\begin{array}{c}\text { Unhealthy diet/ } \\
\text { physical activity }\end{array}$ \\
\hline Perceived importance of PE/sports in primary school ethos: & Ref & Ref \\
\hline Very important & $1.176 \pm$ & 1.046 \\
\hline Fairly/not at all important & $0.964^{*}$ & 0.983 \\
\hline Level of student involvement in the second-level school & $0.097^{*}$ & 0.000 \\
\hline Second-level school between-school variance & & \\
\hline
\end{tabular}

Source: $\quad$ GUI, '98 Cohort, Waves 1, 2 and 3.

Notes: $\quad$ Relative to membership of the healthy group.

This controls for the social background variables included in Table 4.2. ${ }^{* * *} p<.001 ;{ }^{* *} p<.01 ;{ }^{*} p<.05 ; \pm p<.10$.

The next step was to test whether the school factors discussed earlier in the chapter had any impact on health behaviours. Because second-level school differences were found to play a more important role, and because of the difficulties in estimating very complex cross-classified models, these models are two-level models, with young people nested within their current (or former) second-level schools. Both primary and second-level factors were analysed. Only two school-level factors were significantly associated with health behaviours (see Table 4.3). Firstly, young people who had attended a primary school which did not place a strong emphasis on $\mathrm{PE} / \mathrm{sports}$ were slightly more likely to fall into the unhealthy drinker/smoker group at a later stage. Secondly, second-level schools which placed a stronger emphasis on student involvement had slightly lower levels of unhealthy drinking/smoking. This pattern is consistent with previous research which shows a positive relationship between student participation in (primary) school life and self-rated health and wellbeing (John-Akinola and Nic Gabhainn, 2014). Other factors, including principal perceptions of the quality of $P E /$ sports facilities, the school healthy eating policy, parent and teacher involvement (as assessed by the principal), were not directly associated with group membership. 
Some international studies have indicated that disaffection with school may act as an influence on unhealthy behaviour, especially drinking, smoking and substance use (see Chapter 1). The GUI study contains rich information on engagement with school and achievement at both primary and second-level stages (see Table 4.4). Primary school experiences were found to have longer-term effects on health behaviours. Young people who had more negative attitudes to primary school (at the age of nine) were more likely to fall into the unhealthy drinker/smoker group later on, as were those who had greater socio-emotional difficulties (Table 4.4). Those who had better mathematics achievement levels at nine were significantly less likely to fall into this group.

At the age of 13, the quality of interaction with teachers was significantly predictive of unhealthy drinking/smoking, with those who had negative interaction with teachers (in the form of being given out to or reprimanded) much more likely to fall into this group while positive interaction (including praise and positive feedback) played a protective role. Those who only liked school 'a bit' or disliked/hated it at 13 were almost 1.5 times more likely to fall into the unhealthy drinking/smoking group. The effects of negative attitudes at the age of nine were mediated by later attitudes to school and no longer significant when perspectives at 13 were taken into account. Numerical reasoning test scores at age 13 played a protective role in reducing the likelihood of unhealthy drinking/smoking.

The third column of results in Table 4.4 adds in information on Junior Certificate performance and on the peer group. The unhealthy drinking/smoking group took significantly fewer Junior Certificate subjects at higher level and were more likely to socialise with a peer group made up solely or partly of older peers. The number of friends was also analysed but made no significant difference to group membership. The effects of interaction with teachers at the age of 13 remained significant, even taking account of these other factors, indicating the important role of school climate in shaping unhealthy drinking/smoking.

Membership of the unhealthy diet/activity group was less strongly influenced by school engagement processes but some factors did make a difference (Table 4.4). Young people with higher Maths test scores at the age of nine were less likely to fall into this group while those with socio-emotional difficulties were somewhat more likely to do so. In contrast to the pattern for unhealthy drinking/smoking, this group had lower levels of positive and negative interaction with their teachers, suggesting some level of withdrawal or isolation from the school context. Attitudes to school were not significantly associated with unhealthy diet/activity, though students with fewer higher-level subjects were slightly more likely to fall into this group. The age composition of the peer group played little role in shaping membership of this group. 
Comparing the models in Table A6 provides insights into the processes through which school social mix influences health behaviour. The effect of attending a primary school in a very disadvantaged setting (Urban Band 1 DEIS) on later unhealthy drinking/smoking is largely explained by the more negative attitudes to school and lower achievement levels evident among these young people by the age of nine. However, young people who had attended Urban Band 1 primary schools had higher levels of unhealthy diet/activity, even taking account of a wide range of other factors, including their school experiences and peer composition.

The effect of attending a DEIS second-level school on unhealthy drinking/smoking is largely driven by the tendency of these young people to have already left school by $17 / 18$ years (because of early school leaving, earlier school start and/or being less likely to have taken the Transition Year programme) (compare the 'school characteristics' and 'year group' columns in Table A6). The higher prevalence of unhealthy diet/activity in DEIS second-level schools largely reflects more negative attitudes to school and lower achievement levels among this group of young people at primary level (Table A6). The lower levels of this behaviour among those who attended fee-paying second-level schools are mainly explained by higher prior achievement levels at primary school level (compare 'year group' and 'primary school experiences' columns in Table A6).

Even taking account of a wide range of factors capturing experiences at primary and second level, individual second-level schools differed significantly in the prevalence of unhealthy drinking/smoking (see between-school variance coefficients in Table 4.4). In contrast, differences between second-level schools in relation to unhealthy diet/physical activity were accounted for by the family background of the student population (see Table 4.1). 
TABLE 4.4 MULTILEVEL MULTINOMIAL LOGIT MODEL OF GROUP MEMBERSHIP (SCHOOL EXPERIENCE, ACHIEVEMENT AND PEER GROUP FACTORS)

\begin{tabular}{|c|c|c|c|c|c|c|}
\hline & $\begin{array}{l}\text { Unhealthy } \\
\text { drinker/smoker }\end{array}$ & & & $\begin{array}{c}\text { Unhealthy } \\
\text { diet/physical } \\
\text { activity }\end{array}$ & & \\
\hline & $\begin{array}{c}\text { Primary school } \\
\text { experiences (age 9) }\end{array}$ & $\begin{array}{c}\text { School } \\
\text { experiences at } 13\end{array}$ & $\begin{array}{l}\text { Junior Certificate } \\
\text { and peer group }\end{array}$ & $\begin{array}{c}\text { Primary school } \\
\text { experiences (age 9) }\end{array}$ & $\begin{array}{c}\text { School } \\
\text { experiences at } 13\end{array}$ & $\begin{array}{l}\text { Junior Certificate } \\
\text { and peer group }\end{array}$ \\
\hline \multicolumn{7}{|l|}{ Liking school at age 9: } \\
\hline Always liked & Ref & Ref & Ref & Ref & Ref & Ref \\
\hline Sometimes liked & $1.310 * *$ & 1.073 & 1.076 & 1.044 & 1.027 & 1.021 \\
\hline Never liked & $1.362 \pm$ & 0.931 & 0.901 & 1.156 & 1.142 & 1.133 \\
\hline Drumcondra Maths test score (age 9) & $0.882 * *$ & 1.027 & $1.092 \pm$ & $0.889 * *$ & 1.105 & $0.932 \pm$ \\
\hline Total SDQ score at age 9 & $1.033^{* * *}$ & $1.018^{*}$ & 1.011 & $1.018^{* *}$ & $1.017 * *$ & $1.016^{*}$ \\
\hline Positive interaction with teachers (at 13) & & $0.889 * * *$ & $0.899 * * *$ & & $0.889 * * *$ & $0.924 * * *$ \\
\hline Negative interaction with teachers (at 13) & & $1.553^{* * *}$ & $1.528 * * *$ & & $0.898 * * *$ & $0.898 * * *$ \\
\hline \multicolumn{7}{|l|}{ Attitudes to school (at 13): } \\
\hline Like it very much & & Ref & Ref & & Ref & Ref \\
\hline Like it quite a bit & & 1.148 & 1.137 & & 0.941 & 0.943 \\
\hline Like it a bit & & $1.498 * * *$ & $1.413^{* *}$ & & 1.077 & 1.070 \\
\hline Don't like/hate it & & $1.435 * *$ & 1.246 & & 0.884 & 0.881 \\
\hline Drumcondra numerical reasoning test score & & $0.821 * * *$ & $0.934 \pm$ & & 1.006 & 1.022 \\
\hline $\begin{array}{l}\text { Number of higher-level subjects taken in } \\
\text { Junior Certificate exam }\end{array}$ & & & $0.882^{* * *}$ & & & $0.971^{*}$ \\
\hline \multicolumn{7}{|l|}{ Composition of friendship group: } \\
\hline None older & & & Ref & & & Ref \\
\hline Some older & & & $1.704^{* * *}$ & & & $0.901 \pm$ \\
\hline All older & & & $1.632 * * *$ & & & 0.906 \\
\hline Between-school variance & $0.125^{* *}$ & $0.108^{*}$ & $0.112 * *$ & 0.000 & 0.000 & 0.000 \\
\hline
\end{tabular}

Notes: $\quad$ Relative to membership of the healthy group.

This controls for the social background variables included in Table 4.2. ${ }^{* *} p<.001 ;{ }^{* *} p<.01 ;{ }^{*} p<.05 ; \pm p<.10$. 


\subsubsection{Robustness checks}

Chapter 2 indicated that health behaviours at 17 years of age are shaped by a number of additional factors, including parental health behaviours and individual personality traits. It may therefore be the case that school disaffection reflects some of these factors rather than the school experience per se. A series of robustness checks were carried out to assess whether the link between school disengagement and unhealthy drinking/smoking held when these factors were taken into account.

Chapter 3 outlined the relationship between parental smoking and drinking and health behaviours among 17-year-olds. The estimates of the effects of school experiences on group membership did not change when parental health behaviours when the young person was 13 were taken into account (analyses not shown here). Thus, the relationship between school disengagement and unhealthy smoking/drinking was not accounted for by differences in parents' patterns of drinking and smoking.

Chapter 3 has shown that some types of socio-emotional difficulties at age 13 are associated with a greater likelihood of unhealthy behaviours. Including the different dimensions of SDQ and/or the experience of depressive symptoms does not alter the findings regarding school experiences (analyses not shown here). Similarly, looking at self-image at age 13 (as measured by the Piers Harris scale) does not alter the patterns for school experiences. However, the effect for most friends being older reduces slightly in size (but remains significant).

The findings on the effects of school experiences remain robust when personality traits at the age of 13 are taken into account (compare the columns in Table A7). Taking account of personality traits and self-image at age 17 does result in a slight reduction in the size of the effect of teacher-student interaction. This pattern is largely driven by the mediating effect of the opposition to authority measure on unhealthy drinking/smoking behaviour. ${ }^{32}$ The way in which some of the effect of negative interaction is mediated by later opposition to authority is consistent with previous research which shows a cycle of negative interaction with teachers and 'acting out' emerging for some groups of young people (see Smyth, 2016). 


\subsection{CONCLUSIONS}

This chapter has looked at schools as a context for young people's health behaviours. Primary schools are found to place a strong emphasis on sports/PE and levels of extracurricular sports provision are high in second-level schools. However, schools are found to differ in the emphasis they place on sports and, to an even greater extent, in the quality of their facilities. Among young people, levels of involvement in physical activity are found to be higher among more socioeconomically advantaged groups and among males. These patterns are mirrored at the school level, with lower levels of provision in single-sex girls' schools and schools serving disadvantaged communities, and greater emphasis and better quality facilities in single-sex boys' schools and in fee-paying schools. While these patterns may reflect schools being responsive to the interests of their students (for example, in providing certain extra-curricular activities), there is a risk of reinforcing differentiation in participation by gender and social background. In addition, there appear to be challenges for small schools in terms of the, on average, poorer quality of sports facilities at both primary and second level.

Provision of free or subsidised meals tends to be greater in schools serving disadvantaged communities, representing a potential lever for promoting healthy eating, ${ }^{33}$ at least for part of the day. Second-level schools adopt a range of measures to promote healthy eating among their students, including guidelines for students and their parents, providing healthy food and prohibiting certain foods/ drinks. Smaller schools and single-sex boys' schools are less likely than other types of schools to be proactive in relation to healthy eating. In terms of social mix, DEIS schools and, at the other end of the social spectrum, fee-paying schools are more likely to be proactive in this respect than non-fee-paying, non-DEIS schools.

The multilevel models indicated slight variation in health behaviours according to the individual primary school attended but more marked differences between second-level schools. The measures of school policy and practice examined here were found to have little substantive effect on health behaviours, though unhealthy drinking/smoking behaviour was somewhat less evident where primary schools had emphasised PE/sports and where second-level schools gave students more say in school life. School social mix emerged as a more important factor, with higher rates of both types of unhealthy behaviour in Urban Band 1 DEIS primary schools and DEIS second-level schools. Much of variation by school social mix was explained by differences in student engagement and school climate. In keeping with international research, disaffection with school and academic underperformance played a role in increased drinking and smoking among young people. Previous research has shown that the quality of interaction between 
teachers and students has a significant effect on the ease of transition to secondlevel education, school retention and academic performance (Smyth, 2016). This study highlights the important role teacher-student interaction plays in health behaviours, with the unhealthy drinking/smoking group having had much more negative relations with their teachers. A new finding relates to the potential role of isolation (low levels of interaction with teachers) in contributing to unhealthy diet/activity. 



\section{CHAPTER 5}

\section{Summary and policy implications}

\section{$5.1 \quad$ INTRODUCTION}

The World Health Organization (WHO) estimates that about a third of the burden of disease in developed countries is directly attributable to four key modifiable health behaviours: smoking, excessive consumption of alcohol, poor diet and low levels of physical activity (WHO, 2002). While most deaths from noncommunicable or chronic diseases occur in adulthood, many health behaviours initiate in adolescence, and patterns established in adolescence often track into adult life. Previous research on health behaviours in adolescence has tended to focus on one or two of these health behaviours, with little regard to how major risk factors for disease cluster together. Using data from Waves 1-3 of the Growing Up in Ireland (GUI) '98 Cohort (corresponding to ages nine, 13 and 17), this report analysed how these four main health behaviours cluster among the adolescent population, how they are distributed across this population, and the relative importance of individual, family and school characteristics in determining these patterns. In this chapter we summarise the findings from our analyses and discuss implications for policy.

Before doing so, however, there are a number of limitations of the analysis that need to be noted. First, the indicators for the health behaviours examined (smoking, alcohol consumption, physical activity and diet) are all self-reported by the young person. There is an extensive literature documenting the potential for recall and social desirability bias with the use of self-reported data (see, for example, Adams et al., 2005; Cawley and Choi, 2018), but the use of a selfcompletion mode (rather than interviewer administered) for the collection of information on smoking and alcohol consumption in GUI should minimise these potential sources of bias for these measures at least. Second, with the exception of smoking, the indicators for alcohol consumption, physical activity and diet do not map easily onto current guidelines for adolescents (e.g. 60 minutes of moderate to vigorous exercise per day). The clusters must therefore be interpreted in terms of relative levels of behaviour. Third, the absence of data on smoking and alcohol consumption at ages nine and 13 , and consistent measures of physical activity and diet at all ages, prevented an examination of trajectories of health behaviour between ages nine and 17 .

Despite these limitations, the analysis has a number of strengths. Rather than examining adolescent health behaviours in isolation, or simply examining how they co-occur, this report used latent class analysis to classify young people into three 
broad groups that reflect an underlying latent or unobserved factor. The availability of detailed longitudinal data on different dimensions of young people's lives (demographic characteristics, family background, cognitive and non-cognitive skills, school-level factors) allowed for an analysis of the relative importance of these factors to health behaviour cluster membership at age 17. The existence of comprehensive data on the young person's school (both primary and second level) allowed for the use of cross-classified multilevel analysis to unpick the relative role of school type, social mix and climate in explaining health behaviour cluster membership. Finally, the focus here was on the four main risk factors for disease identified by the WHO. However, GUI contains data on other health and risky behaviours (e.g. sedentary behaviour, eating breakfast, sexual health, substance use, etc.), all of which could be considered in future research examining wider dimensions of health behaviours among adolescents.

\subsection{SUMMARY}

\section{Clusters of health behaviours among young adults}

Focusing on the four main risk factors for chronic disease identified by the WHO (smoking, alcohol consumption, diet, physical activity), we identified three health behaviour clusters among young adults in Ireland; 'unhealthy smokers and drinkers' who accounted for 21 per cent of the young adult population; 'unhealthy diet and physical activity' who accounted for 36 per cent of the population; and a 'healthy' group who accounted for the remaining 43 per cent of the population. Significant associations between cluster group membership and a variety of individual and family characteristics such as gender, non-cognitive skills and family social background were identified. Examining the influence of individual and family background characteristics measured at ages nine and 13 showed considerable stability in the role of these various factors in predicting health behaviour cluster membership at age 17 .

\section{The role of schools}

Schools can influence health behaviour directly through the provision of $\mathrm{PE} / \mathrm{sports}$ and healthy food or indirectly through the school climate. Primary schools are found to place a strong emphasis on sports/PE, and levels of extracurricular (individual and team) sports provision are high in second-level schools. However, schools are found to differ in the emphasis they place on sports and, to an even greater extent, in the quality of their facilities. On average, smaller schools (both primary and second level) tend to report poorer quality PE/sports facilities. DEIS schools are more likely to offer free or subsidised meals, representing a potential lever for promoting healthy eating, and (along with fee-paying schools) are more proactive in promoting healthy eating. Smaller schools and single-sex boys' schools are less likely than other types of schools to be proactive in relation to healthy eating. 
The study findings indicate that the prevalence of health behaviours differs according to the second level, and, to some extent, the primary school attended. This pattern had been found in relation to substance use in international studies (see, for example, Olsson and Fritzell, 2015; Maes and Lievens, 2003) but our findings suggest that patterns of unhealthy diet and physical activity also vary by school. Young people attending schools with a concentration of socio-economic disadvantage are more likely to engage in both types of unhealthy behaviours, even taking account of their family background characteristics. This is partly related to differences in school engagement and disengagement, with negative relations with teachers and disaffection with school emerging as an important factor in unhealthy drinking/smoking. In contrast, those who engage in unhealthy diet/ activity do not appear disaffected with school but instead seem to be somewhat isolated from their teachers, with lower levels of both positive and negative interaction.

\subsection{IMPLICATIONS FOR POLICY AND PRACTICE}

There has been a growing recognition of the importance of health behaviours for population health and wellbeing (Government of Ireland, 2013), and that tackling unhealthy behaviour clusters requires a multi-faceted approach that recognises that these behaviours do not exist in isolation, but instead need to be approached as behaviours that may be interdependent (Department of Health, 2016). Current government strategies in relation to tobacco control, physical activity, sexual health, and obesity have been developed and new legislation in relation to alcohol consumption and tobacco marketing has been enacted (Department of Health, 2013; Government of Ireland, 2015; 2016; 2018).

In this context, an understanding of health behaviour clusters at the individual level and among specific population subgroups will be of interest to policymakers and practitioners tasked with implementing these strategies. Focusing in particular on children and young people, policy and practice in Ireland has increasingly moved towards a more holistic concept of wellbeing among children and young people, which encompasses physical, mental, social and emotional dimensions (see, for example, DES, 2018). The national strategy for children and younger people, Better Outcomes, Brighter Futures, highlights the importance of healthy lifestyles for physical and mental health and wellbeing. The findings presented in this study provide support for such an approach by demonstrating the interconnection between cognitive and non-cognitive development, social relationships and health behaviours. School is found to make a difference to health behaviours, mainly through the quality of relationships between teachers and students and engagement in school life. The concentration of socio-economic disadvantage in some schools results not only in poorer educational outcomes but also in greater health risks. 
The WHO (1999) has characterised schools as the 'ideal setting' for health promotion. The study findings suggest there is considerable potential to use the school context to help encourage healthy behaviours, and in particular point to the importance of supporting the Department of Education and Skills' Wellbeing Framework for Practice (2018-2023) for the prevention of risky health behaviours that lead to chronic disease (DES, 2018). The Framework recognises that schools play a significant role in the promotion of wellbeing through a range of activities and approaches, which support the physical, mental and emotional well-being of young people. In particular, the Framework acknowledges the role of schools in enhancing protective factors related to wellbeing, including positive relationships with teachers and peers, a positive school climate, opportunities for social and emotional learning, and formal and informal supports for students. This research therefore reinforces the need for a preventive whole-school approach - as identified by the Framework - and further emphasises the importance of schools in the promotion of health and wellbeing of young people.

In addition, both the Junior Certificate Physical Education Syllabus and Physical Education Framework for Senior Cycle recognise that Physical Education (PE) aims to motivate students to adopt a positive attitude to physical activity, and an active and healthy lifestyle. Curricular provision takes place against the broader backdrop of the Department of Education and Skills' Physical Education, Physical Activity and Sport for Children and Young People Framework (DES, 2012), which highlights the importance of the provision of sport as a co-curricular activity, as well as students choosing an active transport mode (such as walking or cycling) for everyday travel needs. The findings of this research therefore highlight the importance of schools as an arena for involvement in sports and other physical activities. Further research could usefully examine the relative role of PE classes and extracurricular provision in influencing young people's physical activity levels. The study findings point to a significant gender gap with regards to participation in school-based physical activity, and the provision of sports facilities in girls' schools. Again, further research could help identify potential levers for involving young women in physical activity to a greater extent.

In the Irish context, existing research has shown the value placed by teachers on subjects such as Social, Personal and Health Education (SPHE) but tensions in allocating sufficient time to them; the need for teacher professional development has also been highlighted (Nic Gabhainn et al., 2010). Moynihan et al. (2016) have indicated challenges in adopting a whole-school approach to health promotion, with schools tending to focus on curriculum or diet/physical activity rather than changes in day-to-day practice or school climate. Our study findings show variation in the quality of PE/sports facilities available to schools, with small schools facing particular challenges. There are also challenges in using school as a vehicle for 
health promotion for those groups of young people for whom school is a more negative experience. ${ }^{34}$ From a positive perspective, however, it appears that measures to enhance student engagement and promote a positive school climate are likely to have positive spill-overs for health behaviours, especially the prevalence of drinking and smoking. Similarly, the new junior cycle framework sets out to promote the kinds of non-cognitive skills (including self-care, selfmanagement, coping strategies and building positive relationships) that are likely to enhance more healthy behaviours (Schwarzer and Renner, 2000; Frech, 2012). While some school-level initiatives have been successful in promoting levels of physical activity (see, for example, O'Leary et al., 2019), ${ }^{35}$ the findings suggest that a whole-school approach is likely to prove more effective given the clustering of health behaviours. Teacher professional development is likely to be crucial in the success of this endeavour.

However, there are challenges in securing change in health behaviours through school-based initiatives alone. The international evidence on the effectiveness of school-based interventions targeting health behaviours is mixed (see for example, Dobbins et al., 2013, for a review of physical activity interventions and Thomas et al., 2013, for smoking interventions). A recent systematic review of 'healthpromoting school' interventions found evidence for positive effects on certain health behaviours (i.e. increased physical activity and fitness levels, improved fruit and vegetable consumption, decreased cigarette use) but not others (i.e. fat intake, alcohol and drug use) (Langford et al., 2014). In addition, the review highlighted the dearth of evidence available on the effectiveness of interventions targeting multiple health behaviours simultaneously. Complementary approaches that involve the home environment (particularly important given the intergenerational persistence in health behaviours), will also be necessary. For example, there is some evidence that active travel (i.e., walking or cycling to school) is associated with increased physical activity and improved health outcomes (Jones et al., 2019; Lubans et al., 2011).

Our findings also point to an important gender dimension to health behaviour clusters in the Irish context. Young females were significantly more likely to belong to the 'unhealthy diet and physical activity' and somewhat more likely to be in the 'unhealthy smokers and drinkers' groups than young males, largely due to their relatively poorer diets and physical activity levels. While previous international research has also found that young males have higher levels of physical activity than young females (e.g. Alamian and Paradis, 2009; Champion et al., 2018; Daw et al., 2017), females have generally been shown to have better diet than males, 
although this is not a universal finding (Frech, 2012). Approximately 90 per cent of our sample were still in school, facing Leaving Certificate examinations, the 'high stakes' examinations that determine entry to third-level education. Previous research in the Irish context has demonstrated the sharp drop-off in sports participation, particularly among young females, as students approach their Leaving Certificate examinations (Lunn et al., 2013); our findings in relation to relatively poorer diet on the part of young females have not previously been identified, however, and merit further research.

Our results also demonstrate strong intergenerational persistence in health behaviours. Young people with parents who were smokers and more frequent drinkers were themselves much more likely to belong to the 'unhealthy smokers and drinkers' group. These effects persist even when controlling for different dimensions of family background (which are highly correlated with parental health behaviours). These results highlight the importance of public health policies to reduce the prevalence of smoking and harmful alcohol consumption for future generations. For example, the HSE's Tobacco Cessation Support Programme should continue to support parents to quit smoking. ${ }^{36}$

Finally, while data limitations precluded a comprehensive analysis of health behaviour cluster trajectories from childhood to adolescence, significant associations between aspects of health behaviours measured at ages nine and 13 and cluster group membership at age 17 were identified (i.e. those exhibiting 'better' health behaviours at ages nine and 13 were more likely to be in the 'healthy' group at age 17). As further waves of data for the ' $98 \mathrm{GUI}$ Cohort become available in the future, research on the antecedents of health behaviour trajectories into adulthood will become possible.

${ }^{36}$ Data from the recent Healthy Ireland survey showed that while the prevalence of smoking was lower among parents than non-parents, 19 per cent of parents in Ireland were daily or occasional smokers (Department of Health, 2019). 


\section{APPENDIX}

TABLE A1 VARIABLE DEFINITIONS

\begin{tabular}{|c|c|c|}
\hline Variable & Description & Availability \\
\hline \multicolumn{3}{|c|}{$\begin{array}{l}\text { Parental health behaviour and } \\
\text { early health }\end{array}$} \\
\hline Birthweight & Birthweight (kgs) & 9 \\
\hline Gestation & $\begin{array}{l}\text { Distinguishes between late ( } 42+\text { weeks), on time (38-41 } \\
\text { weeks) and early ( } 37 \text { weeks or earlier) }\end{array}$ & 9 \\
\hline Breastfed & Breastfed/never breastfed & 9 \\
\hline Smoking in pregnancy & $\begin{array}{l}\text { Distinguishes mother smoking daily, occasionally or } \\
\text { never in pregnancy }\end{array}$ & 9 \\
\hline Drinking in pregnancy & $\begin{array}{l}\text { Distinguishes mother drinking daily/occasionally or never } \\
\text { in pregnancy }\end{array}$ & 9 \\
\hline Parental smoking & $\begin{array}{l}\text { Distinguishes neither parent smokes, at least one parent } \\
\text { smokes occasionally, at least one parent smokes daily, } \\
\text { both parents smoke daily }\end{array}$ & $9,13,17$ \\
\hline Parental drinking & $\begin{array}{l}\text { Distinguishes neither parent drinks alcohol, at least one } \\
\text { parent drinks monthly or less, at least one parent drinks } \\
\text { 1-2 times per month, at least one parent drinks 1-2 times } \\
\text { per week, at least one parent drinks 3-4 times per week }\end{array}$ & $9,13,17$ \\
\hline \multicolumn{3}{|c|}{$\begin{array}{l}\text { Socio-emotional wellbeing, self- } \\
\text { image and personality traits }\end{array}$} \\
\hline SDQ Emotional & $\begin{array}{l}\text { Strengths and Difficulties Questionnaire (SDQ) Emotional } \\
\text { Symptoms (z-score) }\end{array}$ & $9,13,17$ \\
\hline SDQ Conduct & SDQ Conduct Problems (z-score) & $9,13,17$ \\
\hline SDQ Hyperactivity & SDQ Hyperactivity/Inattention (z-score) & $9,13,17$ \\
\hline SDQ Peer & SDQ Peer Relationship Problems (z-score) & $9,13,17$ \\
\hline SDQ Prosocial & SDQ Prosocial Behaviour (z-score) & $9,13,17$ \\
\hline Extraversion & $\begin{array}{l}\text { Ten-item Personality Inventory (TIPI) Extraversion } \\
\text { (z-score) }\end{array}$ & 13,17 \\
\hline Agreeableness & TIPI Agreeableness (z-score) & 13,17 \\
\hline Conscientiousness & TIPI Conscientiousness (z-score) & 13,17 \\
\hline Emotional Stability & TIPI Emotional Stability (z-score) & 13,17 \\
\hline Openness & TIPI Openness (z-score) & $\begin{array}{l}13,17 \\
\text { Contd. }\end{array}$ \\
\hline
\end{tabular}


TABLE A1 CONTD.

\begin{tabular}{|c|c|c|}
\hline Variable & Description & Availability \\
\hline Piers Harris Behaviour & Piers Harris Behavioural Adjustment scale (z-score) & 9,13 \\
\hline $\begin{array}{l}\text { Piers Harris Intellectual and } \\
\text { School }\end{array}$ & Piers Harris Intellectual and School Status scale (z-score) & 9,13 \\
\hline Piers Harris Physical Appearance & $\begin{array}{l}\text { Piers Harris Physical Appearance and Attributes scale } \\
\text { (z-score) }\end{array}$ & 9,13 \\
\hline Piers Harris Freedom from Anxiety & Piers Harris Freedom from Anxiety scale (z-score) & 9,13 \\
\hline Piers Harris Popularity & Piers Harris Popularity scale (z-score) & 9,13 \\
\hline $\begin{array}{l}\text { Piers Harris Happiness and } \\
\text { Satisfaction }\end{array}$ & Piers Harris Happiness and Satisfaction scale (z-score) & 9,13 \\
\hline Self-efficacy & Self-efficacy scale (z-score) & 17 \\
\hline Self-esteem & Rosenberg self-esteem scale (z-score) & 17 \\
\hline Opposition to authority & Opposition to authority scale (z-score) & 17 \\
\hline \multicolumn{3}{|l|}{$\begin{array}{l}\text { Socio-demographic and family } \\
\text { background variables }\end{array}$} \\
\hline Gender & Male/female & $9,13,17$ \\
\hline Age & Age (years) & $9,13,17$ \\
\hline Family structure & $\begin{array}{l}\text { Distinguishes between lone parent and two parent } \\
\text { families (Chapter } 4) \text { with additional categories for large } \\
(3+) \text { and smaller (1-2) families }\end{array}$ & $9,13,17$ \\
\hline Income quintile & $\begin{array}{l}\text { Household equivalised income grouped into quintiles } \\
\text { (fifths) }\end{array}$ & $9,13,17$ \\
\hline $\begin{array}{l}\text { Educational qualifications of } \\
\text { Primary Caregiver (PCG) }\end{array}$ & $\begin{array}{l}\text { Distinguishes between: Junior Cert or lower; Leaving } \\
\text { Certificate; post-secondary; degree or higher }\end{array}$ & $9,13,17$ \\
\hline Social class & $\begin{array}{l}\text { Based on the higher class where two parents are } \\
\text { employed, distinguishes between: professional; } \\
\text { managerial/technical; other non-manual; skilled manual; } \\
\text { semi/unskilled manual; and never employed. }\end{array}$ & $9,13,17$ \\
\hline Migrant & $\begin{array}{l}=1 \text { if parents were not born in Ireland; if lone parent } \\
\text { family, PCG not born in Ireland }\end{array}$ & $9,13,17$ \\
\hline \multicolumn{3}{|l|}{ School characteristics } \\
\hline Primary school social mix & $\begin{array}{l}\text { Distinguishes between Urban Band } 1 \text { DEIS, Urban Band } 2 \\
\text { DEIS, Rural DEIS, fee-paying and other non-DEIS schools }\end{array}$ & 9 \\
\hline Primary school gender mix & $\begin{array}{l}\text { Distinguishes between boys', girls' and coeducational } \\
\text { schools }\end{array}$ & 9 \\
\hline Primary school size & $\begin{array}{l}\text { Categorises schools into: }<50,50-99,100-199,200-299 \\
\text { and } 300+\end{array}$ & 9 \\
\hline & & Contd. \\
\hline
\end{tabular}


TABLE A1 CONTD.

\begin{tabular}{|c|c|c|}
\hline Variable & Description & Availability \\
\hline $\begin{array}{l}\text { Principal perceptions of the } \\
\text { importance of PE/sports to the } \\
\text { school ethos }\end{array}$ & $\begin{array}{l}\text { Categories: very important, fairly important, not at all } \\
\text { important }\end{array}$ & 9 \\
\hline $\begin{array}{l}\text { Principal perceptions of the } \\
\text { importance of } \mathrm{PE} / \text { sports as a } \\
\text { curricular activity }\end{array}$ & $\begin{array}{l}\text { Categories: very important, fairly important, not at all } \\
\text { important }\end{array}$ & 9 \\
\hline $\begin{array}{l}\text { Principal perceptions of the } \\
\text { importance of PE/sports as an } \\
\text { extra-curricular activity }\end{array}$ & $\begin{array}{l}\text { Categories: very important, fairly important, not at all } \\
\text { important }\end{array}$ & 9 \\
\hline $\begin{array}{l}\text { Principal perceptions of quality of } \\
\text { PE/sports facilities }\end{array}$ & Categories: excellent, good, fair, poor & 9 \\
\hline $\begin{array}{l}\text { Principal perceptions of quality of } \\
\text { playground facilities }\end{array}$ & Categories: excellent, good, fair, poor & 9 \\
\hline $\begin{array}{l}\text { Time devoted to PE (as reported } \\
\text { by classroom teacher) }\end{array}$ & Time in minutes & 9 \\
\hline Provision of food at school & $\begin{array}{l}\text { Whether school offered a breakfast club; whether } \\
\text { offered free lunches }\end{array}$ & 9 \\
\hline $\begin{array}{l}\text { Principal reports of personnel } \\
\text { involved in providing support to } \\
\text { children with emotional/ } \\
\text { behavioural problems }\end{array}$ & $\begin{array}{l}\text { Categories; principal, classroom teacher, learning } \\
\text { support/resource teacher, other staff member, external } \\
\text { assistance }\end{array}$ & 9 \\
\hline Bullying policy & $\begin{array}{l}\text { Whether the principal reports the school has an explicit } \\
\text { anti-bullying policy; whether this is a written policy }\end{array}$ & 9 \\
\hline Bullying prevalence & $\begin{array}{l}\text { Principal reports of the prevalence of bullying in the } \\
\text { school, ranging from 'major problem' to 'no problem at } \\
\text { all' }\end{array}$ & 9 \\
\hline Day-to-day problems in the school & $\begin{array}{l}\text { Principal reports of scale of day-to-day problems } \\
\text { compared to other schools, ranging from much greater } \\
\text { to much less }\end{array}$ & 9 \\
\hline Second-level school social mix & $\begin{array}{l}\text { Distinguishes between DEIS, fee-paying and other non- } \\
\text { DEIS schools }\end{array}$ & 13 \\
\hline Second-level school gender mix & $\begin{array}{l}\text { Distinguishes between boys', girls' and coeducational } \\
\text { schools }\end{array}$ & 13 \\
\hline Second-level school size & Categorises schools into: $<240,241-400$ and $401+$ & 13 \\
\hline Extra-curricular sports provision & $\begin{array}{l}\text { Principal reports of whether offers team sports/ } \\
\text { individual sports }\end{array}$ & 13 \\
\hline $\begin{array}{l}\text { Principal perceptions of quality of } \\
\mathrm{PE} / \text { sports facilities }\end{array}$ & Categories: excellent, good, fair, poor & 13 \\
\hline $\begin{array}{l}\text { Principal perceptions of quality of } \\
\text { outdoor facilities }\end{array}$ & Categories: excellent, good, fair, poor & 13 \\
\hline \multirow[t]{2}{*}{ Provision of food at school } & $\begin{array}{l}\text { Whether school offered a breakfast club; whether } \\
\text { offered free lunches }\end{array}$ & 13 \\
\hline & & Contd. \\
\hline
\end{tabular}


TABLE A1 CONTD.

Variable
Healthy eating

Personnel involved in providing personnel and social support to students

Provision of transition supports for students

Parental involvement and support

Teacher support

Student engagement

Student involvement

\section{School experiences}

\begin{tabular}{l} 
Year group \\
Attitudes to primary school \\
\hline Drumcondra Mathematics Test
\end{tabular}

Positive interaction with teachers

\section{Principal reports of:}

Whether the school has a healthy eating policy; whether certain foods/drinks are prohibited; whether pupils are given healthy eating guidelines; whether parents are given healthy eating guidelines; whether mostly healthy foods/drinks are provided; whether students are allowed to leave the school at lunchtime; whether healthy eating is addressed during subject lessons; whether the school has a vending machine for food/drink and, if so, whether offers sugary drinks or unsweetened juices/water

Principal reports of involvement of the following staff (ranging from to a great extent to not at all): principal, guidance counsellor, pastoral care team, year head, class tutor, student mentors, other

Whether the school offers: induction day; formal transition programme; link with primary school; class tutor; student mentors; study skills programme

Principal reports of the extent to which parents: think this is a good school; show support for the school; given their children help and support with schoolwork; attend meetings or events organised by the school; have contact with the school only if there is a problem; expect their children to go on to higher education (responses range from true of nearly all to true of only a few) Principal reports of the extent to which teachers: are positive about the school; get a lot of help and support from colleagues; are open to new developments and challenges; are eager to take part in continuing professional development (responses range from true of nearly all to true of only a few)

Principal reports of the extent to which students: enjoy being at school; are well-behaved in class; show respect for their teachers; are rewarding to work with (responses range from true of nearly all to true of only a few)

Principal reports of the extent to which students' opinions are taken into account in: school rules; the way classes are taught; teaching/learning materials; school uniform (responses range from to a large extent to not at all)

Whether the school has a student council and how its members are appointed

Whether in $5^{\text {th }}$ year, $6^{\text {th }}$ year or has left school

Always, sometimes or never like

Logit score

Scale based on frequency of: told by teacher that work is good; encouraged to ask questions in class; praised for answering a question; asked questions in class by a teacher 
TABLE A1 CONTD.

\begin{tabular}{|c|c|c|}
\hline Variable & Description & Availability \\
\hline $\begin{array}{l}\text { Negative interaction with } \\
\text { teachers }\end{array}$ & $\begin{array}{l}\text { Scale based on frequency of: being given out to because } \\
\text { work is untidy or not done on time; being given out to for } \\
\text { misbehaving in class }\end{array}$ & 13 \\
\hline Attitudes to second-level school & $\begin{array}{l}\text { Likes school very much, quite a bit, a bit, don't like it or } \\
\text { hate it }\end{array}$ & 13 \\
\hline $\begin{array}{l}\text { Drumcondra numerical reasoning } \\
\text { test }\end{array}$ & Logit score & 13 \\
\hline $\begin{array}{l}\text { Number of higher-level subjects } \\
\text { taken in Junior Certificate exam }\end{array}$ & Self-report of subject levels & 13 \\
\hline
\end{tabular}

Source: GUI, '98 cohort, Waves 1, 2 and 3.

Note: The TIPI was completed by the PCG in Wave 2 (age 13) and by the young person themselves at Wave 3 (age 17).

TABLE A2 ASSOCIATION BETWEEN DETAILED DIET ITEMS AND GENDER

\begin{tabular}{|l|c|c|c|}
\hline \multicolumn{1}{|c|}{ Variable } & Male & Female & Chi' Test Result \\
\hline Fresh fruit & 1.180 & 1.233 & $7.045^{* *}$ \\
\hline Fruit juice & 0.728 & 0.630 & $24.276^{* * *}$ \\
\hline Meat/chicken/fish & 1.648 & 1.394 & $254.331^{* * *}$ \\
\hline Eggs & 0.562 & 0.390 & $98.440^{* * *}$ \\
\hline Cooked vegetables & 1.174 & 1.102 & $19.215^{* * *}$ \\
\hline Raw vegetables/salad & 0.451 & 0.574 & $48.348^{* * *}$ \\
\hline Hamburger & -0.381 & -0.208 & $155.768 * * *$ \\
\hline Chips & -0.407 & -0.336 & $24.552 * * *$ \\
\hline Crisps & -0.692 & -0.558 & $53.923 * * *$ \\
\hline Biscuits/cakes & -0.895 & -0.832 & $12.185 * * *$ \\
\hline Cheese/yoghurt & 0.691 & 0.591 & $35.193 * * *$ \\
\hline Cheese/yoghurt (low fat) & 0.139 & 0.147 & 3.333 \\
\hline Water & 1.891 & 1.873 & 4.236 \\
\hline Soft drinks (not diet) & -0.582 & -0.421 & $85.249 * * *$ \\
\hline Soft drinks (diet) & -0.192 & -0.165 & $5.486 *$ \\
\hline Full cream milk & 1.114 & 0.740 & $270.358^{* * *}$ \\
\hline Skimmed milk & 0.387 & 0.395 & $28.323 * * *$ \\
\hline Total dietary quality score & & & \\
\hline
\end{tabular}

Source: $\quad$ GUI, '98 cohort, Wave 3.

Notes: $\quad$ The dietary items are positively scored (range -2 to +2 ), with higher scores indicating 'better' diet. Items with a negative value are considered less beneficial (e.g. hamburger), while those with a positive value are considered more beneficial (e.g. fresh fruit).

The chi-squared test tests the null hypothesis of no statistically significant association between each diet components and gender. ${ }^{*} p<0.1 ;{ }^{* *} p<0.05 ;{ }^{* * *} p<0.01$. 
TABLE A3 GOODNESS OF FIT STATISTICS

\begin{tabular}{|c|c|}
\hline Model & Pseudo- $\mathbf{R}^{2}$ \\
\hline 1. Tables $3.8 a, 3.8 b$ and $3.8 c$ & \\
\hline Controlling for sex, age and still at school & 0.0280 \\
\hline Adding controls for family background & 0.0405 \\
\hline Adding controls for cognitive and non-cognitive skills & 0.1253 \\
\hline - $\quad$ Adding controls for parental health behaviours & 0.1311 \\
\hline
\end{tabular}

Source: GUI, '98 Cohort, Wave 3.

Notes: In a linear model, the $\mathrm{R}^{2}$ indicates the fraction of the variation in the dependent variable that is explained by the independent variables. The pseudo- $\mathrm{R}^{2}$ is an extension to the $\mathrm{R}^{2}$ for non-linear models such as the multinomial logit (Cameron and Trivedi, 2010).

TABLE A4 MULTINOMIAL LOGIT MODEL OF GROUP MEMBERSHIP (RELATIVE RISK RATIOS, WAVE 1 PREDICTORS)

\begin{tabular}{|c|c|c|}
\hline & $\begin{array}{c}\text { Class } 1 \\
\text { 'Unhealthy smokers and } \\
\text { drinkers' }\end{array}$ & $\begin{array}{c}\text { Class } 2 \\
\text { 'Unhealthy diet and } \\
\text { physical activity' }\end{array}$ \\
\hline Male & Ref & Ref \\
\hline \multirow[t]{2}{*}{ Female } & $1.695 * * *$ & $2.667 * * *$ \\
\hline & $(0.152)$ & $(0.195)$ \\
\hline \multirow[t]{2}{*}{ Age } & $2.071 * *$ & 0.993 \\
\hline & $(0.667)$ & $(0.281)$ \\
\hline \multirow[t]{2}{*}{ Birth weight } & $1.158 * *$ & 0.935 \\
\hline & $(0.086)$ & $(0.060)$ \\
\hline \multirow[t]{2}{*}{ Born early ( 37 weeks or earlier) } & 1.016 & 1.026 \\
\hline & (0.099) & $(0.083)$ \\
\hline Born on time (38-41 weeks) & Ref & Ref \\
\hline \multirow[t]{2}{*}{ Born late $(42+$ weeks $)$} & 0.811 & 1.001 \\
\hline & $(0.118)$ & $(0.110)$ \\
\hline Ever breastfed & Ref & Ref \\
\hline \multirow[t]{2}{*}{ Never breastfed } & 0.924 & $1.222 * * *$ \\
\hline & $(0.084)$ & $(0.089)$ \\
\hline Mother never smoked in pregnancy & Ref & Ref \\
\hline \multirow[t]{2}{*}{ Mother smoked occasionally in pregnancy } & 1.192 & 1.105 \\
\hline & $(0.174)$ & $(0.141)$ \\
\hline \multirow[t]{2}{*}{ Mother smoked daily in pregnancy } & 1.211 & 1.054 \\
\hline & $(0.176)$ & $(0.132)$ \\
\hline Mother never drank in pregnancy & Ref & Ref \\
\hline \multirow[t]{2}{*}{ Mother drank occasionally in pregnancy } & $1.335 * * *$ & 0.892 \\
\hline & $(0.120)$ & $(0.065)$ \\
\hline \multirow[t]{2}{*}{ Mother drank daily in pregnancy } & 1.580 & 1.088 \\
\hline & $(0.532)$ & $(0.342)$ \\
\hline
\end{tabular}


TABLE A4 CONTD.

\begin{tabular}{|c|c|c|}
\hline & $\begin{array}{c}\text { Class } 1 \\
\text { 'Unhealthy smokers and } \\
\text { drinkers' }\end{array}$ & $\begin{array}{c}\text { Class } 2 \\
\text { 'Unhealthy diet and } \\
\text { physical activity' }\end{array}$ \\
\hline Two parents with 1 or 2 children & Ref & Ref \\
\hline \multirow[t]{2}{*}{ Two parents with $3+$ children } & 0.870 & $0.821 * * *$ \\
\hline & $(0.079)$ & $(0.060)$ \\
\hline \multirow[t]{2}{*}{ Lone parent with 1 or 2 children } & $1.546^{* *}$ & 0.814 \\
\hline & $(0.272)$ & $(0.128)$ \\
\hline \multirow[t]{2}{*}{ Lone parent with $3+$ children } & $2.217^{* * *}$ & 1.434 \\
\hline & $(0.643)$ & $(0.345)$ \\
\hline Household equivalised income (lowest) & Ref & Ref \\
\hline \multirow[t]{2}{*}{ Household equivalised income (Q2) } & 1.046 & 1.005 \\
\hline & $(0.169)$ & $(0.132)$ \\
\hline \multirow[t]{2}{*}{ Household equivalised income (Q3) } & 1.066 & 0.888 \\
\hline & $(0.172)$ & $(0.119)$ \\
\hline \multirow[t]{2}{*}{ Household equivalised income (Q4) } & 0.950 & 0.854 \\
\hline & $(0.156)$ & $(0.115)$ \\
\hline \multirow[t]{2}{*}{ Household equivalised income (highest) } & 1.001 & 0.865 \\
\hline & $(0.171)$ & $(0.121)$ \\
\hline PCG primary level education & Ref & Ref \\
\hline \multirow[t]{2}{*}{ PCG lower secondary education } & 1.063 & 0.784 \\
\hline & $(0.345)$ & $(0.189)$ \\
\hline \multirow[t]{2}{*}{ PCG upper secondary education } & 1.019 & 0.781 \\
\hline & $(0.328)$ & $(0.184)$ \\
\hline \multirow[t]{2}{*}{ PCG post-secondary education } & 0.984 & $0.662 *$ \\
\hline & $(0.321)$ & $(0.159)$ \\
\hline \multirow[t]{2}{*}{ PCG degree education } & 0.993 & $0.657^{*}$ \\
\hline & $(0.335)$ & $(0.165)$ \\
\hline \multirow[t]{2}{*}{ PCG postgraduate degree education } & 0.993 & 0.806 \\
\hline & $(0.351)$ & $(0.212)$ \\
\hline \multirow[t]{2}{*}{ Professional } & 0.865 & 0.830 \\
\hline & $(0.177)$ & $(0.134)$ \\
\hline \multirow[t]{2}{*}{ Managerial/technical } & 1.020 & 0.938 \\
\hline & $(0.175)$ & $(0.129)$ \\
\hline \multirow[t]{2}{*}{ Other non-manual } & 1.103 & 0.909 \\
\hline & $(0.195)$ & $(0.129)$ \\
\hline \multirow[t]{2}{*}{ Skilled manual } & 1.201 & 0.951 \\
\hline & $(0.222)$ & $(0.142)$ \\
\hline Semi-/unskilled manual & Ref & Ref \\
\hline \multirow[t]{2}{*}{ Never employed } & 1.217 & 1.259 \\
\hline & $(0.350)$ & $(0.296)$ \\
\hline
\end{tabular}

Contd. 
TABLE A4 CONTD.

\begin{tabular}{|l|c|c|}
\hline & $\begin{array}{c}\text { Class 1 } \\
\text { 'Unhealthy smokers and } \\
\text { drinkers' }\end{array}$ & $\begin{array}{c}\text { Class 2 } \\
\text { 'Unhealthy diet and } \\
\text { physical activity' }\end{array}$ \\
\hline PCG born in Ireland & $\begin{array}{c}\text { Ref } \\
\text { Ref }\end{array}$ \\
\hline PCG not born in Ireland & 1.134 & 1.022 \\
\hline
\end{tabular}

Cognitive test score (numeracy)

\begin{tabular}{|c|c|}
\hline 1.009 & 0.960 \\
\hline$(0.050)$ & $(0.039)$ \\
\hline
\end{tabular}

\begin{tabular}{|l|c|c|}
\hline SDQ Emotional & & \\
& 0.930 & $1.098^{* *}$ \\
\hline SDQ Conduct & $(0.043)$ & $(0.042)$ \\
\hline SDQ Hyperactivity & $1.142 * * *$ & 0.951 \\
\hline SDQ Peer & $(0.054)$ & $(0.039)$ \\
\hline SDQ Prosocial & $1.175 * * *$ & 1.036 \\
\hline
\end{tabular}

\begin{tabular}{|l|c|c|}
\hline Piers Harris Behaviour & $0.897^{* *}$ & 0.963 \\
\hline Piers Harris Intellectual and School & $(0.048)$ & $(0.045)$ \\
\hline & $0.805^{* * *}$ & 1.023 \\
\hline Piers Harris Physical Appearance & $(0.052)$ & $0.055)$ \\
\hline Piers Harris Freedom from Anxiety & $1.167^{* *}$ & $(0.043)$ \\
\hline Piers Harris Popularity & $(0.078)$ & $0.917^{*}$ \\
\hline Piers Harris Happiness and Satisfaction & 0.936 & $(0.047)$ \\
\hline Neither parent smokes & $(0.057)$ & 0.964 \\
\hline At least one parent smokes occasionally & 1.009 & $(0.050)$ \\
\hline & $(0.064)$ & $1.218^{* * *}$ \\
\hline One parent smokes daily & 0.994 & $(0.061)$ \\
\hline & $(0.059)$ & Ref \\
\hline Both parents smoke daily & & 0.863 \\
\hline & $R e f$ & $(0.109)$ \\
\hline
\end{tabular}


TABLE A4 CONTD.

\begin{tabular}{|l|c|c|}
\hline & $\begin{array}{c}\text { Class 1 } \\
\text { 'Unhealthy smokers and } \\
\text { drinkers' }\end{array}$ & $\begin{array}{c}\text { Class 2 } \\
\text { 'Unhealthy diet and } \\
\text { physical activity' }\end{array}$ \\
\hline Neither parent drinks & $\begin{array}{c}\text { Ref } \\
\text { Ref }\end{array}$ & 0.828 \\
\hline At least one parent drinks monthly or less & 0.979 & $(0.153)$ \\
\hline At least one parent drinks 1-2 times per month & $(0.235)$ & $0.690^{* *}$ \\
\hline At least one parent drinks 1-2 times per week & 0.907 & $(0.118)$ \\
\hline At least one parent drinks 3-4 times per week & $(0.204)$ & $0.729 *$ \\
\hline N & 0.964 & $(0.120)$ \\
\hline Log-Likelihood & $(0.207)$ & $0.703 * *$ \\
\hline
\end{tabular}

Source: $\quad$ GUI, '98 Cohort, Wave 1 and Wave 3.

Note: $\quad *$ significant at 10 per cent level; ${ }^{* *}$ significant at 5 per cent level; ${ }^{* * *}$ significant at 1 per cent level. 
TABLE A5 MULTINOMIAL LOGIT MODEL OF GROUP MEMBERSHIP (RELATIVE RISK RATIOS, WAVE 2 PREDICTORS)

\begin{tabular}{|c|c|c|}
\hline & $\begin{array}{c}\text { Class } 1 \\
\text { 'Unhealthy smokers and } \\
\text { drinkers' }\end{array}$ & $\begin{array}{c}\text { Class } 2 \\
\text { 'Unhealthy diet and } \\
\text { physical activity' }\end{array}$ \\
\hline Male & Ref & Ref \\
\hline \multirow[t]{2}{*}{ Female } & $1.609 * * *$ & $2.444 * * *$ \\
\hline & $(0.146)$ & $(0.180)$ \\
\hline \multirow[t]{2}{*}{ Age } & 0.976 & $1.650 *$ \\
\hline & $(0.330)$ & $(0.447)$ \\
\hline Two parents with 1 or 2 children & Ref & Ref \\
\hline \multirow{2}{*}{ Two parents with $3+$ children } & $0.784 * * *$ & 0.903 \\
\hline & $(0.071)$ & $(0.064)$ \\
\hline \multirow[t]{2}{*}{ Lone parent with 1 or 2 children } & $1.509 * * *$ & 0.838 \\
\hline & $(0.229)$ & $(0.118)$ \\
\hline \multirow[t]{2}{*}{ Lone parent with $3+$ children } & $1.709 * *$ & 1.210 \\
\hline & $(0.394)$ & $(0.238)$ \\
\hline Household equivalised income (lowest) & Ref & Ref \\
\hline \multirow[t]{2}{*}{ Household equivalised income (Q2) } & 1.111 & 1.192 \\
\hline & $(0.159)$ & $(0.148)$ \\
\hline \multirow[t]{2}{*}{ Household equivalised income (Q3) } & 0.908 & 1.140 \\
\hline & $(0.134)$ & $(0.139)$ \\
\hline \multirow[t]{2}{*}{ Household equivalised income (Q4) } & 0.895 & 1.076 \\
\hline & $(0.130)$ & $(0.131)$ \\
\hline \multirow[t]{2}{*}{ Household equivalised income (highest) } & 0.924 & 1.057 \\
\hline & $(0.137)$ & $(0.134)$ \\
\hline PCG primary level education & Ref & Ref \\
\hline \multirow{2}{*}{ PCG lower secondary education } & 0.704 & $0.461 * *$ \\
\hline & $(0.290)$ & $(0.155)$ \\
\hline \multirow[t]{2}{*}{ PCG upper secondary education } & 0.718 & $0.460 * *$ \\
\hline & $(0.287)$ & $(0.149)$ \\
\hline \multirow[t]{2}{*}{ PCG post-secondary education } & 0.688 & $0.360 * * *$ \\
\hline & $(0.277)$ & $(0.118)$ \\
\hline \multirow[t]{2}{*}{ PCG degree education } & 0.701 & $0.317^{* * *}$ \\
\hline & $(0.287)$ & $(0.106)$ \\
\hline \multirow[t]{2}{*}{ PCG postgraduate degree education } & 0.837 & $0.414^{* * *}$ \\
\hline & $(0.348)$ & $(0.140)$ \\
\hline \multirow[t]{2}{*}{ Professional } & 0.723 & $0.759 *$ \\
\hline & $(0.147)$ & $(0.121)$ \\
\hline
\end{tabular}


TABLE A5 CONTD.

\begin{tabular}{|l|c|c|}
\hline & $\begin{array}{c}\text { Class 1 } \\
\text { 'Unhealthy smokers and } \\
\text { drinkers' }\end{array}$ & $\begin{array}{c}\text { Class 2 } \\
\text { 'Unhealthy diet and } \\
\text { physical activity' }\end{array}$ \\
\hline Managerial/technical & 0.933 & 0.804 \\
\hline Other non-manual & $(0.165)$ & $(0.113)$ \\
\hline Skilled manual & 0.939 & 0.920 \\
\hline Semi-/unskilled manual & $(0.172)$ & $(0.134)$ \\
\hline Never employed & 1.119 & 0.839 \\
\hline
\end{tabular}

\begin{tabular}{|l|c|c|}
\hline PCG born in Ireland & Ref & Ref \\
\hline PCG not born in Ireland & 1.066 & 1.095 \\
\hline
\end{tabular}

Cognitive test score (numeracy)

\begin{tabular}{|c|c|}
\hline $0.842 * * *$ & $0.913^{* *}$ \\
\hline$(0.046)$ & $(0.038)$ \\
\hline
\end{tabular}

\begin{tabular}{|l|c|c|}
\hline & & \\
\hline SDQ Emotional & $0.909 *$ & 0.973 \\
\hline SDQ Conduct & $(0.047)$ & $(0.040)$ \\
\hline SDQ Hyperactivity & $1.118^{* *}$ & $0.915^{* *}$ \\
\hline & $(0.056)$ & $(0.041)$ \\
\hline SDQ Peer & 1.080 & 1.040 \\
\hline SDQ Prosocial & $(0.054)$ & $(0.045)$ \\
\hline Extraversion & 0.998 & $1.179 * * *$ \\
\hline Agreeableness & $(0.049)$ & $(0.045)$ \\
\hline Conscientiousness & 0.945 & 0.974 \\
\hline Emotional Stability & $(0.044)$ & $(0.039)$ \\
\hline & & $0.933^{* *}$ \\
\hline & 1.061 & $(0.033)$ \\
\hline & $(0.046)$ & $1.076^{*}$ \\
\hline & 0.972 & $(0.041)$ \\
\hline
\end{tabular}

Contd. 
TABLE A5 CONTD.

\begin{tabular}{|c|c|c|}
\hline & $\begin{array}{c}\text { Class } 1 \\
\text { 'Unhealthy smokers and } \\
\text { drinkers' }\end{array}$ & $\begin{array}{c}\text { Class } 2 \\
\text { 'Unhealthy diet and } \\
\text { physical activity' }\end{array}$ \\
\hline \multirow[t]{2}{*}{ Piers Harris Behaviour } & $0.740 * * *$ & 1.025 \\
\hline & $(0.037)$ & $(0.049)$ \\
\hline \multirow[t]{2}{*}{ Piers Harris Intellectual and School } & 0.917 & 1.010 \\
\hline & $(0.056)$ & $(0.052)$ \\
\hline \multirow[t]{2}{*}{ Piers Harris Physical Appearance } & 0.899 & $0.775^{* * *}$ \\
\hline & $(0.062)$ & $(0.043)$ \\
\hline \multirow[t]{2}{*}{ Piers Harris Freedom from Anxiety } & 0.989 & 0.945 \\
\hline & $(0.064)$ & $(0.051)$ \\
\hline \multirow[t]{2}{*}{ Piers Harris Popularity } & 1.053 & $0.856 * * *$ \\
\hline & $(0.065)$ & $(0.042)$ \\
\hline \multirow[t]{2}{*}{ Piers Harris Happiness and Satisfaction } & 0.984 & $1.136^{* *}$ \\
\hline & $(0.063)$ & $(0.063)$ \\
\hline Neither parent smokes & Ref & Ref \\
\hline \multirow[t]{2}{*}{ At least one parent smokes occasionally } & $1.443 * * *$ & $0.744 * *$ \\
\hline & $(0.203)$ & $(0.097)$ \\
\hline \multirow[t]{2}{*}{ One parent smokes daily } & $1.542 * * *$ & $1.158^{*}$ \\
\hline & $(0.155)$ & $(0.099)$ \\
\hline \multirow[t]{2}{*}{ Both parents smoke daily } & $1.636 * *$ & 1.073 \\
\hline & $(0.314)$ & $(0.187)$ \\
\hline Neither parent drinks & Ref & Ref \\
\hline \multirow[t]{2}{*}{ At least one parent drinks monthly or less } & 1.086 & 0.818 \\
\hline & $(0.217)$ & $(0.125)$ \\
\hline \multirow[t]{2}{*}{ At least one parent drinks 1-2 times per month } & 1.036 & $0.662 * * *$ \\
\hline & $(0.203)$ & $(0.100)$ \\
\hline \multirow[t]{2}{*}{ At least one parent drinks 1-2 times per week } & 1.248 & $0.655^{* * *}$ \\
\hline & $(0.229)$ & $(0.092)$ \\
\hline \multirow{2}{*}{ At least one parent drinks 3-4 times per week } & 1.259 & $0.700 * *$ \\
\hline & $(0.244)$ & $(0.105)$ \\
\hline $\mathrm{N}$ & \multicolumn{2}{|c|}{5,153} \\
\hline Log-Likelihood & \multicolumn{2}{|c|}{$-4,859.30$} \\
\hline
\end{tabular}

Source: $\quad$ GUI, '98 Cohort, Waves 2 and 3.

Note: $\quad *$ significant at 10 per cent level; ${ }^{* *}$ significant at 5 per cent level; ${ }^{* *}$ significant at 1 per cent level. 
TABLE A6 MULTILEVEL MULTINOMIAL LOGIT MODEL OF GROUP MEMBERSHIP (RELATIVE TO MEMBERSHIP OF THE HEALTHY GROUP): EFFECTS OF SCHOOL SOCIAL MIX AND BETWEEN-SCHOOL VARIANCE, CONTROLLING FOR DIFFERENT SETS OF FACTORS

\begin{tabular}{|c|c|c|c|c|c|c|c|}
\hline & $\begin{array}{c}\text { School } \\
\text { characteristics }\end{array}$ & Year group & $\begin{array}{l}\text { Primary school } \\
\text { experiences } \\
\text { (age 9) }\end{array}$ & $\begin{array}{c}\text { School } \\
\text { experiences at } 13\end{array}$ & $\begin{array}{l}\text { Junior Certificate } \\
\text { higher level } \\
\text { take-up }\end{array}$ & Older peer group & $\begin{array}{c}\text { Personality traits } \\
\text { at } 13\end{array}$ \\
\hline \multicolumn{8}{|l|}{ Unhealthy drinker/smoker } \\
\hline \multicolumn{8}{|l|}{ Primary school social mix: } \\
\hline Urban Band 1 DEIS & $1.436^{*}$ & $1.438^{*}$ & $1.317^{*}$ & $1.155 \pm$ & 1.155 & 1.213 & 1.199 \\
\hline Urban Band 2 DEIS & 0.973 & 0.929 & 0.962 & $\begin{array}{r}2 \\
025\end{array}$ & 0.945 & 0.922 & 0.944 \\
\hline Rural DEIS & $1.366 \pm$ & 1.317 & 1.373 & 1.332 & 1.280 & 1.309 & 1.363 \\
\hline Non-DEIS & Ref & Ref & Ref & Ref & & Ref & Ref \\
\hline Fee-paying & 1.395 & 1.257 & 1.223 & 1.223 & 1.201 & 1.114 & 1.046 \\
\hline \multicolumn{8}{|c|}{ Second-level school social mix: } \\
\hline DEIS & $1.259 * *$ & 1.075 & 1.007 & 1.006 & 0.898 & 0.907 & 0.902 \\
\hline Non-DEIS & Ref & Ref & Ref & Ref & & Ref & Ref \\
\hline Fee-paying & 1.141 & 1.209 & 1.245 & 1.214 & 1.225 & 1.269 & 1.279 \\
\hline Between-school variance & $0.116 * *$ & $0.119 * *$ & $0.121 * *$ & $0.125^{* *}$ & $0.094^{*}$ & $0.108^{* *}$ & $0.111^{* *}$ \\
\hline \multicolumn{8}{|c|}{ Unhealthy diet/physical activity } \\
\hline \multicolumn{8}{|l|}{ Primary school social mix: } \\
\hline Urban Band 1 DEIS & $1.694 * * *$ & $1.701 * *$ & $1.567^{* *}$ & $1.637^{*}$ & $1.542^{*}$ & $1.556^{*}$ & $1.605^{*}$ \\
\hline Urban Band 2 DEIS & 1.184 & 1.190 & 1.188 & 1.219 & 1.203 & 1.23 & 0.976 \\
\hline Rural DEIS & 0.950 & 0.966 & 0.986 & 0.973 & 0.967 & 0.970 & 0.976 \\
\hline Non-DEIS & Ref & Ref & Ref & Ref & & Ref & Ref \\
\hline Fee-paying & 0.634 & 0.564 & $0.538 \pm$ & $0.548 \pm$ & $0.541 \pm$ & 0.540 & 0.553 \\
\hline \multicolumn{8}{|c|}{ Second-level school social mix: } \\
\hline DEIS & $1.301^{* *}$ & $1.203^{*}$ & 1.153 & 1.131 & 1.103 & 1.106 & 1.101 \\
\hline Non-DEIS & Ref & Ref & Ref & Ref & & Ref & Ref \\
\hline Fee-paying & $0.803^{*}$ & $0.800 *$ & 0.801 & 0.824 & 0.878 & 0.877 & 0.870 \\
\hline Between-school variance & 0.006 & 0.003 & 0.000 & 0.000 & 0.000 & 0.000 & 0.000 \\
\hline
\end{tabular}

Source: $\quad$ GUI, '98 cohort, Waves 1, 2 and 3. 
TABLE A7 MULTINOMIAL LOGIT MODEL OF GROUP MEMBERSHIP (RELATIVE RISK RATIOS, WAVE 2 PREDICTORS): EFFECTS OF SCHOOL EXPERIENCES BEFORE AND AFTER CONTROLLING FOR PERSONALITY TRAITS AT 13

\begin{tabular}{|c|c|c|c|c|}
\hline & $\begin{array}{c}\text { Unhealthy } \\
\text { drinker/smoker }\end{array}$ & & $\begin{array}{l}\text { Unhealthy diet/physical } \\
\text { activity }\end{array}$ & \\
\hline & Without personality traits & \begin{tabular}{|} 
Controlling for \\
personality traits and \\
conduct problems at 13 \\
as well as self-image at 17
\end{tabular} & Without personality traits & $\begin{array}{c}\text { Controlling for } \\
\text { personality traits and } \\
\text { conduct problems at } 13 \\
\text { as well as self-image at } 17\end{array}$ \\
\hline \multicolumn{5}{|l|}{ Liking school at age 9: } \\
\hline Always liked & Ref & Ref & Ref & Ref \\
\hline Sometimes liked & 1.076 & 0.926 & 1.021 & 0.988 \\
\hline Never liked & 0.901 & 0.743 & 1.133 & 1.115 \\
\hline Drumcondra Maths test score (age 9) & $1.092 \pm$ & 1.053 & $0.932 \pm$ & $0.925 \pm$ \\
\hline Total SDQ score at age 9 & 1.011 & -0.012 & $1.016^{*}$ & 0.012 \\
\hline Positive interaction with teachers (at 13) & $0.899 * * *$ & $0.969 * *$ & $0.924 * * *$ & $0.959 * *$ \\
\hline Negative interaction with teachers (at 13) & $1.528 * * *$ & $1.261^{* * *}$ & $0.898^{*}$ & $0.905^{* *}$ \\
\hline \multicolumn{5}{|l|}{ Attitudes to school (at 13): } \\
\hline Like it very much & Ref & Ref & Ref & Ref \\
\hline Like it quite a bit & 1.137 & 1.005 & 0.943 & $0.877 \pm$ \\
\hline Like it a bit & $1.413^{* *}$ & 1.168 & 1.070 & 0.991 \\
\hline Don't like/hate it & 1.246 & 0.898 & 0.881 & $0.766^{*}$ \\
\hline Numerical reasoning test score at 13 & $0.904 \pm$ & $0.911 \pm$ & 1.022 & $1.531 \pm$ \\
\hline $\begin{array}{l}\text { Number of higher-level subjects taken in Junior } \\
\text { Certificate exam }\end{array}$ & $0.882 * * *$ & $0.899 * * *$ & $0.971^{*}$ & $0.979 \pm$ \\
\hline \multicolumn{5}{|l|}{ Composition of friendship group: } \\
\hline None older & Ref & Ref & Ref & Ref \\
\hline Some older & $1.704^{* * *}$ & $1.639 * * *$ & $0.901 \pm$ & 0.941 \\
\hline All older & $1.632 * * *$ & $1.387^{* *}$ & 0.906 & 0.939 \\
\hline Between-school variance & $0.112 * *$ & $0.111^{* *}$ & 0.000 & 0.000 \\
\hline
\end{tabular}

Source: $\quad$ GUI, '98 cohort, Waves 1, 2 and 3. 


\section{REFERENCES}

Adams, S.A., C.E., Matthews, C.B., Ebbeling, C.G., Moore, J.E., Cunningham, J. Fulton and J.R. Hebert (2005). 'The Effect of Social Desirability and Social Approval on SelfReports of Physical Activity', Am. J. Epidemiol, 161, 389-398.

Alamian, A. and G. Paradis (2009). 'Clustering of chronic disease behavioral risk factors in Canadian children and adolescents', Preventive Medicine 48(5): 493-499.

Banks, J., S. McCoy and E. Smyth (2018). Senior Cycle Review: Analysis of Discussions in Schools on the Purpose of Senior Cycle Education in Ireland. Dublin: ESRI.

Baumeister, R., J. Campbell, J.I. Krueger and K.D. Vohs (2003). 'Does High Self-Esteem Cause Better Performance, Interpersonal Success, Happiness, or Healthier Lifestyles?', Psychological Science in the Public Interest, 4(1): 1-44.

Bogg, T. and B. Roberts (2004). 'Conscientiousness and Health-Related Behaviors: A MetaAnalysis of the Leading Behavioral Contributors to Mortality', Psychological Bulletin, 130(6): 887-919.

Bonell, C., W. Parry, H. Wells, F. Jamal, A. Fletcher, A. Harden, J. Thomas, R. Campbell, M. Petticrew, S. Murphy, M. Whitehead and L. Moore (2013). 'The effects of the school environment on student health: a systematic review of multi-level studies', Health and Place, 21, 180-191.

Buck, D. and F. Frosini (2012). Clustering of Unhealthy Behaviours over Time. Implications for Policy and Practice. London, The King's Fund.

Cameron, A. and P. Trivedi (2010). Microeconometrics Using Stata. Stata Press, Texas.

Carlson, P. and Y.B. Almquist (2016). 'Are area-level effects just a proxy for school-level effects? Socioeconomic differences in alcohol consumption patterns among Swedish adolescents', Drug and Alcohol Dependence, 166, 243-248.

Cawley, J. and A. Choi (2018). 'Health Disparities Across Education: The Role of Differential Reporting Error', Health Economics, 27, e1-e29.

Champion, K., M. Mather, B. Spring, F. Kay-Lambkin, M. Teeson and N.C. Newton. (2018). 'Clustering of Multiple Risk Behaviors Among a Sample of 18-Year-Old Australians and Associations With Mental Health Outcomes: A Latent Class Analysis', Frontiers in public health, 6: 135-135.

Choi, H., Y. Lu, M. Schulte and J.R. Temple (2018). 'Adolescent substance use: Latent class and transition analysis', Addictive Behaviors, 77: 160-165.

Cobb-Clark, D., S. Kassenboehmer and S. Schurer (2012). 'Healthy Habits: The Connection between Diet, Exercise and Locus of Control'. IZA DP No. 6789. Bonn, IZA.

Conry, M., K. Morgan, P. Curry, H. McGee, J. Harrington, M. Ward and E. Shelley (2011). 'The clustering of health behaviours in Ireland and their relationship with mental health, self-rated health and quality of life', BMC Public Health, 11(1): 692.

Cradock, A.L., S.J. Melly, J.G. Allen, J.S. Morris and S.L. Gortmaker (2007). 'Characteristics of school campuses and physical activity among youth', American Journal of Preventive Medicine, 33 (2), 106-113. 
Cuenca-García, M., I. Huybrechts, J.R. Ruiz, F.B. Ortega, C. Ottevaere, M. Gonazlez-Gross, L.A. Moreno, G. Vicente-Rodriguez et al. (2013). 'Clustering of Multiple Lifestyle Behaviors and Health-related Fitness in European Adolescents', Journal of Nutrition Education and Behavior, 45(6): 549-557.

Czerwinski, F., E. Finne, P. Kolip and J. Bucksch (2015). 'Individual and school level correlates of moderate to vigorous physical activity among school-children in Germany - a multi-level analysis', BMC Public Health, 15(1), 393-400.

Darmody, M., E. Smyth and C. Doherty (2010). Designing Primary Schools for the Future. Dublin: ESRI.

Davis, J., E. Banfield, H.Y. Lee, H. Peng, S. Chang and A.C. Wood (2019). 'Lifestyle behavior patterns and mortality among adults in the NHANES 1988-1994 population: A latent profile analysis', Preventive Medicine 120: 131-139.

Daw, J., R. Margolis and L. Wright (2017). 'Emerging Adulthood, Emergent Health Lifestyles: Sociodemographic Determinants of Trajectories of Smoking, Binge Drinking, Obesity, and Sedentary Behavior', Journal of Health and Social Behavior, 58(2): 181197.

de Looze, M., T.F. Ter Bogt, Q.A. Raaijmakers, W. Pickett, E. Kuntsche and W.A. Vollebergh (2015). 'Cross-national evidence for the clustering and psychosocial correlates of adolescent risk behaviours in 27 countries', The European Journal of Public Health, 25(1), 50-56.

Department of Children and Youth Affairs (2014). Better Outcomes Brighter Futures. The National Policy Framework for Children and Young People. Dublin, Stationery Office.

Department of Education and Skills (2012). Physical Education, Physical Activity and Sport for Children and Young People: A Guiding Framework. Dublin: DES.

Department of Education and Skills (2015). A Framework for Junior Cycle. Dublin: DES.

Department of Education and Skills (2018). Wellbeing Policy Statement and Framework for Practice. 2018-2023. Dublin, Department of Education and Skills.

Department of Health (2013). Tobacco Free Ireland. Report of the Tobacco Policy Review Group. Dublin, Department of Health.

Department of Health (2016). Healthy Ireland Survey (2016). Summary of Findings. Dublin, Stationery Office.

Department of Health (2019). Healthy Ireland Survey (2018). Summary of Findings. Dublin, Stationery Office.

Dobbins, M., H. Husson, K. DeCorby and R. LaRocca (2013). 'School-based physical activity programs for promoting physical activity and fitness in children and adolescents aged 6 to 18', Cochrane Database Syst. Rev.

Dooley, B. and A. Fitzgerald (2002). My World Survey: National Study of Youth Mental Health in Ireland. Dublin, UCD School of Psychology.

Doron, J., R. Trouillet, A. Maneveau, D. Neveu and G. Ninot (2014). 'Coping profiles, perceived stress and health-related behaviors: a cluster analysis approach', Health Promotion International: 1-13. 
Dunn, E.C., T.K. Richmond, C.E. Milliren and S.V. Subramanian (2015). 'Using cross-classified multilevel models to disentangle school and neighborhood effects: an example focusing on smoking behaviors among adolescents in the United States', Health and Place, 31, 224-232.

Fletcher, A., C. Bonell and J. Hargreaves (2008). 'School effects on young people's drug use: a systematic review of intervention and observational studies', Journal of Adolescent Health, 42(3), 209-220.

Frech, A. (2012). 'Healthy Behavior Trajectories between Adolescence and Young Adulthood', Advances in Life Course Research, 17(2): 59-68.

Frydenberg, E., E. Care, E. Chan and E. Freeman (2009). 'Interrelationships between coping, school connectedness and wellbeing', Australian Journal of Education, 53(3), 261-276.

Goldstein, H. (2003). Multilevel Statistical Models. London: Wiley.

Gordon-Larsen, P. and S.B. Heymsfield (2018). 'Obesity as a Disease, Not a Behavior', Circulation, 137, 1543-1545.

Government of Ireland (2013). Healthy Ireland. A Framework for Improved Health and Wellbeing 2013-2025. Dublin, Stationery Office.

Government of Ireland (2015). National Sexual Health Strategy 2015-2020. Dublin, Stationery Office.

Government of Ireland (2016a). Get Ireland Active! National Physical Activity Plan for Ireland. Dublin, Stationery Office.

Government of Ireland (2016b). A Healthy Weight for Ireland. Obesity Policy and Action Plan. Dublin, Stationery Office.

Government of Ireland (2018). Public Health (Alcohol) Act 2018.

Growing Up in Ireland (2016a). Health, Weight, Physical Activity and Diet. Key Findings: Child Cohort at 17/18 Years. Dublin, Economic and Social Research Institute.

Growing Up in Ireland (2016b). Risky Health Behaviours and Sexual Activity. Key Findings: Child Cohort at 17/18 Years. Dublin, Economic and Social Research Institute.

Hartz, J., L. Yingling, C. Ayers, J. Adu-Brimpong, J. Rivers, C. Ahuja and T.M. Powell-Wiley (2018). 'Clustering of Health Behaviors and Cardiorespiratory Fitness Among U.S. Adolescents', Journal of Adolescent Health, 62(5): 583-590.

Harvey, A., G. Faulkner, L. Giangregorio and S.T. Leatherdale (2017). 'An examination of school- and student-level characteristics associated with the likelihood of students' meeting the Canadian physical activity guidelines in the COMPASS study', Revue Canadienne de Santé Publique, 108(4): 348-354.

Henry, K.L., L.R. Stanley, R.W. Edwards, L.C. Harkabus and L.A. Chapin (2009). 'Individual and contextual effects of school adjustment on adolescent alcohol use', Prevention Science, 10(3), 236-247.

HSE (2013). Schools for Health in Ireland: Framework for Developing a Health Promoting School. Dublin: HSE. 
Krølner, R., P. Due, M. Rasmussen, M.T. Damsgaard, B.E. Holstein, K.I. Klepp and J. Lynch (2009). 'Does school environment affect 11-year-olds' fruit and vegetable intake in Denmark?', Social Science and Medicine, 68(8), 1416-1424.

Janssen, I., P.T. Katzmarzyk, W.F. Boyce, C. Vereecken, C. Mulvihill, C. Roberts, C. Currie, W. Pickett, T.H.B. Group (2005). 'Comparison of overweight and obesity prevalence in school-aged youth from 34 countries and their relationships with physical activity and dietary patterns', Obes. Rev. 6, 123-132.

John-Akinola, Y. O. and S. Nic-Gabhainn (2014). 'Children's participation in school: a crosssectional study of the relationship between school environments, participation and health and well-being outcomes', BMC public health, 14(1), 964.

John-Akinola, Y.O. and S. Nic Gabhainn (2015). 'Socio-ecological school environments and children's health and wellbeing outcomes', Health Education, 115(3/4), 420-434.

Jones, R., N. Blackburn, C. Woods, M. Byrne, F. van Nassau and M. Tully (2019). Interventions promoting active transport to school in children: A systematic review and metaanalysis. Preventive Medicine, 123, 232-241.

Kelly, C., M. Callaghan, M. Molcho, S. Nic Gabhainn and A. Alforque Thomas (2019). 'Food environments in and around post-primary schools in Ireland: Associations with youth dietary habits', Appetite, 132, 182-189.

Langford, R., C. Bonell, H. Jones, T. Pouliou, S. Murphy, E. Waters, K. Komro, L. Gibbs, D. Magnus and R. Campbell (2014). 'The WHO Health Promoting School framework for improving the health and well-being of students and their academic achievement', Cochrane Database Syst. Rev.

Lawlor, D., M. O'Callaghan, A.A. Abdullah, G.M. Williams, W. Bor and J.M. Najman (2005). 'Socioeconomic Position, Cognitive Function, and Clustering of Cardiovascular Risk Factors in Adolescence: Findings From the Mater University Study of Pregnancy and Its Outcomes', Psychosomatic Medicine, 67(6): 862-868.

Layte, R. and C. McCrory (2011). Overweight and Obesity Among 9-Year Olds Dublin, Department of Children and Youth Affairs.

Leech, R., S. McNaughton and A. Timperio (2014) 'The clustering of diet, physical activity and sedentary behavior in children and adolescents: a review', The international journal of behavioral nutrition and physical activity, 11, 4 DOI: 10.1186/1479-5868-11-4.

Leech, R., S. McNaughton and A. Timperio (2015). 'Clustering of diet, physical activity and sedentary behaviour among Australian children: cross-sectional and longitudinal associations with overweight and obesity', International Journal of Obesity, 39(7): 1079-1085.

Levy, K. (2001). 'The relationship between adolescent attitudes towards authority, selfconcept, and delinquency', Adolescence, 36(142): 333-346.

Loef, M. and H. Walach (2012). 'The combined effects of healthy lifestyle behaviors on all cause mortality: A systematic review and meta-analysis', Preventive Medicine, 55(3): 163-170.

Lubans, D., C. Boreham, P. Kelly and C. Foster (2011). The relationship between active travel to school and health-related fitness in children and adolescents: a systematic review. International Journal of Behavioral Nutrition and Physical Activity, 8, 5, 1-12. 
Lunn, P., E. Kelly and N. Fitzpatrick (2013). Keeping Them in the Game: Taking Up and Dropping Out of Sport and Exercise in Ireland. ESRI Research Series No. 33. Dublin: Economic and Social Research Institute.

Maes L. and J. Lievens (2003). 'Can the school make a difference? A multilevel analysis of adolescent risk and health behaviour', Social Science and Medicine, 56, 517-29.

Martin-Diener, E., J. Meyer, J. Braun, S. Tarnutzer, D. Faeh, S. Rohrmann and B.W. Martin (2014). 'The combined effect on survival of four main behavioural risk factors for non-communicable diseases', Preventive Medicine, 65: 148-152.

Martinez, A., C. Coker, S.D. McMahon, J. Cohen and A. Thapa (2016). 'Involvement in extracurricular activities: Identifying differences in perceptions of school climate', The Educational and Developmental Psychologist, 33(1), 70-84.

Mawditt, C., A. Sacker, A. Britton, Y. Kelly and N. Cable (2016). 'The clustering of healthrelated behaviours in a British population sample: Testing for cohort differences', Preventive Medicine, 88: 95-107.

Mawditt, C., A. Sacker, A. Britton, Y. Kelly and N. Cable (2018). 'Social influences on healthrelated behaviour clustering during adulthood in two British birth cohort studies', Preventive Medicine, 110: 67-80.

Mawditt, C., A. Sacker, A. Britton, Y. Kelly and N. Cable (2019). 'The stability of health-related behaviour clustering during mid-adulthood and the influence of social circumstances on health-related behaviour change', Preventive Medicine, 121: 141-148.

McCoy, S., A. Quail and E. Smyth (2014). 'The effects of school social mix: Unpacking the differences', Irish Educational Studies, 33(3), 307-330.

McHugh, D. and O. McGowan (2019). 'Future direction of wellbeing in education', presentation to the conference, Building a Healthy Ireland: Promoting Health and Wellbeing in Educational Settings, UCC.

McMullen, J., D. Ní Chróinín, T. Tammelin, M. Pogorzelska and H. Van Der Mars (2015). 'International approaches to whole-of-school physical activity promotion', Quest, 67(4), 384-399.

McNeely, C. and C. Falci (2004). 'School connectedness and transition into and out of healthrisk behaviour among adolescents: a comparison of social belonging and teacher support', Journal of School Health, 74, 284 -92.

Meader, N., K. King, T. Moe-Byrne, K. Wright, H. Graham, M. Petticrew, C. Power, M. White and A.J. Sowden (2016). 'A systematic review on the clustering and co-occurrence of multiple risk behaviours', BMC Public Health, 16(1): 657.

Moynihan, S., D. Jourdan and P. Mannix McNamara (2016). 'An examination of health promoting schools in Ireland', Health Education, 116(1), 16-33.

Murphy, M., J. Williams, A. Murray and E. Smyth (2019). Cohort '98 (formerly Child Cohort). Design, Instrumentation and Procedures for Cohort' 98 at 17/18 years of age. Dublin, Department of Children and Youth Affairs.

NCCA (2009). Aistear: The Early Childhood Curriculum Framework. Dublin: NCCA.

NCCA (2017). Guidelines for Wellbeing in Junior Cycle. Dublin: NCCA. 
Nelson, L. and C. McNamara Barry (2005). 'Distinguishing Features of Emerging Adulthood: The Role of Self-Classification as an Adult', Journal of Adolescent Research, 20(2): 242-262.

Nic Gabhainn, S., S. O'Higgins and M. Barry (2010). 'The implementation of social, personal and health education in Irish schools', Health Education, 110(6), 452-470.

Noble, N., C. Paul, H. Turon and C. Oldmeadow (2015). 'Which modifiable health risk behaviours are related? A systematic review of the clustering of Smoking, Nutrition, Alcohol and Physical activity ('SNAP') health risk factors', Preventive Medicine, 81: 16-41.

O'Brien, M. (2008). Well-being and post-primary schooling. Dublin: NCCA.

O'Leary, M., E. Rush, S. Lacey, C. Burns and T. Coppinger (2019). 'Project Spraoi: two year outcomes of a whole school physical activity and nutrition intervention using the REAIM framework', Irish Educational Studies, 38(2), 219-243.

Olsson, G., and J. Fritzell (2015). 'A Multilevel Study on Ethnic and Socioeconomic School Stratification and Health-Related Behaviors among Students in Stockholm', Journal of School Health, 85(12), 871-879.

Ottevaere, C., I. Huybrechts, J. Benser, I. De Bourdeaudhuij, M. Cuenca-Garcia, J. Dallongeville, M. Zaccaria, F. Gottrand et al. (2011). 'Clustering patterns of physical activity, sedentary and dietary behavior among European adolescents: The HELENA study', BMC Public Health, 11(1): 328.

Owen, A.L. and J. Videras (2016). 'Classifying human development with latent class analysis', Social Indicators Research, 127(3): 959-981.

Pampel, F., P. Krueger and J.T. Denney (2010). 'Socioeconomic Disparities in Health Behaviors', Annual Review of Sociology, 36(1): 349-370.

Pearce, L.D., E.M. Foster and J.H. Hardie (2013). 'A person-centered examination of adolescent religiosity using latent class analysis', Journal for the Scientific Study of Religion, 52(1): 57-79.

Pedersen, W., A. Bakken and T. von Soest (2017). 'Neighbourhood or school? Influences on alcohol consumption and heavy episodic drinking among urban adolescents', Journal of Youth and Adolescence, 47, 2073-2087.

Perra, O., A. Fletcher, C. Bonell, K. Higgins and P. McCrystal (2012). 'School-related predictors of smoking, drinking and drug use: Evidence from the Belfast Youth Development Study', Journal of Adolescence, 35(2), 315-324.

Quail, A., J. Williams, C. McCrory, A. Murray and M. Thornton (2011). A Summary Guide to Wave 1 of the Infant Cohort (at 9 months) of Growing Up in Ireland. Dublin, Economic and Social Research Institute.

Rasbash, J., F. Steele, W.J. Browne and H. Goldstein (2012). A User's Guide to MLWiN. Bristol: University of Bristol.

Roman C.G. and C.J. Taylor (2013). 'A multilevel assessment of school climate, bullying victimization, and physical activity', Journal of School Health, 83(6), 400-407.

Rosenberg, M. (1965). Society and the Adolescent Self-Image. Princeton, NJ: Princeton University Press. 
Saab, H. and D. Klinger (2010). 'School differences in adolescent health and wellbeing: Findings from the Canadian Health Behaviour in School-aged Children Study', Social Science and Medicine, 70(6), 850-858.

Scarborough, P., P. Bhatnagar, K.K. Wickramasinghe, S. Allender, C. Foster and M. Rayner (2011). 'The economic burden of ill health due to diet, physical inactivity, smoking, alcohol and obesity in the UK: an update to 2006-07 NHS costs,' Journal of Public Health, 33(4): 527-535.

Schwarzer, R. and B. Renner (2000). 'Social-cognitive predictors of health behavior: action self-efficacy and coping self-efficacy', Health Psychology, 19(5): 487-495.

Shah, R., and A. Hagell (2019). International comparisons of health and wellbeing in adolescence and early adulthood Research report February 2019. London, Nuffield Foundation.

Sherer, M., J.E. Maddux, B. Mercandante, S. Prentice-Dunn, B. Jacobs and R.W. Rogers (1982). 'The Self-Efficacy Scale: Construction and validation', Psychological Reports, $51,663-671$.

Skalamera, J. and R. Hummer (2016). 'Educational attainment and the clustering of healthrelated behavior among U.S. young adults', Preventive Medicine, 84: 83-89.

Smyth, E. (2016). Students' experiences and perspectives on secondary education: Institutions, transitions and policies. London: Palgrave Macmillan.

Smyth, E., J. Banks and E. Calvert (2011). From Leaving Certificate to Leaving School: A Longitudinal Study of Sixth Year Students. Dublin: ESRI.

Smyth, E., J. Banks, J. O'Sullivan, S. McCoy, P. Redmond and S. McGuinness (2019). Evaluation of the National Youthreach Programme. Dublin: ESRI.

Steenholt, C. B., V.S.C. Pisinger, I.H. Danquah and J.S. Tolstrup (2018). 'School and class-level variations and patterns of physical activity: a multilevel analysis of Danish high school students', BMC Public Health, 18(1), 255-265.

Takakura, M., N. Wake and M. Kobayashi (2010). 'The contextual effect of school satisfaction on health-risk behaviors in Japanese high school students', Journal of School Health, 80(11), 544-551.

Teddlie, C. and D. Reynolds (2000). The International Handbook of School Effectiveness Research. New York: Psychology Press.

The Lancet (2019). 'Health and wellbeing in adolescence and early adulthood', The Lancet, 393(10174): 847.

Thornton, M., J. Williams, C. McCrory, A. Murray and A. Quail (2011). Guide to the Datasets Wave 1 of the Nine-Year Cohort of Growing Up in Ireland. Dublin, Economic and Social Research Institute.

Townsend, N., S. Murphy and L. Moore (2011). 'The more schools do to promote healthy eating, the healthier the dietary choices by students', Journal of Epidemiology and Community Health, 65(10), 889-895.

Vereecken, C., M. Dupuy, M. Rasmussen, C. Kelly, T.R. Nansel, H. Al Sabbah, D. Baldassari, M.D. Jordan, L. Maes, B.V.-L Niclasen, N. Ahluwalia and the HBSC Eating and Dieting Focus Group (2009). 'Breakfast consumption and its socio-demographic and lifestyle 
correlates in schoolchildren in 41 countries participating in the HBSC study', Int. J. Public Health, 54, 180-190.

Viner, R., D. Hargreaves, J.V. dos Santos Motta, B. Horta, A.H. Mokdad and G. Patten (2017). 'Adolescence and Later Life Disease Burden: Quantifying the Contribution of Adolescent Tobacco Initiation From Longitudinal Cohorts', Journal of Adolescent Health, 61(2): 171-178.

Viner, R., D. Ross, R. Hardy, D. Kuh, C. Power, A. Johnson, K. Wellings, J. McCambridge, T.J. Cole, Y. Kelly and G.D. Batty (2015). 'Life course epidemiology: recognising the importance of adolescence', Journal of Epidemiology and Community Health.

West, P., H. Sweeting and A. Leyland (2004). 'School effects on pupils' health behaviours: evidence in support of the health promoting school', Research Papers in Education, 19(3), 261-291.

WHO (1999). Improving Health through Schools. Geneva: World Health Organisation.

WHO (2002). Reducing Risks, Promoting Healthy Life. The World Health Report 2002. Geneva, World Health Organization.

Zhou, Y. and L. Wang (2019). 'Correlates of physical activity in students in secondary school physical education: a systematic review of literature', BioMed Research International, https://doi.org/10.1155/2019/4563484. 
Whitaker Square,

Sir John Rogerson's Quay, Dublin 2

Telephone +35318632000

Email admin@esri.ie

Web www.esri.ie

Twitter @ESRIDublin

ISBN 978-0-7070-0516-4 